\title{
DESEMPENHO DE OVINOS E RESPOSTAS DE PASTAGENS DE Cynodon spp SUBMETIDAS A REGIMES DE DESFOLHA SOB LOTAÇÃO CONTÍNUA
}

\section{ROBERTA APARECIDA CARNEVALLI}

\author{
Engenheira Agrônoma
}

Orientador: Prof. Dr. SILA CARNEIRO DA SILVA

\begin{abstract}
Dissertação apresentada à Escola Superior de Agricultura "Luiz de Queiroz", Universidade de São Paulo, para obtenção do título de Mestre em Agronomia, Área de Concentração: Ciência Animal e Pastagens.
\end{abstract}

\author{
PIR A C I C A B A \\ Estado de São Paulo - Brasil \\ Setembro - 1999
}


Dados Internacionais de Catalogação na Publicação (CIP) DIVISÃo DE BIBLIOTECA E DOCUMENTAÇÃO - Campus "Luiz de Queiroz"/USP

Carnevalli, Roberta Aparecida

Desempenho de ovinos e respostas de pastagens de Cynodon spp submetidas a regimes de desfolha sob lotação contínua / Roberta Aparecida Carnevalli. - . Piracicaba, 1999.

90 p. : il.

Dissertação (mestrado) - - Escola Superior de Agricultura Luiz de Queiroz, 1999. Bibliografia.

1. Capim Coastcross 2. Capim Tifton 3. Desempenho animal 4. Forragem 5. Grama bermuda 6. Nutrição animal 7. Ovino 8. Pastagem cultivada 9. Planta forrageira 10. Valor nutritivo I. Título 


\section{ERRATA}

A descrição da espécies de Cynodon presentes na página 7 foram feitas por Burton (1988) e não por Rezende \& Alvim (1996) que apenas citaram em seu artigo.

O teste de comparação de médias utilizado no experimento foi LSMEANS.

A adubação realizada foi de $40 \mathrm{~kg} \mathrm{~N} \cdot \mathrm{ha}^{-1} \mathrm{em} 8$ de julho, $40 \mathrm{~kg} \cdot \mathrm{ha}^{-1}$ em 19 de setembro, $50 \mathrm{~kg} \mathrm{~N} \cdot \mathrm{ha}^{-1}$ em 21 de outubro, $25 \mathrm{~kg} \mathrm{~N} \cdot \mathrm{ha}^{-1}$ em 7 de dezembro, $50 \mathrm{~kg} \mathrm{~N} \cdot \mathrm{ha}^{-1}$ em 23 de fevereiro, $75 \mathrm{~kg} \mathrm{~N} \cdot \mathrm{ha}^{-1}$ em 20 de março.

A análise de Proteína Bruta foi feita de acordo com o método descrito pela A.O.A.C.(p.18)

Na página 50 , Tabela 22 , mês de setembro, tratamento $50 \mathrm{~mm}$ :

$\begin{array}{ccccc}\text { Setembro } & \text { TF } & \text { FLK } & \text { CC } & \text { EPM } \\ 50 & 78,7 \mathrm{aA} & 81,1 \mathrm{aA} & 76,7 \mathrm{aA} & 1,5\end{array}$.

Na página 34 deveria estar a figura 8 citada na página anterior.

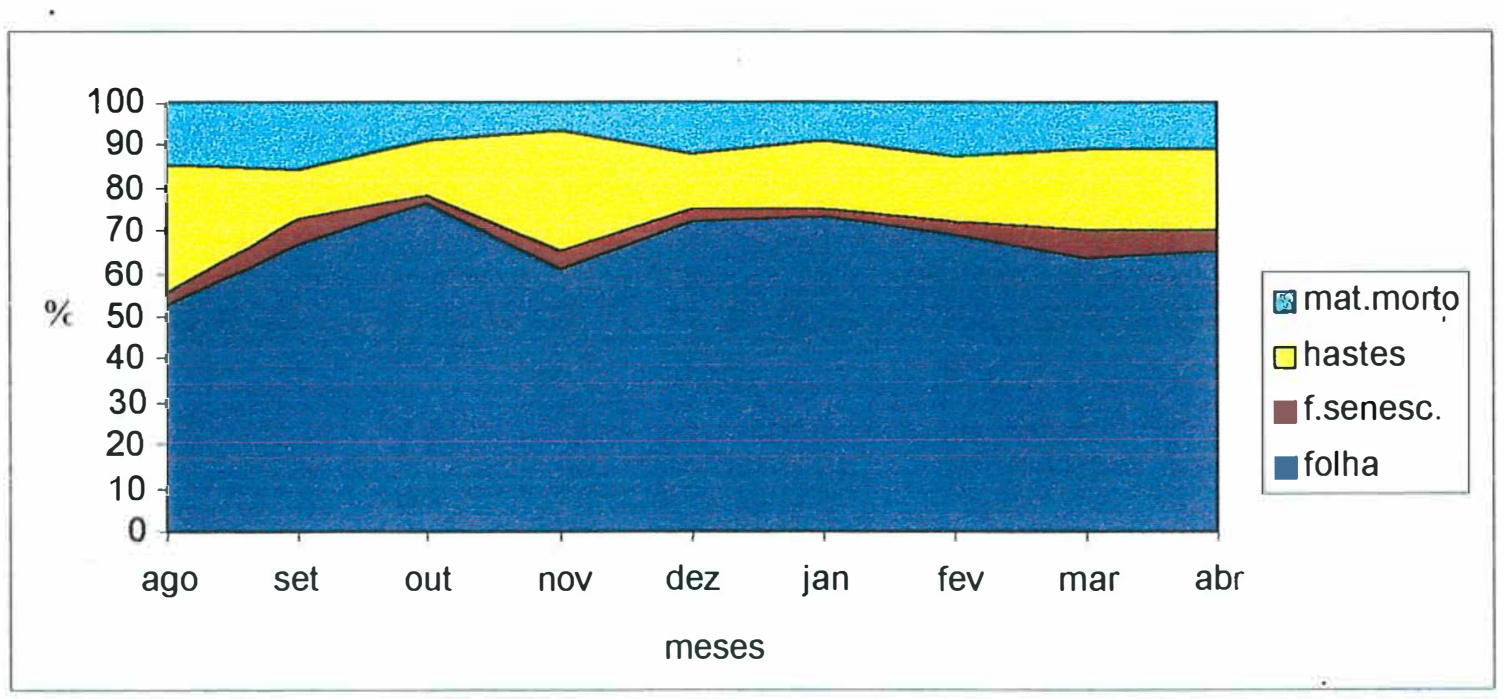

Figura 8: Composição morfológica da simulação de pastejo para a intensidade de pastejo de $50 \mathrm{~mm}$ no periodo experimental. 


\section{AGRADECIMENTOS}

À Universidade de São Paulo, por meio do Departamento de Produção Animal pela oportunidade de realização do curso.

À Coordenação de Aperfeiçoamento de Pessoal de Nível Superior - CAPES, pela concessão de bolsa de estudo.

Ao professor Sila Carneiro da Silva pela orientação, estímulo, compreensão e companherismo.

Aos professores do Departamento de Produção Animal que de alguma forma colaboraram no esclarecimento de dúvidas, especialmente à Prof ${ }^{a}$ Ivanete Susin pela atenção e cessão dos animais para o experimento.

Ao técnico de laboratório Carlos César Alves e ao José Manuel Correia de Simas pela atenção e compreensão no latoratório de bromatologia.

Aos companheiros de Mestrado : Jaílson, Carlos Augusto, André e Luiz Felipe pela colaboração na exxecução do experimento e pela amizade.

Às estagiárias Milena, Daniela e Marina pela dedicação especial e companherismo.

Aos estágiários do Grupo de Estudo de Plantas Forrageiras pela grandiosa ajuda nos trabalhos de campo.

À todos que direta ou indiretamente contribuíram para a realização do experimento. 


\section{SUMÁRIO}

Página

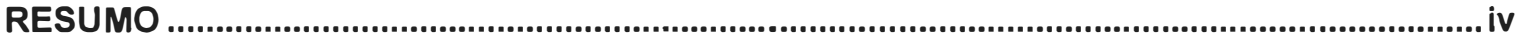

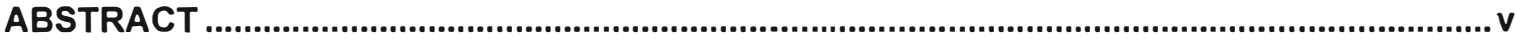

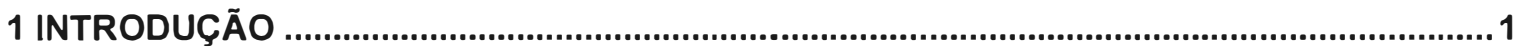

2 REVISÃO DE LITERATURA

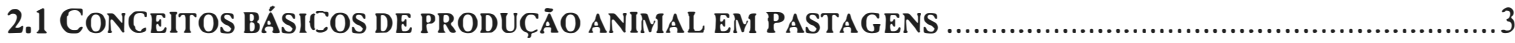

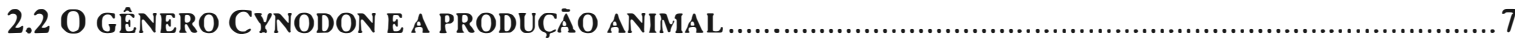

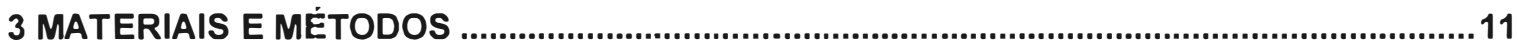

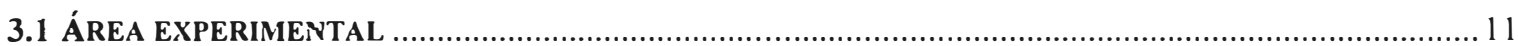

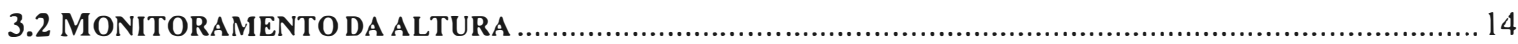

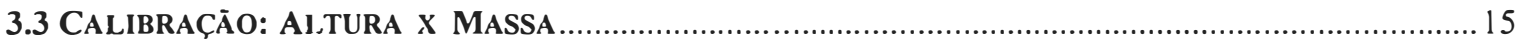

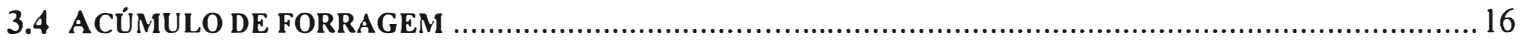

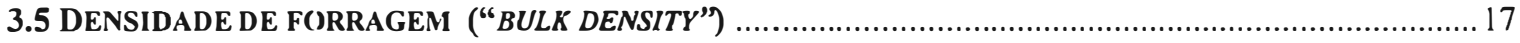

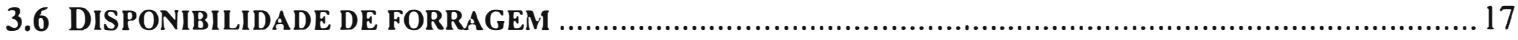

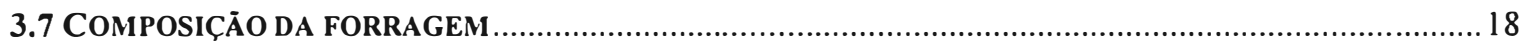

3.7.1 Coleta e armazenamento das amostras....................................................................... 18

3.7.2 Processamento e análise do material ........................................................................... 18

3.7.3 Composiçäo morfológica da forragem................................................................... 19

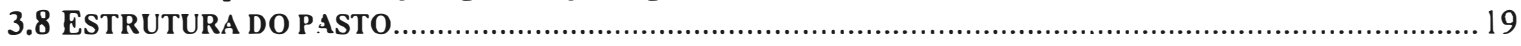

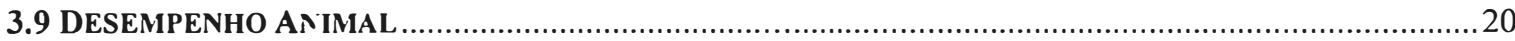

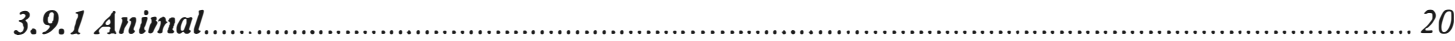

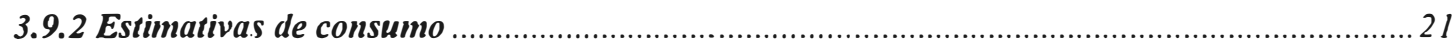

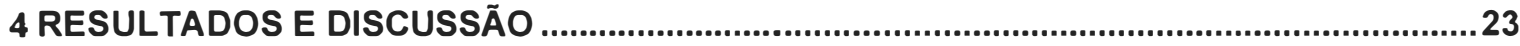

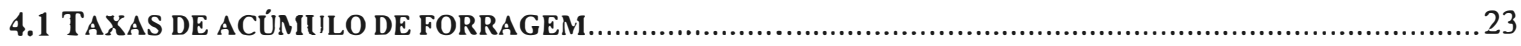

4.2 COMPOSIÇÃO MIORFOLÓGICA E VALOR NUTRITIVO DA FORRAGEM “CONSUMIDA" ....................26

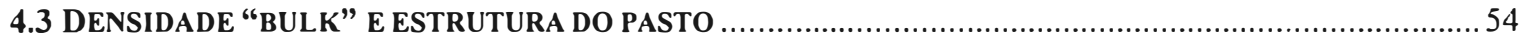

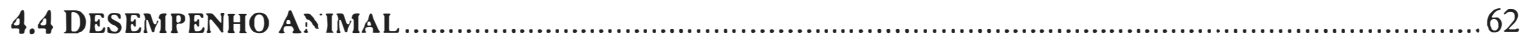

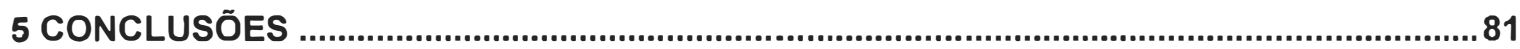

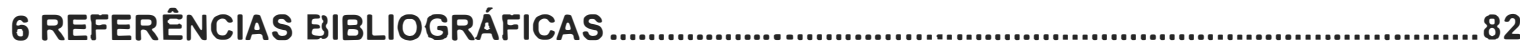




\title{
DESEMPENHO DE OVINOS E RESPOSTAS DE PASTAGENS DE Cynodon spp SUBMETIDAS A REGIMES DE DESFOLHA SOB LOTAÇÃO CONTÍNUA
}

\author{
Autora: Roberta Aparecida Carnevalli \\ Orientador: Prof. Dr. Sila Carneiro da Silva
}

\section{RESUMO}

O comportamento das plantas e o desempenho de ovinos foram avaliados em pastagens de Cynodon spp (Tifton-85, Florakirk e Coastcross). Os pastos foram mantidos sob quatro intensidades de pastejo correspondentes às alturas 50, 100, $150 \mathrm{e}$ $200 \mathrm{~mm}$, por ovinos em regime de lotação contínua com carga variável de agosto/1998 a abril/1999. As condições de pasto foram alocadas às unidades experimentais aleatoriamente num delineamento de blocos completos com parcelas subdivididas (split-plot) e quatro repetições, sendo que os cultivares foram dispostos nas parcelas e as alturas nas sub-parcelas. Cada unidade experimental $\left(400 \mathrm{~m}^{2}\right)$ teve no mínimo dois cordeiros marcadures para resposta animal e três gaiolas de exclusão para acúmulo de forragem. As respostas avaliadas foram: proteina bruta (PB), fibra em detergente neutro (FDN), fibra em detergente ácido (FDA), lignina, digestibilidade 'in vitro' da matéria orgânica e composição da forragem como pastejada e a proporção de folhas, hastes e material morto nos pastos, densidade de forragem, taxa de acúmulo de forragem, capacidade de suporte, disponibilidade de forragem, ganho de peso por animal e por hectare e estimativas de consumo. As diferenças observadas no valor nutritivo foram maiores para os pastos de $50 \mathrm{~mm}$, que tiveram os maiores valores de PB e DIVMO. O desempenho animal foi mais dependente da capacidade de suporte e da disponibilidade? de forragem, com animais tendo melhor desempenho nos pastos mais altos (150 e 200mm). Desempenho animal e produção de forragem aumentaram nos meses de vierão, como consequência do aumento das taxas de acúmulo. Os cultivares apresentaram diferenças no padrão e qualidade da produção de forragem, razão pela qual cuidados específicos devem ser tomados quando utilizados para pastejo. 


\title{
PASTURE AND ANIMAL RESPONSES OF Cynodon spp SWARDS GRAZED BY SHEEP UNDER CONTINOUS STOCKING
}

\author{
Author: Roberta Aparecida Carnevalli \\ Advisor: Prof. Dr. Sila Carneiro da Silva
}

\section{ABSTRACT}

Pasture and animal performance were evaluated on Cynodon spp (Tifton-85, Florakirk e Coastcross) swards kept in four steady state conditions ( 50, 100, 150 and $200 \mathrm{~mm}$ sward surface heights) maintained by sheep under continuous stocking with variable stocking rate during august/1998 to april/1999. Treatments were allocated to experimental units according to a complete randomised block design with four replications in a split-plot arrangement. Grass cultivars were allocated to plots and sward conditions to subplots. Individual experimental units (400 $\mathrm{m}^{2}$ each) had at least two lambs, testers for animal responses, and three exclosure cages for herbage accumulation measurements. Experimental responses evaluated were: crude protein (CP), neutral detergent fiber , acid detergent fiber and lignin, 'in vitro' organic matter digestibility (IVOMD) and morphological composition in forage as grazed, proportion of leaf, stem and dead material in swards, sward bulk density, herbage accumulation rate, carrying capacity, herbage allowance, live weight gain per animal and per hectare and estimates of herbage intake. Despite the differences observed in nutritive value overall $(P<0,05)$ where short swards $(50 \mathrm{~mm})$ had the highest values for CP and IVOMD, animal performance was more dependent of carrying capacity and herbage allowance, with animals performing better on longer swards (150 and $200 \mathrm{~mm}$ ). Animal performance and pasture production increased during summer months, a likely consequence of increased herbage accumulation rates. Grass cultivars differed in pattern and quality of herbage production, justifying specific grazing plans when utilised under grazing. 


\section{Introdução}

A pecuária mundial tem se baseado em sistemas de produção utilizando pastagens (exclusivas ou suplementadas) ou confinamentos, onde se fornecem silagens e resíduos de indústrias alimentícias em geral. A tendência é que a adoção de sistemas de pastagens venha a crescer e estes passem a ser bastante utilizados, pois é a maneira mais econômica de alimentação de ruminantes.

Para uma planta forrageira ter sucesso como pastagem é necessário que ela apresente algumas características como perenidade, rebrota rápida após a desfolha, tolerância à presença do animal, vigor, valor nutritivo adequado e, principalmente, qualidade. A qualidade da pastagem está diretamente relacionada à forma que o alimento está disponível ao animal (fatores estruturais) aliada às características anatômicas do animal e seu comportamento ingestivo, determinando consumo. Assim, para que uma forragem com valor nutritivo adequado tenha boa qualidade é necessário que o animal consiga consumi-la em quantidade satisfatória. Se houver sucesso nessa etapa do processo, o desempenho animal estará assegurado, considerando que as condições de sanidade do rebanho estejam adequadas.

Além de todos os fatores descritos, é de interesse que a pastagem tenha alto potencial de prodıção de matéria seca e também apresente características estruturais que permitam flexibilidade de utilização durante o ano.fum gênero vem destacando-se por apresentar todas estas características. Trata-se das plantas do gênero Cynodon spp. Este gênero é composto por plantas prostradas, que colocam seus pontos de crescimento perto do nível do solo e, portanto, toleram pastejo baixo. Apresentam boa produção de matéria seca e alto valor nutritivo e, ainda, podem ser conservadas na forma de feno elou silagem.

Por existir um crescente interesse na utilização dessas plantas como pastagens, o pressente estudo teve por objetivo investigar as respostas ao pastejo de alguns cultivares de Cynodon spp. e avaliar o desempenho de ovinos em crescimento 
submetidos a pastejo exclusivo, sem suplementação protéica ou energética. Os três cultivares de Cynodon spp. (Tifton-85, Florakirk e Coastcross) estudados foram submetidos a quatro intensidades de desfolha, que foram mantidas "constante" através de um regime de lotação contínua com carga variável. Procurou-se estabelecer relações entre aspectos de produção de forragem, valor nutritivo e desempenho animal em situações onde houve rigoroso controle da estrutura do pasto (altura). 


\section{Revisão de literatura}

\subsection{Conceitos básicos de produção animal em pastagens}

A utilização de pastagem como forma de uso do solo tem relevada importância mundial. Cerca dè $25 \%$ da área total da Terra é formada por pastagens, dos quais 10 a $15 \%$ são ocupados por animais em regime de pastejo (Hodgson, 1990), sendo muito provável que umá ou mais forrageiras constituam a base do sistema de produção e, em alguns casos, suprindo todos os nutrientes consumidos pelos animais (Matthews, 1994). O pastejo é a forma mais econômica de alimentar o ruminante dentre todas as modalidades de produção de alimentos, por isso deve-se direcionar atenção a este processo a fim de obter-se produção animal a custos menores, tornando a atividade competitiva com outras áreas da agricultura. Para tanto, faz-se necessário o pleno conhecimento da espécie forrageira e suas reações ao ambiente (ecologia) e, principalmente, ao manejo.

Fundamentalmente, em qualquer sistema de produção animal, um princípio básico norteia todas as tomadas de decisão e orienta todas as ações, ou seja, procurase sempre adequar e equacionar suprimento (S) e demanda (D) por alimentos. Todos os esforços e recursos são dispendidos no sentido de que a quantidade de alimento disponivel (massa de forragem) e em oferta seja suficiente para atender as exigências tanto quantitativas como qualitativas do rebanho $(S=D)$ (da Silva \& Pedreira, 1996).

O acúmulo de forragem, entendido como a diferença entre o crescimento de partes da planta forrageira (sintese de tecidos) e a perda de outras (por senescência, morte de tecidos e consumo por animais), é o aspecto mais importante do fator suprimento. Em pastagens, o objetivo do manejo do pastejo é encontrar o compromisso ideial entre as exigências conflitantes da planta forrageira (que precisa conservar sua áréa foliar para fotossintese) e a necessidade fundamental de remover 
esses tecidos através do corte ou pastejo (Parsons, 1988). Esse conflito é mais aparente em sistemmas de pastejo em lotação contínua, onde parte do crescimento da forragem é "continuamente" removido pelos animais em pastejo. Se a taxa bruta de produção de tecidos (crescimento) for igual à soma da remoção pelo pastejo e das perdas de tecido por senescência e morte, não serão observadas mudanças líquidas na massa média (estoque) de forragem na pastagem (Spedding, 1965). Sob o aspecto quantitativo, condições de ambiente favoráveis tendem a aumentar a reserva média de forragem (massa de forragem), ao passo que, em outras épocas do ano, o acúmulo reduzido (e freqüentemente nulo) diminui a média do estoque anual. $O$ valor nutritivo afeta o suprimento à medida em que exerce grande influência sobre o consumo. Este, todavia, é tambérn influenciado por características morfológicas da planta (tais como porcentagem de iolhas) e do relvado (tais como densidade), ou seja, a estrutura da pastagem (Hodgson,1990).

O fenômeno de acúmulo líquido descrito é conseqüência direta da curta duração de vida de folhas individuais, que ao atingirem a maturidade, entram num processo irreversivel de senescência (da Silva \& Pedreira,1996). Esse balanço entre as taxas de crescimento e morte sofre alterações com o tempo, mas é principalmente afetado pela maneira como a pastagem é manejada, podendo ter efeito marcante sobre o formato das curvas de acúmulo de forragem que suceder-se-ão (Hodgson,1990). O consumo do animal está relacionado com o acúmulo de matéria seca, pois este define a massa de forragem que é oferecida para pastejo. $O$ desempenho animal é função direta do consumo de matéria seca digestível. Nesse contexto, 60 a $90 \%$ das variações observadas em desempenho animal decorrem de variações em consumo, enquanto que apenas 10 a $40 \%$ advém de flutuações na digestibilidade (Mertens,1994). Nota-se, portanto, que a contribuição relativa do consumo de matéria seca para o desempenho animal é, em média, três vezes aquela da digestibilidade. Se por um lado o desempenho individual é altamente influenciado pelo consumo, a produção por unidade de área também é função da taxa de lotação (número de animáis por unidade de área).

Em sistemas de produção animal em pastagens, o consumo está sob forte influência da disponibilidade de forragem (kg MS/kg PV) (da Silva \& Pedreira,1996). Sabe-se que um dos aspectos mais relevantes da interação planta $x$ animal é o pastejo seletivo. Em outrás palavras, quando tem oportunidade o animal em pastejo seleciona 
o que vai comer. De maneira geral, folhas são mais preferidas em relação a hastes e material jovem e verde em relação às partes senescentes e mortas. De fato, a porcentagem de folhas presentes exerce influência sobre o consumo, conforme relatado por Wilson \& Minson (1980), que observaram, em muitos casos, que as hastes foram consumidas em quantidades muito menores que folhas, ainda que as digestibilidades de ambas fossem semelhantes. Stobbs (1973) sugeriu que a densidade "bulk" (kg MS/cm.ha) parece ser o principal componente da estrutura da pastagem a determinar a taxa de consumo para plantas tropicais, porém não existe uma massa críticia suficiente de dados para confirmar esta conclusão. Além disso, um fator extremamente importante, é a digestibilidade e composição química da forragem, que se alteram muito com a diferença de estrutura (altura) (Hodgson \& Jamieson , 1981) e idade da planta (Blaser, 1988).

O valor nutritivo de uma forragem pode ser definido como a concentração de nutrientes presentes nesta ou como a resposta animal por unidade de alimento consumido. Pode ser dividido em 2 componentes: digestibilidade aparente e eficiência de utilização, pelo animal, dos nutrientes digeridos para fins de manutenção e produção (Ulyatt. 1973). Os valores de digestibilidade não podem ser usados exclusivamente para se avaliar um alimento pois o consumo e a eficiência de utilização da energia são os maiores determinantes na resposta ou desempenho dos animais. Pode-se, no entanto, considerar que, de forma geral, o consumo e a eficiência estão positivamente correlacionados com a digestibilidade, muito embora esta generalização nem sempre seja verdadeira (Mattos, 1992).

As maiores mudanças que ocorrem na composição química das forrageiras são aquelas que acompanham a maturação da planta (Euclides,1995). Com a maturidade, a forragem tem sua composição química e morfológica modificada e seu valor nutritivo diminuido; ocorre um aumento na lignificação e uma diminuição na relação folha/haste (da Silva \& Pedreira, 1997). À medida que as gramineas passam de estádios vegetativos para estádios fenológicos mais avançados, passam a apresentar aumento em rendimento e nos teores de fibra e lignina. A quantidade de proteina aumenta a taxas decrescente:S, as quais finalmente declinam com o avançado estádio de floração, havendo acúmulo acelerado de hastes em relação às folhas, indicando maturidade da planta. Maturidade associada ao incremento nos teores de lignina e fibra, restringe a produção animal (Blaser, 1988). 
Os animais ingerem alimentos para satisfazer suas necessidades nutricionais. A ingestão é condicionada por diversos fatores, principalmente necessidade energética no tocante ao aspecto nutricional mas, fisiologicamente, também é condicionada pelo volume do alimento ingerido, sendo a capacidade do aparelho digestivo diferente para as várias espécies (Maynard et al., 1984). A análise química é o ponto de partida para se determinar o valor nutritivo dos alimentos. Assim sendo, alimentos analisados podem ter parâmetros como teor de matéria seca, proteina bruta, fibra em detergente neutro, fibra em detergente ácido, lignina, cinzas e digestibilidade quantificados e a dieta dos animais pode ser ajustada às suas necessidades. $A$ digestibilidade doss alimentos é uma determinação muito importante na análise química, pois sua variação é de apenas 3 a $7 \%$. O conhecimento desta se aproxima bastante de seu valor de nutrientes digestiveis totais (NDT) e permite uma avaliação razoável do alimento (Mattos, 1992). Dados da literatura revelam que o gênero Cynodon possui plantas com alto valor nutritivo (11 a $13 \%$ de proteina bruta e 58 a $65 \%$ de digestibilidade) e que poderiam, dessa maneira, apresentar um potencial grande para 0 desenvolvimento de sistemas de produção animal em pastagens baseados na sua utilização (da Silva \& Pedreira, 1997).

Alteração na estrutura do pasto, especialmente na altura média de pastejo, temse revelado determinante de variações em composição morfológica da planta nos diferentes estratos de pastejo, no valor nutritivo e digestibilidade da forragem e, consequentemente, no nivel de consumo e desempenho animal. A literatura mostra dados de condições temperadas em que altura do pastejo é um fator de grande importância no gånho de peso e produção leiteira dos animais criados em pastagens. Hodgson (1990) cita que a altura ideal para pastejo de ovinos em condições de clima temperado utilizando pastagens de azevém e trevo branco compreende a faixa de 3 a $5 \mathrm{~cm}$ para obter a máxima produção. Com plantas tropicais foi desenvolvido um trabalho por Chacion et al. (1978) na Venezuela onde foram estudadas espécies de Setaria e Digitaria sob regime de lotação contínua com novilhas Hereford, testando diferentes taxas de lotação. Verificaram que as variáveis de produção, estrutura do pasto, densidade populacional de perfilhos e valor nutritivo foram significativamente afetadas pelas diferentes intensidades de pastejo. 


\subsection{0 gênero Cynodon e a produção animal}

Recentemente, um interesse renovado pelas plantas do gênero Cynodon spp. tem-se tornado aparente. Resende \& Alvim (1996) trabalhando com gado leiteiro, destacaram um potencial de produção de Coastcross de 20 toneladas de matéria seca (MS) por hectare oor ano de foragem de alta palatabilidade e alto valor nutritivo (13,9\% de proteína bruta (PB), $68 \%$ de fibra em detergente neutro (FDN) e $35 \%$ de fibra em detergente ácido (FDA)). Os autores relatam ainda tratar-se de plantas de fácil manejo, que poderiam ser utilizadas para pastejo ou fenação, sendo bem aceita pelos animais. Descrevem-nas como não tolerantes a encharcamento contínuo e exigentes em fertilidade do solc. A lotação obtida no experimento foi de 6 vacas em lactação/ha no verão e 3 no inverno, sem qualquer suplementação. A produção obtida foi de 20 a $25 \mathrm{t}$ MS/ha.ano ou 25 a $30 \mathrm{t}$ feno/ha.ano, com $85 \%$ de MS. Carnevalli \& Silva (1999) obtiveram para Coastcross taxas de acúmulo variando de 30 a $90 \mathrm{~kg} \mathrm{MS} / \mathrm{ha}$.dia durante $o$ ano e uma produção estimada de $23 \mathrm{t} \mathrm{MS/ha.} \mathrm{ano} \mathrm{em} \mathrm{pastejo} \mathrm{rotacionado.}$

Fonseca et al. (1984) trabalharam com Coastcross e testaram nitrogênio nas doses de 0,100, 200, 300 e $400 \mathrm{~kg} / \mathrm{ha}$.ano, aplicados na forma de uréia após cada um dos seis cortes realizados durante o período chuvoso. Como média de 3 anos relataram incrementos significativos na produção de matéria seca com até 300 $\mathrm{kgN} / \mathrm{ha}$.ano. A menor conversão de $\mathrm{N}(7,8 \mathrm{~kg} \mathrm{MS} / \mathrm{kg} \mathrm{N})$ foi obtida no nível de 100 $\mathrm{kgN} / \mathrm{ha}$ e a maior delas $(21 \mathrm{~kg} \mathrm{MS} / \mathrm{kg} \mathrm{N}$ ) com dose de $300 \mathrm{~kg} / \mathrm{ha}$. A porcentagem de $\mathrm{N}$ nas plantas foi incrementada significativamente até a dose de $300 \mathrm{~kg} \mathrm{~N} /$ ha.ano no período chuvoso e $400 \mathrm{~kg} \mathrm{~N} /$ ha.ano no período seco. A recuperação aparente do $\mathrm{N}$ variou entre 32,6 ? $200 \mathrm{~kg} \mathrm{~N} / \mathrm{ha}$.ano) e $44,7 \%$ (300 e $400 \mathrm{~kg} \mathrm{~N} / \mathrm{h}$ a.ano).

No mesmo sentido, Fernandez et al. (1983) trabalharam com áreas de Coastcross recém-estabelecidas, porém usando doses de 0,225, 450,675 e $810 \mathrm{~kg}$ $\mathrm{N} /$ ha.ano. Neste caso, os autores observaram incremento significativo de produção até $225 \mathrm{~kg} \mathrm{~N} / \mathrm{ha}$.ano no verão e $675 \mathrm{~kg} \mathrm{~N} /$ ha.ano no inverno. A conversão obtida foi da ordem de 42,5 a $19 \mathrm{~kg} \mathrm{MS} / \mathrm{kg} \mathrm{N}$ no período chuvoso e 32,1 a $14,8 \mathrm{~kg} \mathrm{MS} / \mathrm{kg} \mathrm{N}$ na época seca com irrigação. Resende et al. (1996) testaram 4 niveis de adubação nitrogenada $0,250,500$ e $750 \mathrm{~kg} \mathrm{~N} / \mathrm{ha}$.ano associados a 6 intervalos de corte de 2, 3, $4,5,6$ e 7 semanas nas águas e 4, 5, 6, 7, 8 e 9 semanas na seca. Os resultados obtidos revelaram produções que variaram de 2,2 a 18,6 tha na época das águas e 
produções anuais que variaram de 3,4 a $30,8 \mathrm{~kg} \mathrm{MS} / \mathrm{ha}$.ano. As menores produções foram obtidas na ausência de $\mathrm{N}$ e em cortes mais frequentes. Foi observada uma redução na relaçîio folha/haste quando aumentou-se o intervalo entre cortes (1,7 para 1,1 para os intervalos entre cortes de 2 para 7 semanas) e as doses de nitrogênio ( 1,6 para 1,3 para as doses de 0 a $750 \mathrm{~kg} \mathrm{~N} / \mathrm{ha}$.ano ). Os teores de PB aumentaram com o aumento de $\mathrm{N}(12,8$ a $17,9 \%$ nas águas e 11,1 a $16,1 \%$ na seca) e diminuíram com o aumento do intervalo entre cortes (19,5 a 12,2\% nas águas e 15,5 a 12,2 \% na seca). $O$ teor de F:DN variou de 60 a $73 \%$ sendo, para esta variável, mais expressivo o efeito de intervalo entre cortes.

Segundo Vilela \& Alvim (1998), o cultivar Coastcross é um hibrido estéril, obtido do cruzamento do cultivar Coastal e uma introdução de bermuda, de alta digestibilidade e pouco tolerante ao frio, proveniente do Quênia. No desempenho comparativo com outras bermudas, o Coastcross superou-as em produtividade, qualidade e desempenho animal. Comparado com Coastal em vários testes, foi $12 \%$ mais digestivel, apresentando maiores ganhos de peso quando consumido na forma de pasto $(30 \%)$ e feno (40\%). Este cultivar não cobre rapidamente o solo, mesmo tendo estolões vigorosos, o que torna-o susceptível à competição com outras espécies ou mesmo com bermuda comum. Possui colmos finos e boa relação haste/folha, entretanto essa relação se modifica conforme o manejo. Quando adubado e irrigado adequadamente, produz uma quantidade de forragem de boa qualidade, com boa distribuição ao longo do ano. As folhas são macias apresentando verde menos intenso do que o da grama estrela. Essa forrageira é muito indicada para fenação, já que desidrata com facilidade e também pode ser usada para pastejo.

Em relaççio ao Tifton-85, Burton (1993) cita-o como um cultivar híbrido, resultado do cruzamento de Tifton-68 com uma introdução proveniente da África do Sul. Caracteriza-se pela coloração escura, porte relativamente alto, com hastes maiores e folhas mais largas que Tifton-44 e Coastal, sendo também de qualidade consideravelmente superior à Coastal. Segundo Hill et al. (1998), Tifton-85 é uma pastagem de alto valor nutritivo, altamente tolerante a pastejo baixo e que responde de maneira notável à adubação nitrogenada, se houver disponibilidade de água. Hill et al. (1993) obtiveram uma massa de forragem, média de 3 anos, de $2440 \mathrm{~kg} \mathrm{MS} / \mathrm{ha}, 169$ dias de pastejo/arıo e novilhos com ganho de peso individual de 0,650 kg numa lotação de 1320 animais.dia/ha, o que resultou num ganho por área de $790 \mathrm{~kg} / \mathrm{ha}$.ano. O valor 
nutritivo da forragem pastejada por novilhos canulados foi, em média, $15 \%$ de proteina bruta, $73 \%$ de FDN, 34\% de FDA e $60 \%$ de DIVMO. Em outro experimento de 2 anos, Hill et al. (1997) mantiveram uma massa média de $2800 \mathrm{~kg} / \mathrm{ha}$ em 140 dias de pastejo/ano. O ganho obtido foi de $0,720 \mathrm{~kg} /$ novilho.dia, 1019 animais.dias/ha e um ganho por área de $747 \mathrm{~kg} / \mathrm{ha}$.ano. O valor nutritivo obtido neste experimento foi bastante semelhante ao obtido por Hill et al. (1993).

Pedreira (1995) relatou maiores taxas de lotação, maiores ganhos de peso vivo por ha e maior digestibilidade in vitro da matéria orgânica para Tifton-85 do que para Florakirk, na Flórida. Florakirk é um hibrido irmão de Tifton-68 com duas gramineas de cruzamentos recíprocos. Ambos são híbridos $F_{1}$ do cultivar Callie, contudo, Florakirk tem o cultivar Callie como linhagem paterna e Tifton-44 como linhagem materna. Os nós e entrenós de: Florakirk são glabros. A lígula consiste de uma membrana de 0,15 a 0,5 mm. A lâmina da folha mede de 2,5 a $25 \mathrm{~cm}$ de comprimento, de 1,4 a $5,5 \mathrm{~mm}$ de largura, é lisa, macia e suculenta. A inflorescência é composta de três a seis espiguetas, ocasionalmente oito, predominando a cor avermelhada. Possui rizomas e estolões. Isso caracteriza a Florakirk como sendo mais rústica e resistente ao frio que o cultivar Callie (Vilela \& Alvim, 1998).

Em 1995, Mislevy ${ }^{1}$ citado por Vilela \& Alvim (1998) obteve uma produção de Florakirk de 12,1 t/ha com uma freqüência de pastejo de 2 semanas e 16,5 t/ha para 4, 5 e 7 semanas, com teores de proteina bruta de $11,7,8,1,9,5,7,7$ e digestibilidade de $58,5,55,0,54,8$ e $51,3 \%$ para $2,4,5$ e 7 semanas, respectivamente. Na avaliação de Florakirk, Mislezvy (1995) ${ }^{1}$ citado por Vilela \& Alvim (1998) registrou em 208 dias de pastejo, ganho de peso de $407 \mathrm{~kg} / \mathrm{ha}$. Pedreira (1996) obteve para Florakirk ganho individual de $0,390 \mathrm{~kg} /$ novilho.dia e ganho por área de $541 \mathrm{~kg} / \mathrm{ha}$.ano com uma lotação média de 6,4 novilhos/ha.

Em virtude da pequena quantidade de informações sobre os cultivares de Cynodon spp. submetidos a pastejo por ovinos e o pouco conhecimento das relações planta - animal em plantas tropicais, faz-se necessário o conhecimento e geração de dados em condiçïes controladas de pastejo, visando o estabelecimeto de parâmetros guia importantes para a idealização de sistemas de produção animal eficientes,

\footnotetext{
${ }^{1}$ MISLEVY, P.. Florakirk bermudagrass. Gainsville: University of Florida, 1989. 15 p. (Circular s. 361)
} 
competitivos e econômicos. Assim, o objetivo deste trabalho foi avaliar três cultivares de Cynodon spp. ( Tifton-85, Florakirk e Coastcross) em relação à estrutura do pasto, produção de forragem, valor nutritivo e desempenho animal de ovinos em crescimento sob quatro condições fixas de intensidade de pastejo $(50,100,150,200 \mathrm{~mm})$ mantidas em "steady state" através de sistema de lotação continua e carga variável. 


\section{MATERIAIS E MÉTODOS}

\section{1 Área experimental}

O ensaio foi conduzido na Unidade Experimental de Plantas Forrageiras (UEPF) nas áreas do Departamento de Produção Animal - Setor Ruminantes da Escola Superior de Agricultura "Luiz de Queiroz" da Universidade de São Paulo, em

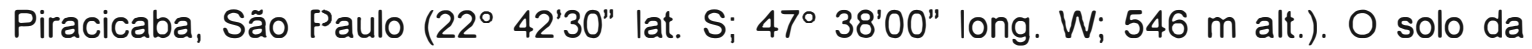
região é caracterizado como Terra Roxa estruturada eutrófica, com horizonte $A$ moderado e de textura argilosa $/$ muito argilosa. Por ocasião da instalação do experimento, a análise de solo revelava $\mathrm{pH}\left(\mathrm{CaCl}_{2}\right)=5,4 ; \mathrm{MO}\left(\mathrm{g} \mathrm{kg}^{-1}\right)=37,0 ; \mathrm{P}(\mathrm{mg}$ $\left.\mathrm{dm}^{-3}\right)=99 ; \mathrm{k}\left(\mathrm{cmol}_{\mathrm{c}}\right)=0,46 ; \mathrm{Ca}\left(\mathrm{cmol}_{\mathrm{c}}\right)=7,50 ; \mathrm{Mg}\left(\mathrm{cmol}_{\mathrm{c}}\right)=2,60 ; \mathrm{H}+\mathrm{Al}\left(\mathrm{cmol}_{\mathrm{c}}\right)=3,00$; $\mathrm{SB}\left(\mathrm{cmol}_{\mathrm{c}}\right)=10,60 ; \mathrm{T}\left(\mathrm{cmol}_{\mathrm{c}}\right)=13,60$ e $\mathrm{V}(\%)=78 \%$. Não foram realizadas adubações de correção devido à alta fertilidade do solo. A espécie utilizada foi Cynodon spp. devido à sua versatilidade de utilização como pasto, feno, silagem, etc.; à sua boa adaptação às condições de Brasil Central e ao renovado interesse pela espécie por parte da pesquisa agropecuária e do setor produtivo, em vista dos recentes lançamentos 'Tifton-85' e 'Florakirk'.

$O$ ensaio seguiu um delineamento em blocos completos casualizados com parcelas subdivididas (split-plot) com 4 repetiçōes, sendo que os cultivares foram dispostos nas parcelas e as alturas nas sub-parcelas. Os cultivares de Cynodon spp. (Tifton-85, Florakirk e Coastcross) foram estudados sob um sistema de lotação contínua e carga variável onde foram geradas quatro sub-parcelas com diferentes condições de pasto mantidas por ovinos sob pastejo. Cada condição de pasto correspondeu a uma altura de relvado $(50,100,150$ e $200 \mathrm{~mm})$ que foi mantida relativamente constante durante todo o período experimental. Assim, 0 ensaio apresentou um total de 48 unidades experimentais ( 4 blocos $\times 12$ unidades/ bloco) com uma área média de $400 \mathrm{~m}^{2}$ cada, totalizando uma área final de cerca de 2 ha (Figura 1 , Foto 1). 

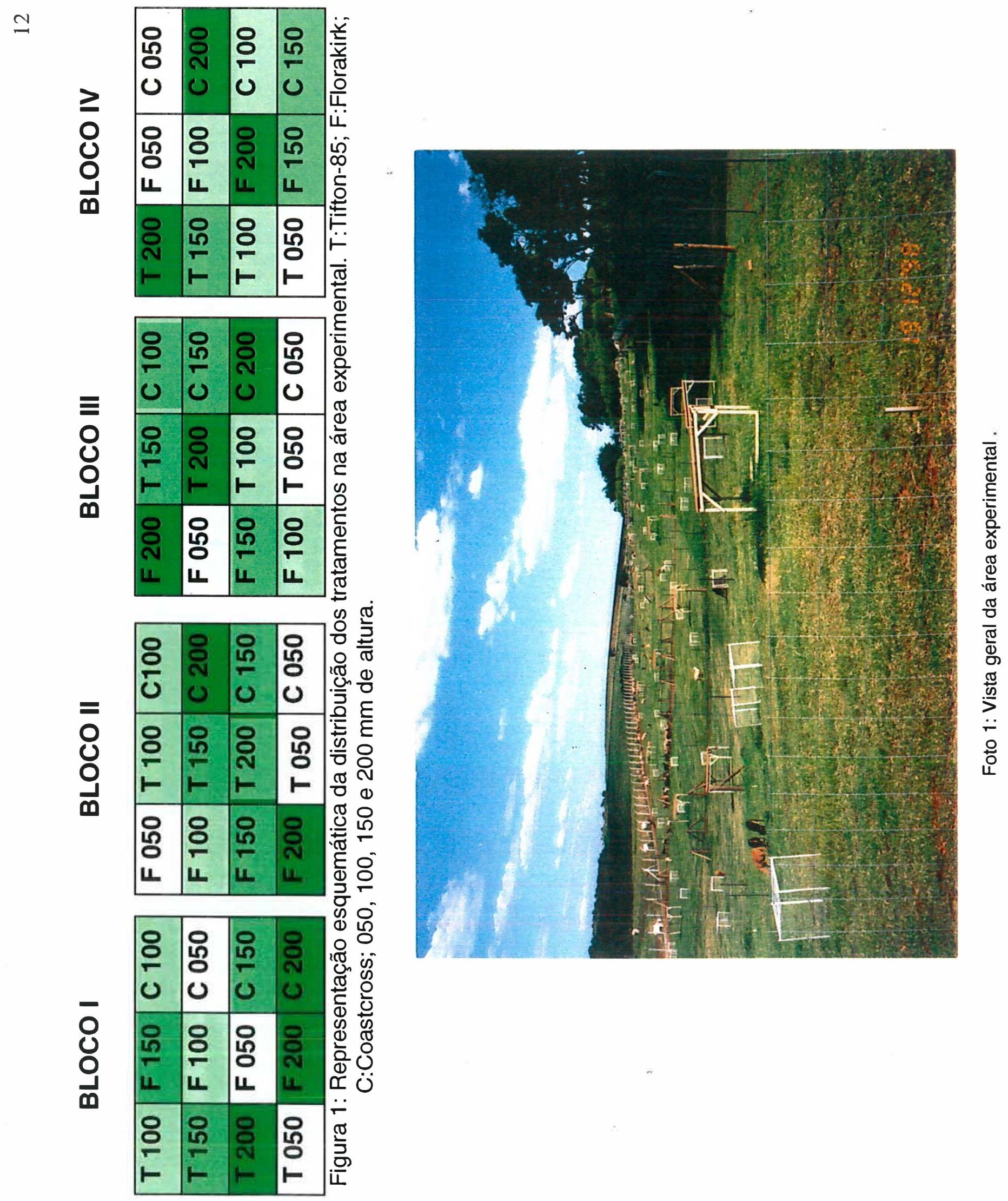
As parcelas atingiram as alturas dos tratamentos e passaram a ser controladas pelos animais a partir de junho de 1998, ocasião em que foram iniciadas as avaliações pré-experimentais. O período experimental efetivo foi de agosto de 1998 a abril de 1999. Durante o período experimental a temperatura média máxima diária foi de 31,4 ${ }^{\circ} \mathrm{C}$ e a mínima de $14,4{ }^{\circ} \mathrm{C}$. A precipitação total foi de $1400 \mathrm{~mm}$ e a umidade relativa do ar variou entre 64 e $90 \%$. Os dados meteorológicos encontram-se na Tabela 1 e Figura 2.

Tabela 1 - Dados climáticos considerados durante o período experimental (de Agosto/98 a Abril/99) e comparação com os dados dos últimos 80 anos.

\begin{tabular}{|c|c|c|c|c|c|c|}
\hline \multirow[b]{2}{*}{ Mês/ano } & \multicolumn{3}{|c|}{ Temperatura $\left({ }^{\circ} \mathrm{C}\right)$} & \multirow{2}{*}{$\begin{array}{c}\text { Chuva } \\
(\mathrm{mm}) \\
\text { Total } \\
\text { mensal }\end{array}$} & \multirow{2}{*}{$\begin{array}{c}\text { Umidade } \\
\text { Relativa (\%) } \\
\text { Média }\end{array}$} & \multirow{2}{*}{$\begin{array}{c}\text { Insolação } \\
\text { (h/dia) } \\
\text { Média }\end{array}$} \\
\hline & $\begin{array}{l}\text { Máxima } \\
\text { média }\end{array}$ & $\begin{array}{l}\text { Mínima } \\
\text { média }\end{array}$ & Média & & & \\
\hline Agosto/98 & 27,40 & 14,36 & 20,88 & 21,80 & 77,00 & 6,22 \\
\hline Média (80 anos) & 26,97 & 10,77 & 18,87 & 29,49 & 61,71 & 7,85 \\
\hline Setembro/98 & 27,65 & 15,29 & 21,47 & 63,30 & 64,78 & 5,68 \\
\hline Média (80 anos) & 27,72 & 13,16 & 20,43 & 62,98 & 62,21 & 6,67 \\
\hline Outubro/98 & 27,06 & 16,33 & 21,70 & 183,10 & 83,42 & 5,43 \\
\hline Média (80 anos) & 28,56 & 15,36 & 21,96 & 110,38 & 68,82 & 6,70 \\
\hline Novembro/98 & 30,04 & 16,45 & 23,24 & 26,60 & 76,60 & 7,79 \\
\hline Média (80 anos) & 23,10 & 16,60 & 29,60 & 128,00 & 69,00 & 7,60 \\
\hline Dezembro/98 & 30,01 & 19,21 & 24,61 & 200,16 & 74,30 & 6,58 \\
\hline Média (80 anos) & 28,86 & 17,68 & 23,26 & 199,00 & 71,45 & 6,33 \\
\hline Janeiro/99 & 30,59 & 20,41 & 25,50 & 382,80 & 87,97 & 4,91 \\
\hline Média (80 anos) & 29,57 & 18,67 & 24,10 & 225,10 & 73,25 & 6,27 \\
\hline Fevereiro/99 & 30,73 & 20,05 & 25,41 & 198,30 & 90,00 & 5,37 \\
\hline Média (80 anos) & 30,22 & 19,01 & 24,60 & 188,03 & 75,49 & 6,38 \\
\hline Março/99 & 31,42 & 18,98 & 25,20 & 210,80 & 80,74 & 7,70 \\
\hline Média (80 anos) & 29,94 & 18,18 & 24,04 & 143,36 & 75,85 & 6,74 \\
\hline Abril/99 & 28,52 & 15,20 & 21,86 & 89,00 & 80,70 & 8,09 \\
\hline Média (81 anos) & 28,32 & 15,36 & 21,81 & 64,79 & 74,17 & 7,50 \\
\hline
\end{tabular}

Fonte: Departamento de Ciências Exatas /Esalq/USP 


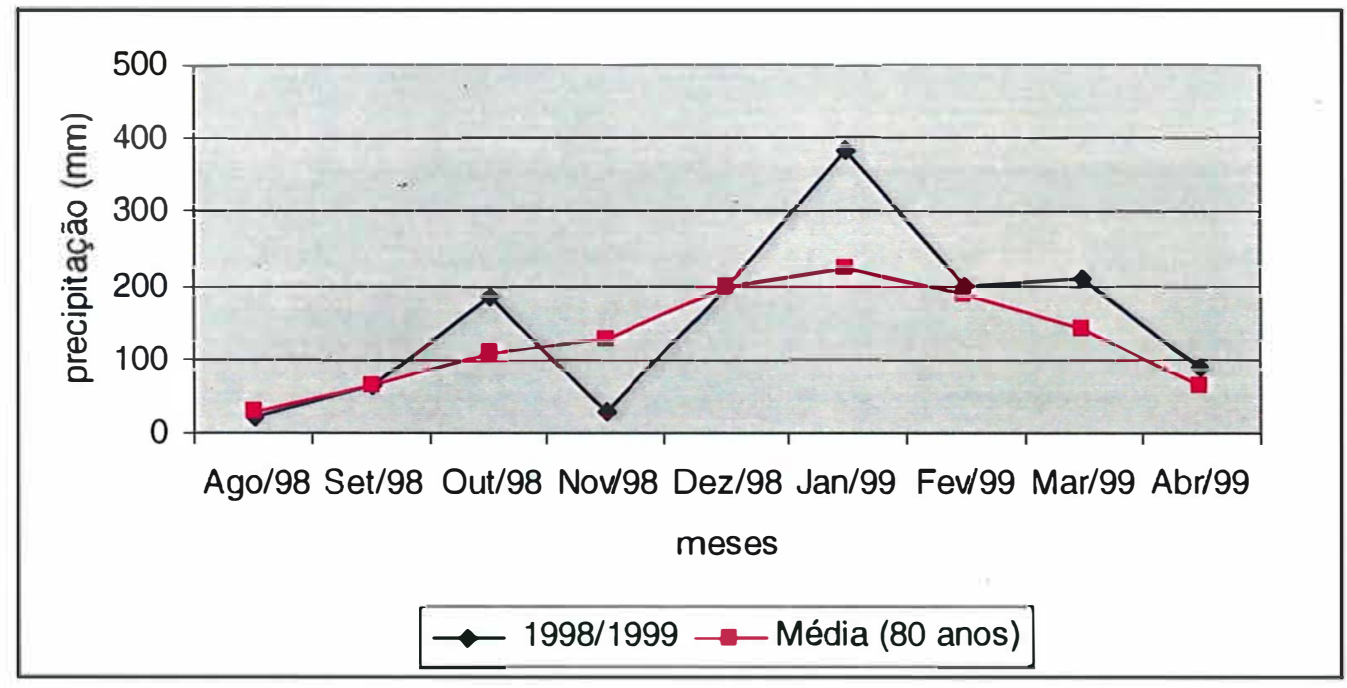

Figura 2: Distribuição do regime pluviométrico médio durante o período experimental (Agosto/98 a Abril/99) em relação à média dos últimos 80 anos.

\subsection{Monitoramento da altura}

Inicialmente as medições de altura dos piquetes foram realizadas com a utilização de uma régua, medindo-se do nível do solo até a curvatura da folha mais alta sem comprimi-la em 18 pontos por piquete e, através da média destes, obtinha-se a altura. Contudo, através deste método, o coeficiente de variação foi muito alto (40$50 \%$ ) e por isso o método foi modificado. Passou-se a utilizar uma folha de acetato (transparência) colocada na pastagem, onde eram lidas a maior e a menor altura com uma régua, obtendo-se assim a média. A princípio foram medidos 18 pontos/piquete mas, como o coeficiente de variação (CV) diminuiu sensivelmente (de 40 para 20\%) usou-se apenas 12 pontos/piquete. A diminuição do CV com o uso da transparência ocorreu porque, com esta, a medição de cada ponto passa a ser a média de uma área e não a medida de um ponto isolado. Contudo, apesar de expressar a altura eficientemente, o método necessitava de grande disponibilidade de tempo e pessoas, o que tornou-se limitante devido à grande quantidade de trabalho demandada para outras avaliações. Assim, a altura passou a ser monitorada semanalmente através de 20 medições, em cada piquete, com o rising plate meter (haste metálica com um prato 
de alumínio muito leve que se eleva quando inserida no dossel). Essa avaliação era feita duas vezes por semana, obtendo-se a altura comprimida. Uma vez por mês era feita a calibração da altura comprimida com a altura não comprimida (régua), sendo esta última a utilizada como referência para o monitoramento dos tratamentos. $\mathrm{O}$ novo método propiciou maior agilidade, economia de tempo e mão-de-obra sem interferir com a precisão dias avaliações. Determinada a altura da parcela, eram adicionados ou retirados animais em função desta e das alturas medidas anteriormente. Os animais traçadores de ganho de peso permaneciam o tempo todo dentro da parcela enquanto que ovinos adultos eram utilizados para a regulagem da carga e manutenção da altura desejada. Todos os animais que entravam ou saiam das parcelas eram submetidos a jejum de 16 horas, pesados e devidamente identificados. Nas situações onde o acúmulo de forraģem não foi suficiente para manter o par de traçadores, estes foram retirados da parcella e o número de dias ausente marcados.

\subsection{Calibração: Altura x Massa}

A calibraçăo entre altura e massa de forragem foi realizada uma vez por mês para relacionar a altura do tratamento com a massa de forragem. A cada mês era gerada uma equação de calibração para cada cultivar. Essas equações foram utilizadas para 0 cálculo de acúmulo de forragem, reduzindo a necessidade de amostragens destrutivas, e para o cálculo de densidade de forragem.

Com anéisi de $0,25 \mathrm{~m}^{2}$ de área, eram escolhidos dois pontos de cada parcela procurando sempre o ponto mais baixo e o ponto mais alto a fim de se obter a maior amplitude de alturas. Era medida a altura dentro do anel com a régua e com o rising plate meter e depois a forragem era cortada ao nivel do solo, lavada para eliminação de residuos de terra e fezes, seca em estufa a $65^{\circ} \mathrm{C}$ e pesada. Com isso foi possivel determinar uma regressão linear entre altura não comprimida e massa e outra entre altura comprimida e massa para cada cultivar em cada mês. As equações geradas são apresentadas no Anexo I. 


\subsection{Acúmulo de forragem}

O acúmulc de forragem foi obtido através do uso de gaiolas de exclusão $(0,70$ $\times 0,70 \times 0,70 m$ ) (vide Foto 2). Foram utilizadas três gaiolas por parcela, que, após um intervalo de 21 dias, eram retiradas e a altura era medida com o rising plate meter (5 leituras por gaiola). Essa altura era posteriormente transformada em massa através da equação de calitıração. Após a medição, as gaiolas eram reancoradas em novos pontos representativos da condição das parcelas, sempre tomando como referência a altura média do piasto.

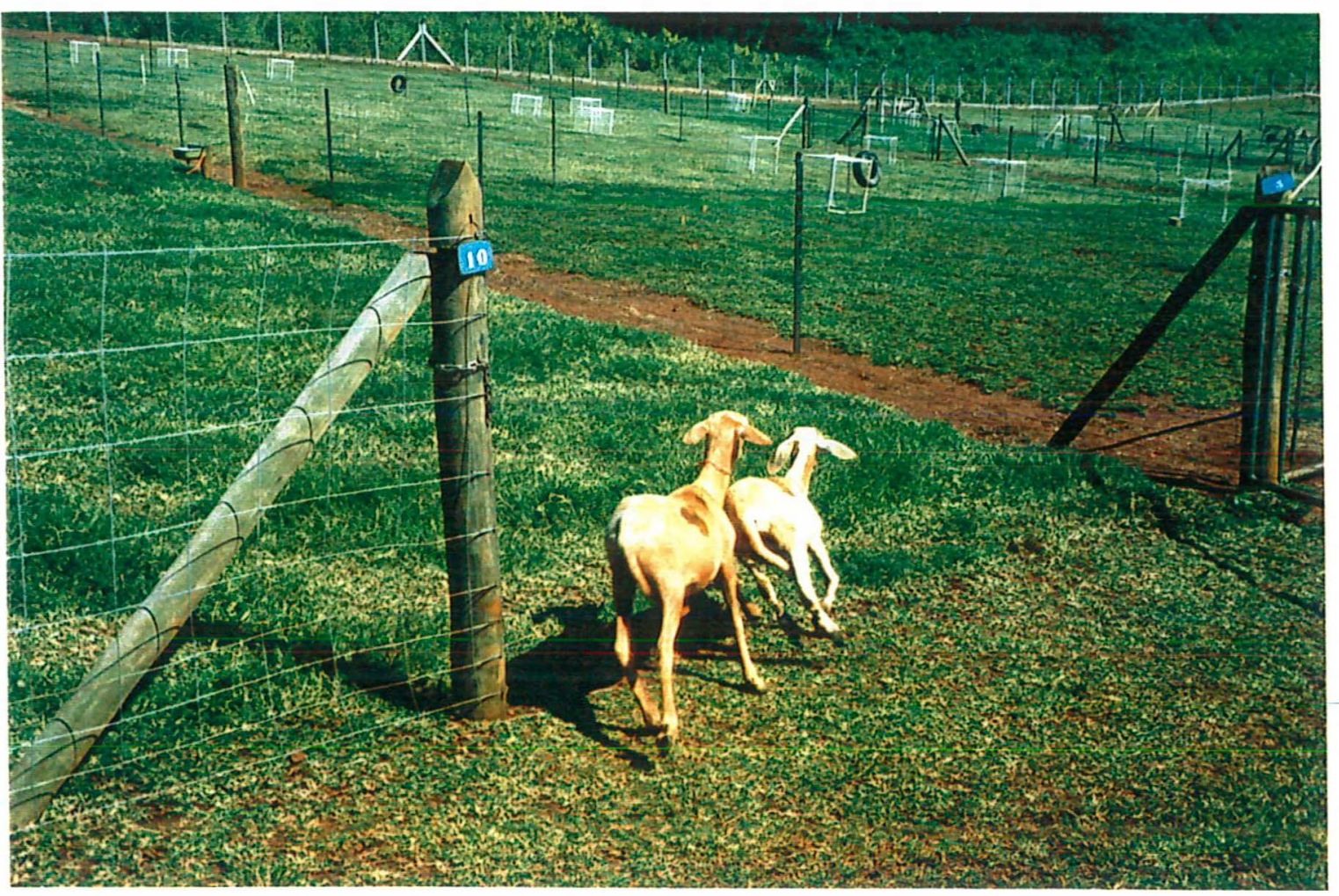

Foto 2: Gaiolas de exclusão (fundo) e animais traçadores na parcela experimental. 
O acúmulı de forragem foi estimado pelo método agronômico da diferença conforme a equação (Davies et al.,1993):

$$
A F=M F_{f}-M F_{i}
$$

sendo:

$\mathbf{A} \mathbf{F}=$ acumulo de forragem;

$\mathbf{M} \mathbf{F}_{\mathbf{f}}=$ massa de forragem, sob a gaiola, no último dia de exclusão (dia 21);

$\mathbf{M} \mathbf{F}_{\mathbf{I}}=$ massa de forragem média da parcela por ocasião da colocação das gaiolas (dia 1).

\subsection{Densidade de forragem ("bulk density")}

A densidade de forragem foi calculada a partir dos dados de altura média não comprimida do pasto e da massa de forragem correspondente, calculada a partir das equações de calibração. $O$ valor de massa de forragem foi dividido pela altura média e o quociente obtido foi a densidade ( $\mathrm{kg} \mathrm{MS} / \mathrm{cm}$.ha).

\subsection{Disponibilidade de forragem}

Foi obtida através da relação entre a taxa de acúmulo de forragem $(\mathrm{kg}$ MS/ha.dia) e o total de peso vivo dos animais presentes na área no periodo correspondente ( $\mathrm{kg}$ PV/ha.dia). Assim, obteve-se a disponibilidade de forragem expressa em $\mathrm{kg} \mathrm{MS} / 100 \mathrm{~kg}$ PV.dia durante todo o periodo. 


\subsection{Composição da forragem}

\subsubsection{Coleta e armazenamento das amostras}

Para a coleta das amostras foi utilizado o método de simulação de pastejo proposto por Sollenberger \& Cherney (1995). Segundo esses autores esta seria a melhor maneira de realizar uma coleta o mais próximo possivel do que os animais estariam consumindo. As amostras foram coletadas pelo método "hand-plucking" no qual coleta-se manualmente a forragem após prévia observação do hábito de pastejo dos animais. Foram coletados aproximadamente $300 \mathrm{~g}$ de forragem fresca por unidade experimental.

\subsubsection{Processamento e análise do material}

O material coletado foi acondicionado em sacos plásticos devidamente identificados. Após a coleta, as amostras foram levadas para uma câmara fria com o intuito de reduzir a perda de água e de nutrientes através de respiração celular. De cada amostra foi retirada uma sub-amostra para fins de separação morfológica. $O$ restante da amostra foi levado para estufa de circulação de ar forçado a $65^{\circ} \mathrm{C}$, onde permanecia por 48 horas (tempo suficiente para 0 material apresentar consistência quebradiça). Após a secagem, o material era moído em moinho tipo Wiley com peneira de $1 \mathrm{~mm}$ e encaminhado para as análises químicas no laboratório de bromatologia.

Em cada amostra foram determinados os teores de matéria seca (MS), matéria mineral (MM) de acordo com Silva (1990), proteina bruta (PB) seguindo Pereira \& Rossi (1996), fibra em detergente neutro (FDN), fibra em detergente ácido (FDA) e lignina segundo o método de Van Soest et al. (1991) e a digestibilidade in vitro da matéria orgânica (DIVMO). Para a obtenção do teor de MS, uma amostra de cada parcela em duplicata foi pesada e colocada em estufa a $105{ }^{\circ} \mathrm{C}$ por 12 horas; o material seco foi pesado. Posteriormente, foi queimado em mufla a $600{ }^{\circ} \mathrm{C}$ por 3 horas obtendo-se, assin, a matéria mineral (MM). O teor de proteína bruta (PB) foi determinado pelo método micro Kjeldahl. $O$ valor de nitrogênio obtido foi multiplicado pelo fator 6,25 porque, em média, a proteína tem $16 \%$ de $N$, resultando no teor de PB 
Para determinação dos teores de fibra em detergente neutro (FDN), fibra em detergente ácido (FDA) e lignina foi utilizado o aparelho Fiber Analyser, que propicia uma maior agilidade das atividades e redução de tempo em relação aos aparelhos convencionais de determinação das frações de fibra, contudo, o principio da análise é - mesmo. A determinação da digestibilidade in vitro da matéria orgânica foi feita através da utilização do aparelho Daisy Incubator /I que também utiliza o mesmo tipo de saquinho utilizado nas análises de fibra. Este aparelho propiciou maior precisão das análises já cque o ambiente é mantido totalmente anaeróbico, não havendo a necessidade de injeção de $\mathrm{CO}_{2}$ durante a digestão e $\circ \mathrm{pH}$ também é mantido pela adição de soluções tamponantes no inicio do processo.

Para a obtenção do NDT ( Nutrientes Digestiveis Totais) , utilizou-se a equação proposta por Harlian et al (1991): NDT = 109,64 - 1,479 * FDA

\subsubsection{Composição morfológica da forragem}

A sub-amcıstra gerada a partir das amostras utilizadas para análise química foi dividida em: folhas verdes (lâminas foliares), folhas senescentes, hastes (hastes + bainhas) e material morto. Cada componente foi colocado em saquinhos de papel, devidamente identificados, secos por 48 horas e pesados. As proporções dos componentes nas amostras foram calculadas como a porcentagem do peso total.

\subsection{Estrutura do pasto}

A avaliação da estrutura do pasto foi feita através de amostragens destrutivas onde fez-se a sepraração morfológica da forragem colhida em folhas (lâminas foliares), hastes (hastes + bainhas) e material morto. Foram utilizados 2 quadrados $0,25 \mathrm{~m}$ de lado por parcela, sendo que toda a forragem colhida no interior de cada quadrado foi cortada ao nivel do solo. 


\subsection{Desempenho Animal}

\subsubsection{Animal}

Para avaliar desempenho animal foram utilizados ovinos deslanados em crescimento, mestiços da raça Santa Inês com grau de sangue variável, com idade média de 9 meses no início do período experimental e que foram, posteriormente, substituidos quando completaram um ano de vida. Os novos animais tinham idade média de 4 meses e foram alocados às parcelas em novembro de 1998. Os animais foram separados segundo raça, sexo, idade e peso seguindo essa ordem de importância. O pares traçadores somavam o mesmo peso para todas as parcelas dentro do bloco. A distribuição dos grupos para os blocos e dos pares para as parcelas foi aleatória.

Para avaliar ganho de peso vivo individual foram utilizados dois animais traçadores por parcela. Foram avaliados Ganho de Peso Vivo (GPV) por animal e por área e Capacidade de Suporte (CS). As pesagens foram mensais (Foto 3), sempre no mesmo horário do dia, com jejum de água e alimento por 16 horas. Os animais eram presos à tarde e pesados na manhã do dia seguinte. De acordo com Matches (1969), o jejum evita possíveis variações diárias de peso devido ao enchimento gastro-intestinal, oferecendo maior segurança e confiabilidade nos resultados obtidos. Os animais que regulavam a carga nas parcelas para manutenção da altura de pastejo eram pesados na entrada e na saída, também após jejum (Foto 2). 


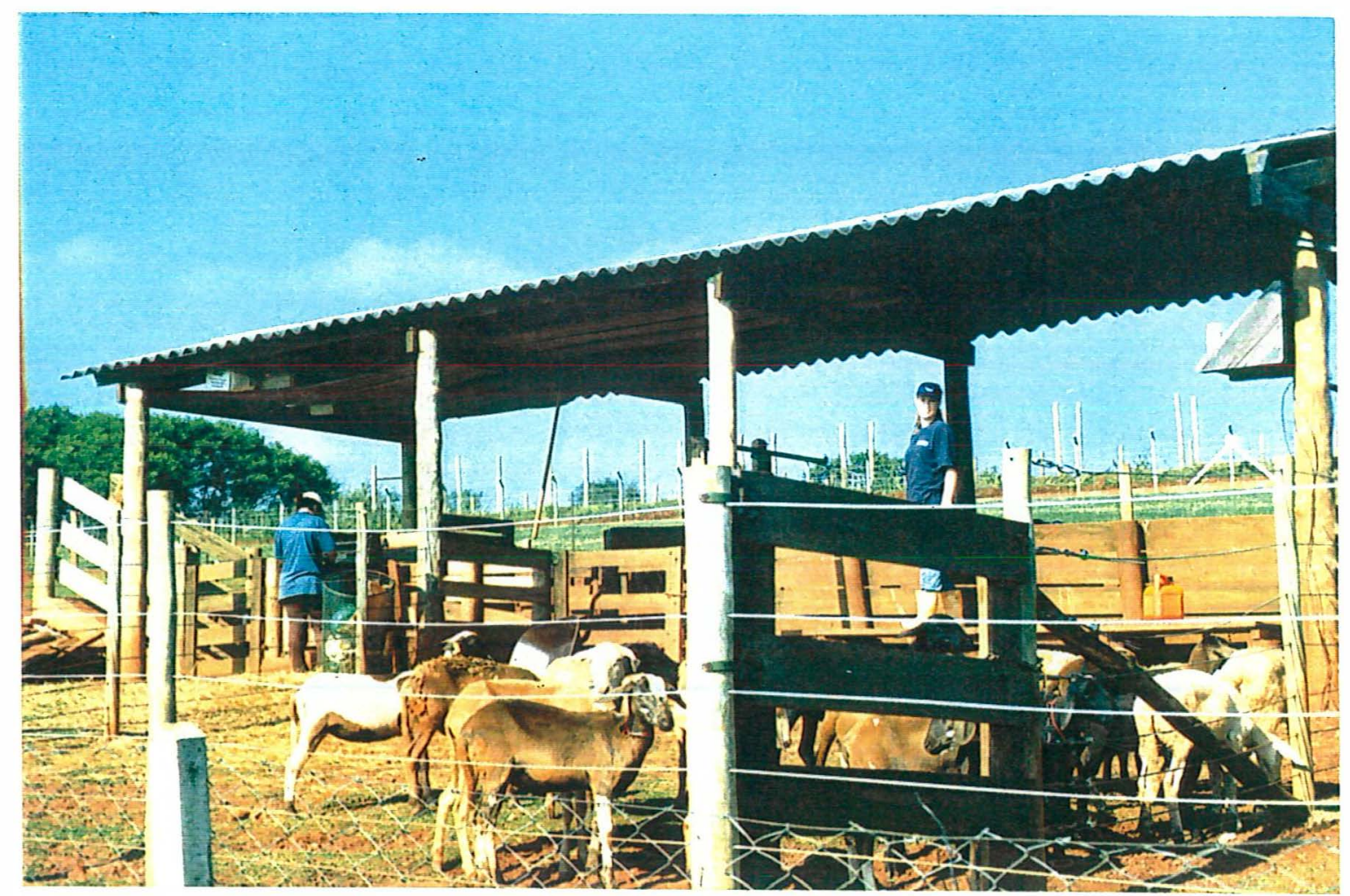

Foto 3: Centro de manejo dos animais onde eram realizadas as pesagens.

\subsubsection{Estimativas de consumo}

O consumo de forragem foi estimado através de cálculos feitos a partir do peso do animal, ganho de peso vivo, energia metabólica do alimento e a exigência nutricional da calegoria animal, segundo Le Du \& Penning (1982). As equações utilizadas para esita estimativa foram as seguintes:

$E D=(0,1233 \times P(3)+(0,17050 \times D M O)+0,2850$

$E m a=0,8150 \times E D$

$E m c=\operatorname{antilog}[1,11 \times \log 10(\mathrm{GPI})+(0,004 \times \mathrm{PV})-2,1] / 0,04350 \times \mathrm{Ema}$

$\mathrm{Emm}=1,4+(0,150 \times \mathrm{PV})$

Consumo $=(E m c+E m m) / E m a$

Onde:

$E D \Rightarrow$ Energia Diçestivel 


$$
\begin{aligned}
& \mathrm{PB} \Rightarrow \text { Proteina Bruta } \\
& \mathrm{DMO} \Rightarrow \text { Digestibilidade da Matéria Orgânica } \\
& \text { Ema } \Rightarrow \text { Energia Metabolizável do alimento } \\
& \text { Emc } \Rightarrow \text { Energia Metabolizável de Crescimento } \\
& \mathrm{GPI} \Rightarrow \text { Ganho de Peso Individual } \\
& \mathrm{PV} \Rightarrow \text { Peso Vivo } \\
& \text { Emm } \Rightarrow \text { Energia Metabolizável de Manutenção }
\end{aligned}
$$

A partir destas equações foi possivel obter-se também os valores de concentração de ennergia metabolizável da forragem "consumida". 


\section{Resultados e Discussão}

Sempre que ocorreu interação significativa $(P<0,05)$ entre os fatores estudados (cultivar e altura do pasto) efetuou-se o desmembramento dos dados.

\subsection{Taxas de acúmulo de forragem}

As taxas cle acúmulo de matéria seca obtidas no periodo apresentaram efeito de tempo e bloco, interação entre tempo $x$ cultivar e tempo $x$ bloco $(P<0,05)$. Os dados mostram, de uma forma geral, uma menor taxa de acúmulo para o cultivar Florakirk e o cultivar Tifton-85 apresenta, na maior parte dos meses, os maiores valores observados (Tabela 2). Observando a Figura 3, nota-se o padrão estacional de produção de forragem. Houve uma redução de produção no mês de novembro devido a uma forte estiagem ocorrida nesse período (Tabela 1 e Figura 3).

Tabela 2: Taxa de acúmulo de forragem expressa em $\mathrm{kg} \mathrm{MS/ha.dia} \mathrm{para} \mathrm{os} \mathrm{cultivares}$ de Cynodon durante o periodo experimental.

\begin{tabular}{ccccc}
\hline Mês & Tifton-85 & Florakirk & Coastcross & EPM \\
\hline Agosto & $27,8 \mathrm{~b}$ & $37,5 \mathrm{ab}$ & $40,0 \mathrm{a}$ & 4,2 \\
Setembro & $29,2 \mathrm{ab}$ & $24,5 \mathrm{~b}$ & $35,3 \mathrm{a}$ & 2,3 \\
Outubro & $70,6 \mathrm{a}$ & $52,3 \mathrm{a}$ & $70,1 \mathrm{a}$ & 6,9 \\
Novembro & $57,1 \mathrm{a}$ & $38,2 \mathrm{~b}$ & $50,7 \mathrm{ab}$ & 5,2 \\
Dezembro & $104,3 \mathrm{a}$ & $79,2 \mathrm{~b}$ & $84,4 \mathrm{ab}$ & 7,3 \\
Janeiro & $105,6 \mathrm{a}$ & $90,1 \mathrm{~b}$ & $90,6 \mathrm{ab}$ & 5,6 \\
Fevereiro & $97,6 \mathrm{a}$ & $71,9 \mathrm{~b}$ & $91,1 \mathrm{a}$ & 5,8 \\
Março & $95,0 \mathrm{a}$ & $88,3 \mathrm{a}$ & $106,5 \mathrm{a}$ & 8,2 \\
Abril & $26,2 \mathrm{a}$ & $43,5 \mathrm{a}$ & $40,4 \mathrm{a}$ & 2,9
\end{tabular}

Médias seguidas de letras diferentes na mesma linha são diferentes $(P<0,05)$.

EPM- Erro padrão da média. 


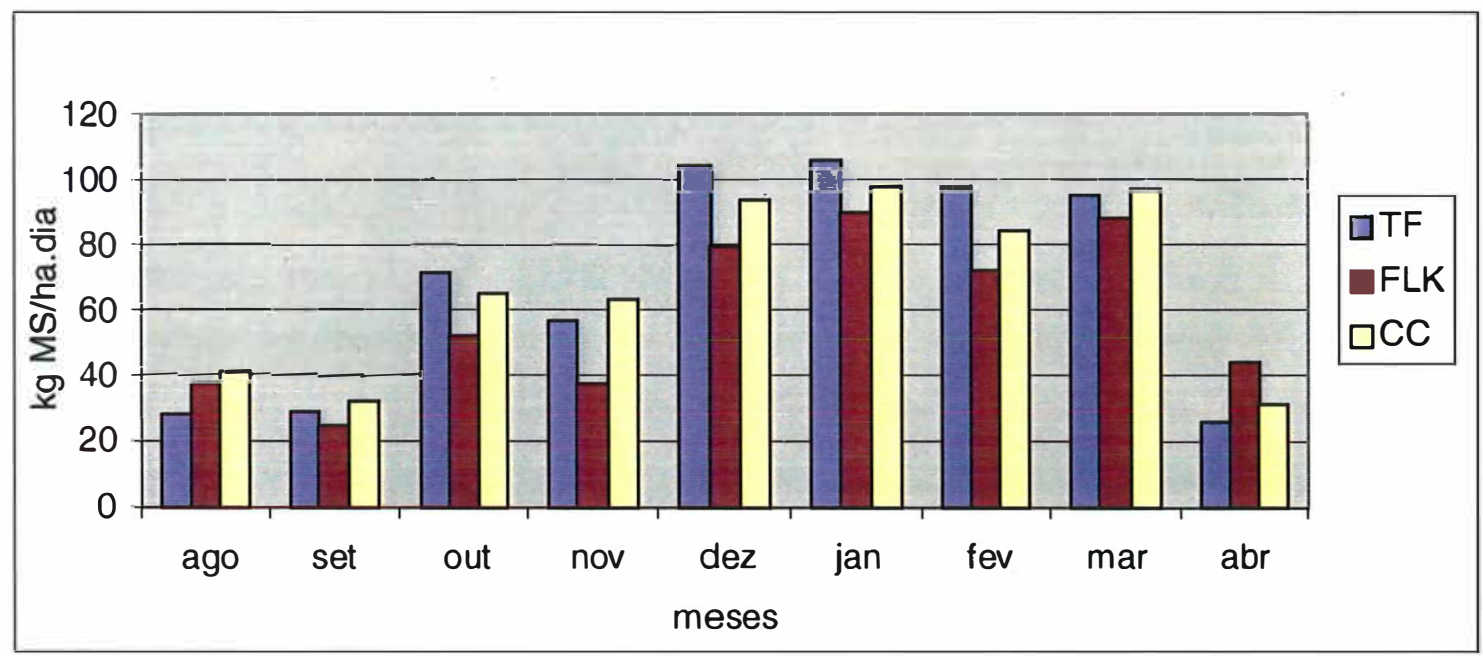

Figura 3: Taxas de acúmulo de forragem para os três cultivares de Cynodon durante o período experimental.

Apesar de não terem sido observadas diferenças $(P>0,05)$ entre as alturas, possivelmente essas diferenças existiram. Elas provavelmente não foram detectadas em função do método utilizado para determinação do acúmulo. Segundo Frame (1981), o método baseado em gaiola de exclusão promove uma superestimativa da quantidade de forragem nos pastos mais baixos e uma subestimativa nos pastos mais altos. Isso acontece porque os pastos mantidos sempre baixos possuem uma alta quantidade de perfilhos pequenos e uma baixa interceptação de luz. Quando estes pastos são isolados da ação do animal, crescem em tamanho sem haver uma redução proporcional na densidade de perfilhos durante o período de avaliação, ou seja, há um lag de tempo entre o sinal de competição por luz e a morte dos perfilhos para um novo equilíbrio. Durante esse período, portanto, estimativas de acúmulo são inflacionadas. Já em pastos mais altos, a interceptação de luz encontra-se mais próxima de valores elevados, diferentemente dos pastos mais baixos. Assim, para o mesmo período de acúmulo (21 dias), chega-se a interceptação de $95 \%$ da luz mais cedo, com redução drástica do acúmulo no período. As taxas de acúmulo para as diferentes alturas de pastejo podem ser visualizadas na Tabela 3 e Figura 4. 
Tabela 3: Taxa de acúmulo de forragem expressa em $\mathrm{kg} \mathrm{MS} / \mathrm{ha}$.dia nas quatro intensidades de pastejo $(50,100,150$ e $200 \mathrm{~mm})$ durante o período experimental.

\begin{tabular}{cccccc}
\hline Mês & 50 & 100 & 150 & 200 & EPM \\
\hline Agosto & $32,2 \mathrm{a}$ & $36,8 \mathrm{a}$ & $30,8 \mathrm{a}$ & $40,6 \mathrm{a}$ & 4,9 \\
Setembro & $29,7 \mathrm{a}$ & $26,7 \mathrm{a}$ & $30,4 \mathrm{a}$ & $31,8 \mathrm{a}$ & 2,7 \\
Outubro & $66,2 \mathrm{a}$ & $65,3 \mathrm{a}$ & $61,3 \mathrm{ab}$ & $64,6 \mathrm{a}$ & 8,1 \\
Novembro & $46,6 \mathrm{ab}$ & $38,1 \mathrm{~b}$ & $46,6 \mathrm{a}$ & $63,4 \mathrm{a}$ & 6,1 \\
Dezembro & $89,1 \mathrm{a}$ & $90,2 \mathrm{a}$ & $84,3 \mathrm{a}$ & $93,5 \mathrm{a}$ & 8,6 \\
Janeiro & $103,6 \mathrm{a}$ & $91,8 \mathrm{a}$ & $88,8 \mathrm{a}$ & $97,5 \mathrm{a}$ & 6,6 \\
Fevereiro & $88,4 \mathrm{a}$ & $92,1 \mathrm{a}$ & $83,5 \mathrm{a}$ & $83,5 \mathrm{a}$ & 6,8 \\
Março & $94,9 \mathrm{a}$ & $103,7 \mathrm{a}$ & $91,2 \mathrm{a}$ & $96,7 \mathrm{a}$ & 9,6 \\
Abril & $45,0 \mathrm{a}$ & $31,7 \mathrm{~b}$ & $39,3 \mathrm{a}$ & $30,8 \mathrm{~b}$ & 3,4 \\
\hline
\end{tabular}

Médias seguidas de letras diferentes na mesma linha são diferentes $(P<0,05)$.

EPM- Erro padrão da média.

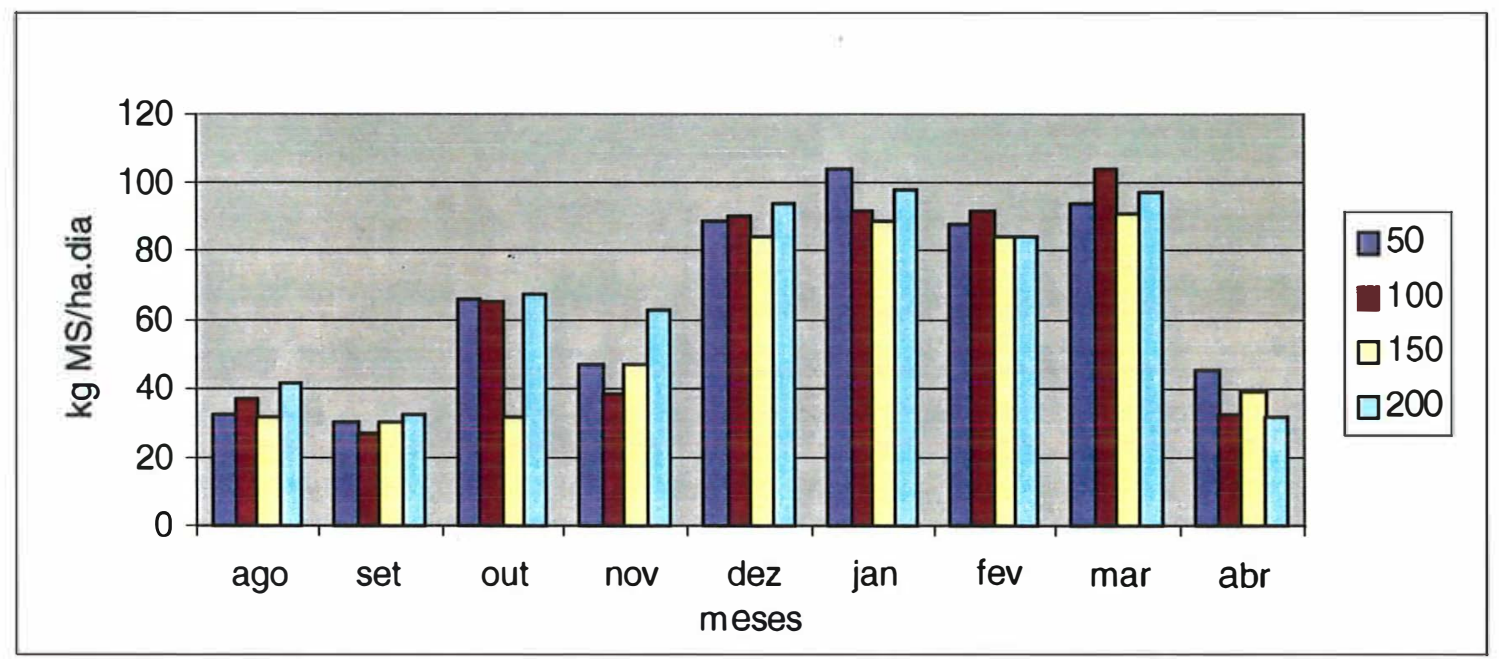

Figura 4: Taxas de acúmulo de forragem para as quatro intensidades de pastejo $(50,100,150$ e $200 \mathrm{~mm}$ ) durante o período experimental. 


\subsection{Composição morfológica e valor nutritivo da forragem "consumida"}

A composiçăo morfológica do material coletado pode ser visualizada nas Tabelas 4, 5, 6, 7, 8, 9, 10 e 11. Foram detectados efeito de tempo, cultivar, bloco e altura e interações entre tempo $x$ cultivar, tempo $x$ bloco e tempo $x$ altura $(P<0,05)$ para $\%$ de folhas; efeito de tempo, cultivar e bloco e interações entre tempo $x$ cultivar, tempo $x$ cultivar $x$ bloco e tempo $x$ altura $(P<0,05)$ para \% de hastes; efeito de tempo e cultivar e interação entre tempo $x$ bloco $(P<0,05)$ para \% de folhas senescentes e efeito de tempo, cultivar, bloco e altura e interações tempo $x$ cultivar e tempo $x$ bloco $(P<0,05)$ para \% de material morto. De agosto/98 a fevereiro/99 Tifton-85 apresentou a maior porcentagem de folhas em relação aos outros cultivares. Florakirk ficou em situação intermediária, encquanto que $\circ$ Coastcross apresentou as menores porcentagens de folhas nas amostras coletadas em simulação de pastejo. Esta tendência foi alterada nos meses de março a abril de 1999 (Tabela 4).

Tabela 4: Porcentagem de folhas em amostras de forragem de simulação de pastejo para os cultivares de Cynodon durante o período experimental.

\begin{tabular}{ccccc}
\hline Mês & Tifton-85 & Florakirk & Coastcross & EPM \\
\hline Agosto & $72,6 \mathrm{a}$ & $62,8 \mathrm{a}$ & $32,3 \mathrm{~b}$ & 3,9 \\
Setembro & $73,4 \mathrm{a}$ & $59,7 \mathrm{~b}$ & $55,8 \mathrm{~b}$ & 3,2 \\
Outubro & $84,5 \mathrm{a}$ & $76,9 \mathrm{~b}$ & $61,4 \mathrm{c}$ & 3,4 \\
Novembro & $60,9 \mathrm{a}$ & $58,2 \mathrm{a}$ & $46,9 \mathrm{~b}$ & 2,4 \\
Dezembro & $65,9 \mathrm{a}$ & $65,6 \mathrm{ab}$ & $56,2 \mathrm{~b}$ & 3,3 \\
Janeiro & $69,7 \mathrm{a}$ & $59,3 \mathrm{~b}$ & $67,6 \mathrm{a}$ & 3,2 \\
Fevereiro & $74,1 \mathrm{a}$ & $70,8 \mathrm{a}$ & $66,8 \mathrm{a}$ & 3,4 \\
Março & $61,8 \mathrm{a}$ & $64,2 \mathrm{a}$ & $66,4 \mathrm{a}$ & 2,9 \\
Abril & $57,0 \mathrm{a}$ & $59,1 \mathrm{a}$ & $63,4 \mathrm{a}$ & 3,6 \\
\hline
\end{tabular}

Médias seguidas dẹ letras diferentes na mesma linha são diferentes $(P<0,05)$.

EPM- Erro padrão cla média. 
Em relação às alturas, os pastos mais baixos tenderam a apresentar maior porcentagem de folhas que pastos mais altos, apesar de em muitos meses não terem sido observadas cliferenças estatísticas $(P>0,05)$ (Tabela 5$)$.

Tabela 5: Porcentagem de folhas em amostras de forragem de simulação de pastejo nas quatro intensidades de pastejo $(50,100150$ e $200 \mathrm{~mm})$ durante $\circ$ periodo experimental.

\begin{tabular}{cccccc}
\hline Mês & 50 & 100 & 150 & 200 & EPM \\
\hline Agosto & $52,6 \mathrm{a}$ & $59,1 \mathrm{a}$ & $53,5 \mathrm{a}$ & $58,4 \mathrm{a}$ & 4,6 \\
Setembro & $66,5 \mathrm{a}$ & $56,7 \mathrm{a}$ & $63,5 \mathrm{a}$ & $63,1 \mathrm{a}$ & 3,8 \\
Outubro & $75,7 \mathrm{a}$ & $73,2 \mathrm{a}$ & $78,6 \mathrm{a}$ & $69,6 \mathrm{a}$ & 4,0 \\
Novembro & $60,6 \mathrm{a}$ & $58,1 \mathrm{a}$ & $48,7 \mathrm{~b}$ & $53,9 \mathrm{ab}$ & 2,8 \\
Dezembro & $72,2 \mathrm{a}$ & $65,1 \mathrm{ab}$ & $55,5 \mathrm{~b}$ & $57,3 \mathrm{~b}$ & 3,9 \\
Janeiro & $73,5 \mathrm{a}$ & $63,6 \mathrm{ab}$ & $63,2 \mathrm{ab}$ & $61,7 \mathrm{~b}$ & 3,7 \\
Fevereiro & $69,4 \mathrm{a}$ & $73,4 \mathrm{a}$ & $70,6 \mathrm{a}$ & $68,9 \mathrm{a}$ & 4,0 \\
Março & $63,8 \mathrm{~b}$ & $58,8 \mathrm{~b}$ & $57,3 \mathrm{~b}$ & $76,6 \mathrm{a}$ & 3,4 \\
Abril & $65,8 \mathrm{a}$ & $59,3 \mathrm{ab}$ & $63,5 \mathrm{a}$ & $50,7 \mathrm{~b}$ & 4,2 \\
\hline
\end{tabular}

Médias seguidas de letras diferentes na mesma linha são diferentes $(P<0,05)$.

EPM- Erro padrão da média.

A porcentagem de hastes foi maior nos meses de novembro e janeiro, atingindo valores de até $28 \%$. Coastcross apresentou, em geral, a maior porcentagem de hastes em relação aos outros cultivares. Tifton- 85 apresentou as menores porcentagens de hastes de agosto a janeiro e Florakirk assumiu um comportamento intermediário (Tabela 6). 
Tabela 6: Porcentagem de hastes de amostras de forragem de simulação de pastejo para os cultivares de Cynodon durante o período experimental.

\begin{tabular}{ccccc}
\hline Mês & Tifton-85 & Florakirk & Coastcross & EPM \\
\hline Agosto & $11,6 \mathrm{~b}$ & $18,9 \mathrm{~b}$ & $37,6 \mathrm{a}$ & 2,9 \\
Setembro & $9,9 \mathrm{~b}$ & $16,8 \mathrm{a}$ & $19,7 \mathrm{a}$ & 2,2 \\
Outubro & $5,5 \mathrm{~b}$ & $7,7 \mathrm{~b}$ & $25,6 \mathrm{a}$ & 1,7 \\
Novembro & $22,6 \mathrm{~b}$ & $27,9 \mathrm{a}$ & $28,4 \mathrm{a}$ & 1,9 \\
Dezembro & $11,9 \mathrm{~b}$ & $14,5 \mathrm{~b}$ & $26,0 \mathrm{a}$ & 3,5 \\
Janeiro & $20,3 \mathrm{a}$ & $25,0 \mathrm{a}$ & $23,1 \mathrm{a}$ & 1,9 \\
Fevereiro & $15,9 \mathrm{ab}$ & $12,3 \mathrm{~b}$ & $20,5 \mathrm{a}$ & 2,2 \\
Março & $22,0 \mathrm{a}$ & $12,5 \mathrm{~b}$ & $18,2 \mathrm{a}$ & 2,2 \\
Abril & $19,1 \mathrm{a}$ & $16,4 \mathrm{a}$ & $19,2 \mathrm{a}$ & 1,9 \\
\hline
\end{tabular}

Médias seguidas de letras diferentes na mesma linha são diferentes $(P<0,05)$.

EPM- Erro padrão da média.

Em relaçäo às alturas, houve uma tendência dos pastos mais baixos apresentarem maior porcentagem de hastes nos meses de agosto e novembro e nos pastos mais altos em novembro, dezembro e janeiro (Tabela 7). 
Tabela 7: Porcentagem de hastes em amostras de simulação de pastejo nas quatro intensidades de pastejo $(50,100,150$ e $200 \mathrm{~mm})$ durante o período experimental.

\begin{tabular}{cccccc}
\hline Mês & 50 & 100 & 15 & 200 & EPM \\
\hline Agosto & $29,9 \mathrm{a}$ & $24,0 \mathrm{ab}$ & $20,4 \mathrm{ab}$ & $16,6 \mathrm{~b}$ & 3,4 \\
Setembro & $12,1 \mathrm{~b}$ & $19,6 \mathrm{a}$ & $16,4 \mathrm{ab}$ & $13,9 \mathrm{ab}$ & 2,6 \\
Outubro & $13,3 \mathrm{a}$ & $13,8 \mathrm{a}$ & $12,4 \mathrm{a}$ & $12,3 \mathrm{a}$ & 2,0 \\
Novembro & $27,7 \mathrm{ab}$ & $22,1 \mathrm{~b}$ & $29,5 \mathrm{a}$ & $26,0 \mathrm{ab}$ & 2,2 \\
Dezembro & $12,7 \mathrm{a}$ & $15,7 \mathrm{a}$ & $22,9 \mathrm{a}$ & $18,4 \mathrm{a}$ & 4,2 \\
Janeiro & $16,0 \mathrm{c}$ & $25,2 \mathrm{ab}$ & $21,1 \mathrm{bc}$ & $29,0 \mathrm{a}$ & 2,2 \\
Fevereiro & $15,1 \mathrm{a}$ & $14,7 \mathrm{a}$ & $17,7 \mathrm{a}$ & $17,4 \mathrm{a}$ & 2,5 \\
Março & $18,8 \mathrm{a}$ & $18,1 \mathrm{a}$ & $19,5 \mathrm{a}$ & $13,8 \mathrm{a}$ & 2,5 \\
Abril & $18,6 \mathrm{a}$ & $18,3 \mathrm{a}$ & $15,0 \mathrm{a}$ & $21,0 \mathrm{a}$ & 2,2 \\
\hline
\end{tabular}

Médias seguidas de letras diferentes na mesma linha são diferentes $(P<0,05)$.

EPM- Erro padrão da média.

A participação da haste no valor nutritivo da dieta é importante, porém a participação de folhas em senescência e material morto, que são as partes da planta menos selecionadas pelos animais, assumem um papel decisivo no valor nutritivo. Quanto maior a proporção desses componentes, menor será o valor nutritivo da dieta. Coastcross foi o cultivar que apresentou as menores proporções de folhas senescentes (Tabela 8) e as maiores proporções de material morto (Tabela 9) na composição total da dieta. Tifton-85 e Florakirk apresentaram a maior proporção de folhas senescentes e menor proporção de material morto em relação ao Coastcross. 
Tabela 8: Porcentagem de folhas senescentes em amostras de forragem de simulação de pastejo para os cultivares de Cynodon durante o periodo experimental.

\begin{tabular}{ccccc}
\hline Mês & Tifton-85 & Florakirk & Coastcross & EPM \\
\hline Agosto & $4,5 \mathrm{a}$ & $5,1 \mathrm{a}$ & $1,6 \mathrm{~b}$ & 0,8 \\
Setembro & $4,8 \mathrm{ab}$ & $7,2 \mathrm{a}$ & $1,8 \mathrm{~b}$ & 1,5 \\
Outubro & $2,0 \mathrm{ab}$ & $3,8 \mathrm{a}$ & $1,1 \mathrm{~b}$ & 0,9 \\
Novembro & $4,3 \mathrm{a}$ & $3,9 \mathrm{a}$ & $4,4 \mathrm{a}$ & 1,4 \\
Dezembro & $6,5 \mathrm{a}$ & $5,8 \mathrm{ab}$ & $3,2 \mathrm{~b}$ & 1,0 \\
Janeiro & $1,6 \mathrm{~b}$ & $3,3 \mathrm{a}$ & $0,9 \mathrm{~b}$ & 0,5 \\
Fevereiro & $1,9 \mathrm{a}$ & $2,6 \mathrm{a}$ & $2,6 \mathrm{a}$ & 0,6 \\
Março & $4,7 \mathrm{~b}$ & $9,7 \mathrm{a}$ & $6,9 \mathrm{ab}$ & 1,3 \\
Abril & $5,3 \mathrm{a}$ & $5,3 \mathrm{a}$ & $3,1 \mathrm{~b}$ & 0,7 \\
\hline
\end{tabular}

Médias seguidas de letras diferentes na mesma linha são diferentes $(P<0,05)$.

EPM- Erro padrão da média.

Tabela 9: Porcentagem de material morto em amostras de forragem de simulação de pastejo para os cultivares de Cynodon durante o período experimental.

\begin{tabular}{ccccc}
\hline Mês & Tifton-85 & Florakirk & Coastcross & EPM \\
\hline Agosto & $11,3 \mathrm{~b}$ & $13,3 \mathrm{~b}$ & $28,5 \mathrm{a}$ & 2,7 \\
Setembro & $11,9 \mathrm{c}$ & $16,3 \mathrm{~b}$ & $22,6 \mathrm{a}$ & 1,5 \\
Outubro & $8,0 \mathrm{a}$ & $11,5 \mathrm{a}$ & $11,9 \mathrm{a}$ & 2,2 \\
Novembro & $12,3 \mathrm{~b}$ & $10,0 \mathrm{~b}$ & $20,3 \mathrm{a}$ & 1,9 \\
Dezembro & $15,7 \mathrm{a}$ & $14,2 \mathrm{a}$ & $14,6 \mathrm{a}$ & 2,3 \\
Janeiro & $8,4 \mathrm{a}$ & $12,5 \mathrm{a}$ & $8,4 \mathrm{a}$ & 2,2 \\
Fevereiro & $8,1 \mathrm{a}$ & $14,3 \mathrm{a}$ & $10,1 \mathrm{a}$ & 2,4 \\
Março & $11,5 \mathrm{ab}$ & $13,6 \mathrm{a}$ & $8,5 \mathrm{~b}$ & 1,3 \\
Abril & $18,6 \mathrm{a}$ & $19,2 \mathrm{a}$ & $14,3 \mathrm{a}$ & 3,1 \\
\hline
\end{tabular}

Médias seguidas de letras diferentes na mesma linha são diferentes $(P<0,05)$.

EPM- Erro padrão da média. 
Não houve efeito de altura na maior parte dos meses para a porcentagem de folhas senescentes e material morto $(P>0,05)$. Isso pode indicar a maior importância das diferenças entre cultivares influenciando o pastejo em relação ao manejo que é imposto às plantas (Tabelas 10 e 11).

Tabela 10: Porcentagem de folhas senescentes em amostras de forragem de simulação de pastejo nas quatro intensidades de pastejo $(50,100,150$ e $200 \mathrm{~mm}$ ) durante o período experimental.

\begin{tabular}{cccccc}
\hline Mês & 50 & 100 & 150 & 200 & EPM \\
\hline Agosto & $2,7 a$ & $5,6 a$ & $4,5 a$ & $5,2 a$ & 1,0 \\
Setembro & $5,7 a$ & $4,6 a$ & $3,9 a$ & $4,2 a$ & 1,8 \\
Outubro & $2,0 a$ & $2,9 a$ & $2,3 a$ & $2,0 a$ & 1,0 \\
Novembro & $4,3 a$ & $5,0 a$ & $5,1 a$ & $2,4 a$ & 1,6 \\
Dezembro & $3,3 b$ & $3,1 a b$ & $5,8 a b$ & $8,5 a$ & 1,2 \\
Janeiro & $1,9 a b$ & $1,4 a$ & $2,9 b$ & $1,4 a b$ & 0,6 \\
Fevereiro & $2,8 a$ & $1,8 a$ & $2,5 a$ & $2,4 a$ & 0,7 \\
Março & $6,8 a b$ & $10,2 a$ & $8,6 a$ & $2,7 b$ & 1,5 \\
Abril & $4,8 a b$ & $2,9 b$ & $5,3 a$ & $5,3 a$ & 0,8 \\
\hline
\end{tabular}

Médias seguidas de! letras diferentes na mesma linha são diferentes $(P<0,05)$.

EPM- Erro padrão da média. 
Tabela 11: Porcentagem de material morto em amostras de forragem de simulação de pastejo nas quatro intensidades de pastejo $(50,100,150$ e $200 \mathrm{~mm}$ ) durante o periodo experimental.

\begin{tabular}{cccccc}
\hline Mês & 50 & 100 & 150 & 200 & EPM \\
\hline Agosto & $14,9 a$ & $14,4 a$ & $21,7 a$ & $19,8 a$ & 3,1 \\
Setembro & $15,7 a$ & $19,1 a$ & $16,2 a$ & $16,8 a$ & 1,8 \\
Outubro & $9,0 a b$ & $10,0 a b$ & $6,7 b$ & $16,1 a$ & 2,6 \\
Novembro & $7,4 b$ & $14,9 a$ & $16,7 a$ & $17,7 a$ & 2,3 \\
Dezembro & $11,6 a$ & $16,1 a$ & $15,7 a$ & $15,8 a$ & 2,7 \\
Janeiro & $8,6 a$ & $9,9 a$ & $12,8 a$ & $7,8 a$ & 2,6 \\
Fevereiro & $12,7 a$ & $10,1 a$ & $9,2 a$ & $11,3 a$ & 2,8 \\
Março & $10,6 a b$ & $12,9 a$ & $14,5 a$ & $6,9 b$ & 1,5 \\
Abril & $10,8 b$ & $19,5 a b$ & $16,2 a b$ & $23,0 a$ & 3,6 \\
\hline Médias seguidas de letras diferentes na mesma linha são diferentes (P<0,05). \\
EPM- Erro padrão da média.
\end{tabular}

Nas Figuras 5, 6 e 7 pode ser visualizado perfil da composição da dieta supostamente pastejada para os diferentes cultivares. Para Tifton-85 a influência da estiagem em novembro foi mais pronunciada. Houve uma queda na proporção de folhas em novembro que, apesar da tendência de aumento nos meses seguintes, não foi restabelecida em seus niveis originais do início da primavera (Figura 5). 


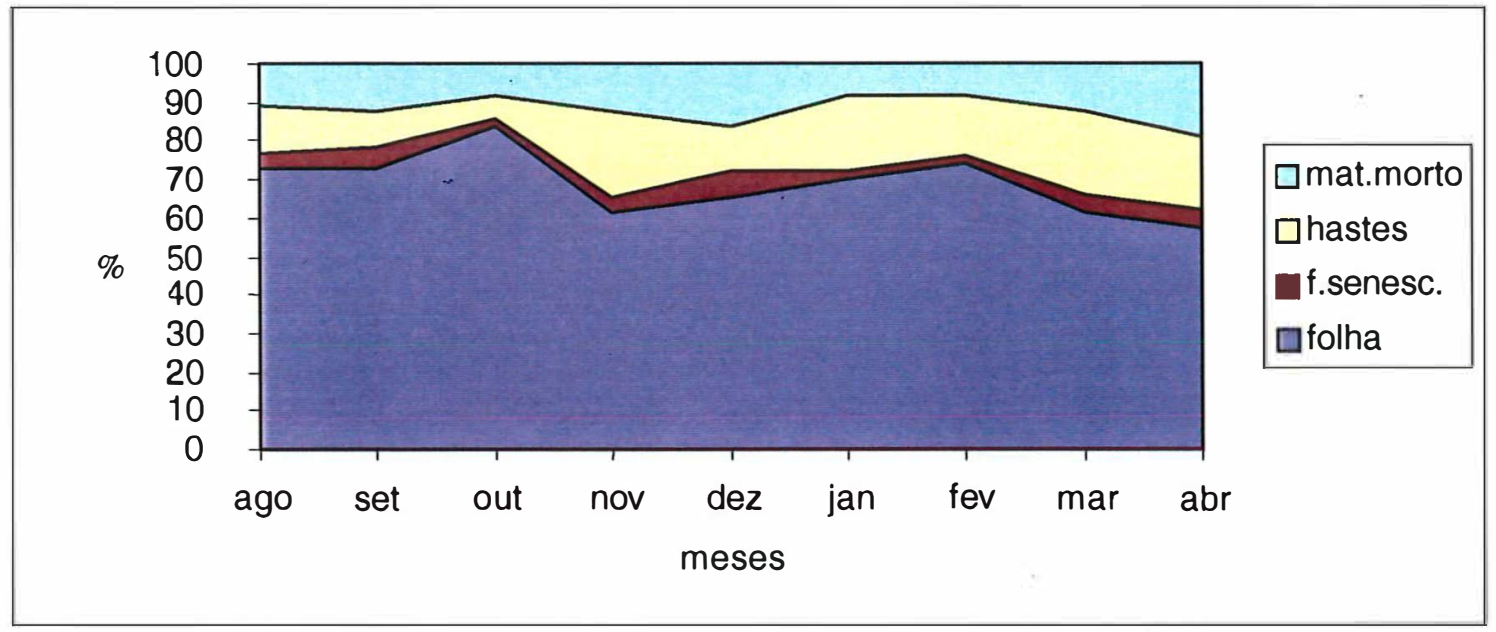

Figura 5: Composição morfológica ( folhas, folhas senescentes, hastes e material morto) da simulação de pastejo para Tifton-85 no período experimental.

Para Florakirk, a queda na \% de folhas em novembro não afetou os meses seguintes, com a proporção de folhas sendo mantida constante apesar de em valor absoluto ser menor que em Tifton-85 (Figura 6).

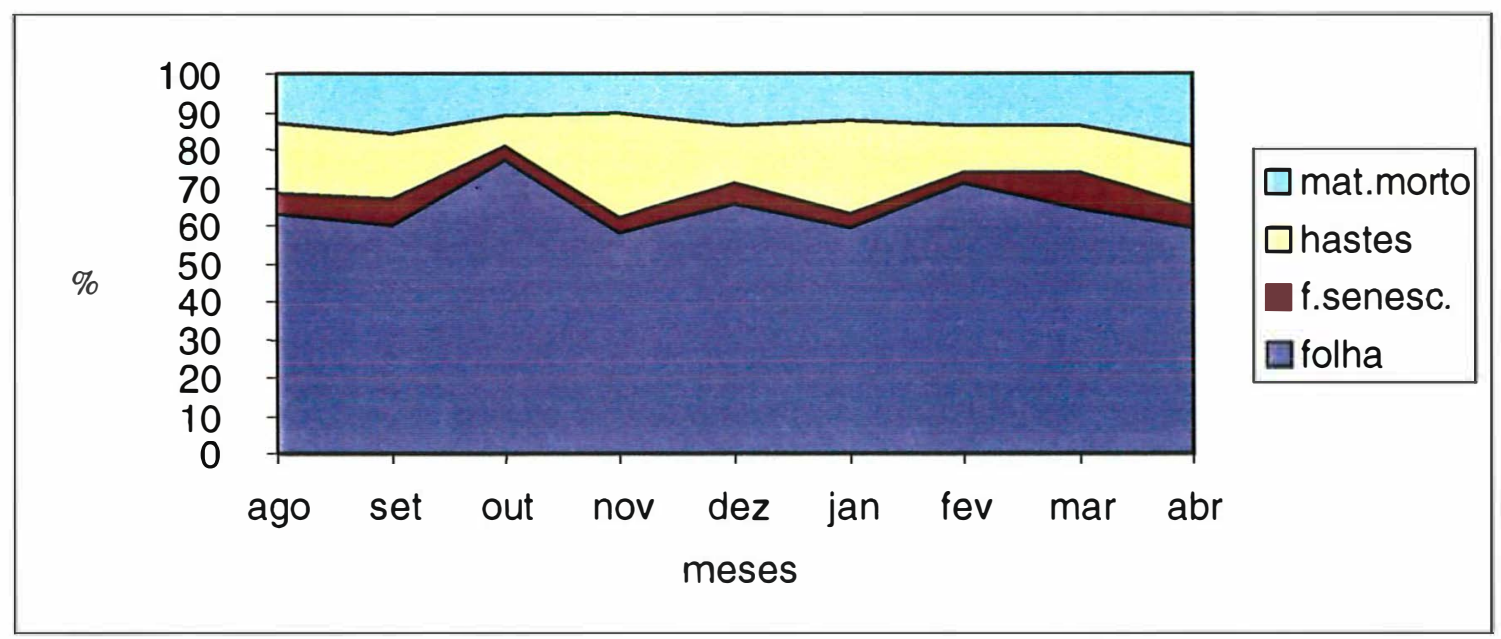

Figura 6: Composição morfológica ( folhas, folhas senescentes, hastes e material morto) da simulação de pastejo para Florakirk no período experimental. 
Para Coastcross o comportamento foi diferente. Este cultivar apresentou um aumento da \% de folhas até outubro e uma redução na \% de hastes e de material morto. Depois da queda de novembro a tendência voltou a ser a mesma (Figura 7).

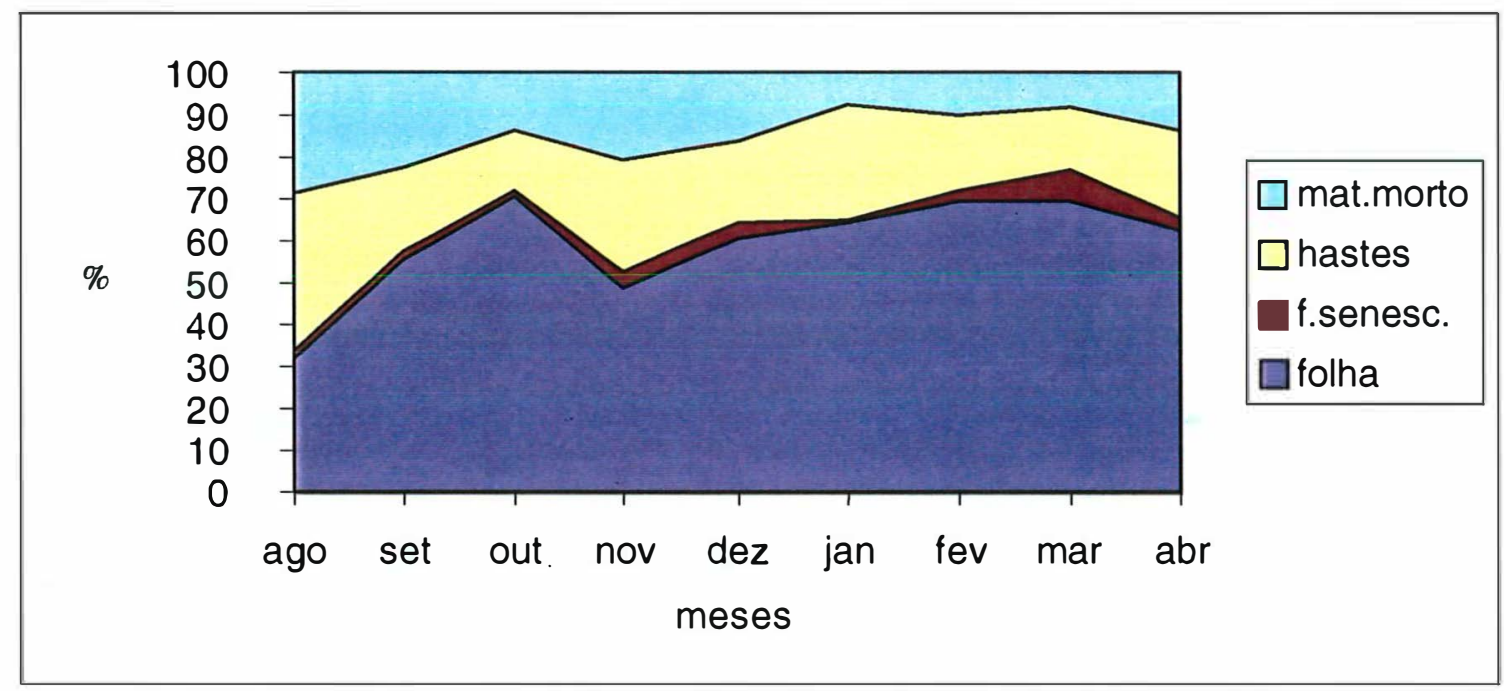

Figura 7: Composição morfológica ( folhas, folhas senescentes, hastes e material morto) da simulação de pastejo para Coastcross no período experimental.

As Figuras 8, 9, 10 e 11 mostram a composição da dieta em função das alturas de pastejo, ou do manejo. Fica evidente o maior efeito da falta de chuva de novembro na proporção de folhas nos pastos mantidos mais altos (Figuras 10 e 11) em relação aos pastos mantidos mais baixos (Figuras 8 e 9), onde as proporções variaram pouco. Esse fato pode estar relacionado ao menor número de pontos de crescimento (perfilhos) nos pastos mais altos. 


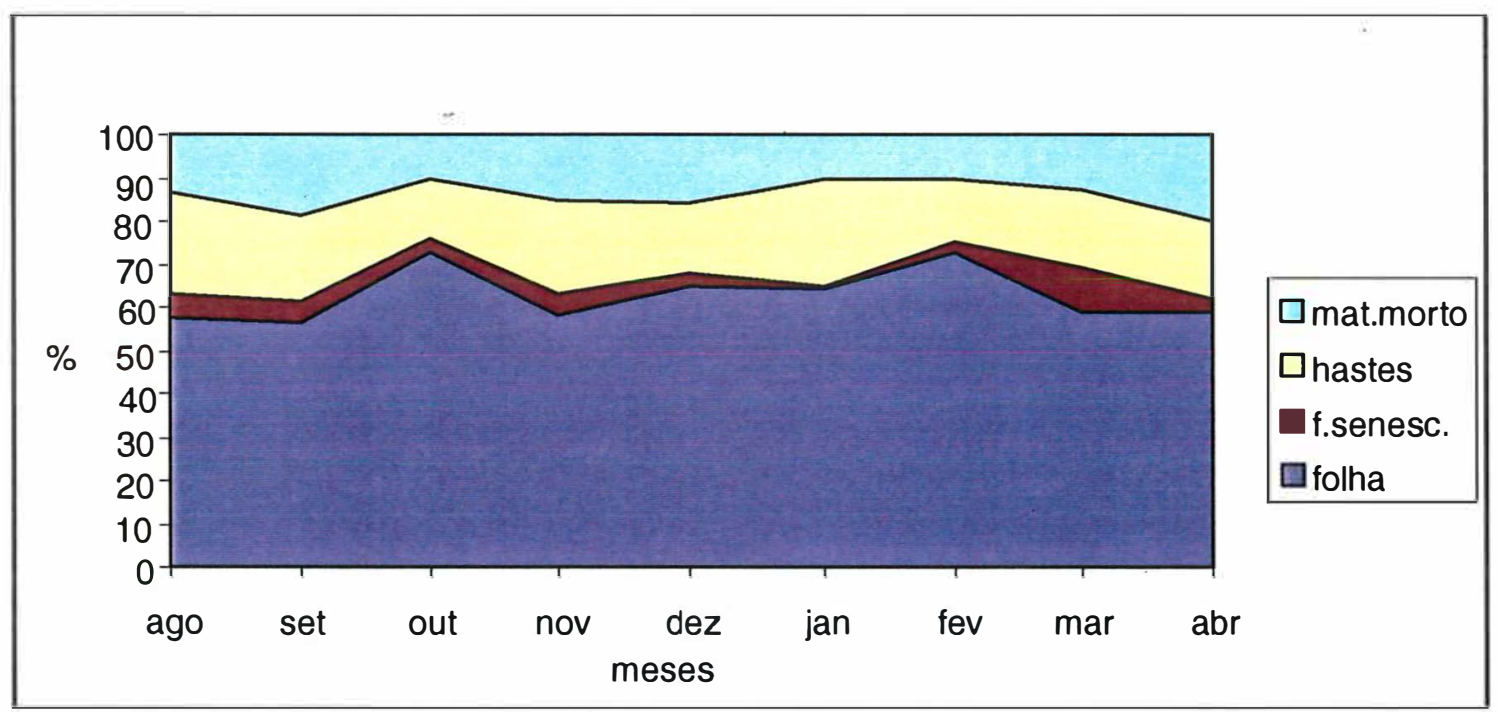

Figura 9: Composição morfológica da simulação de pastejo para a intensidade de pastejo de $100 \mathrm{~mm}$ no período experimental.

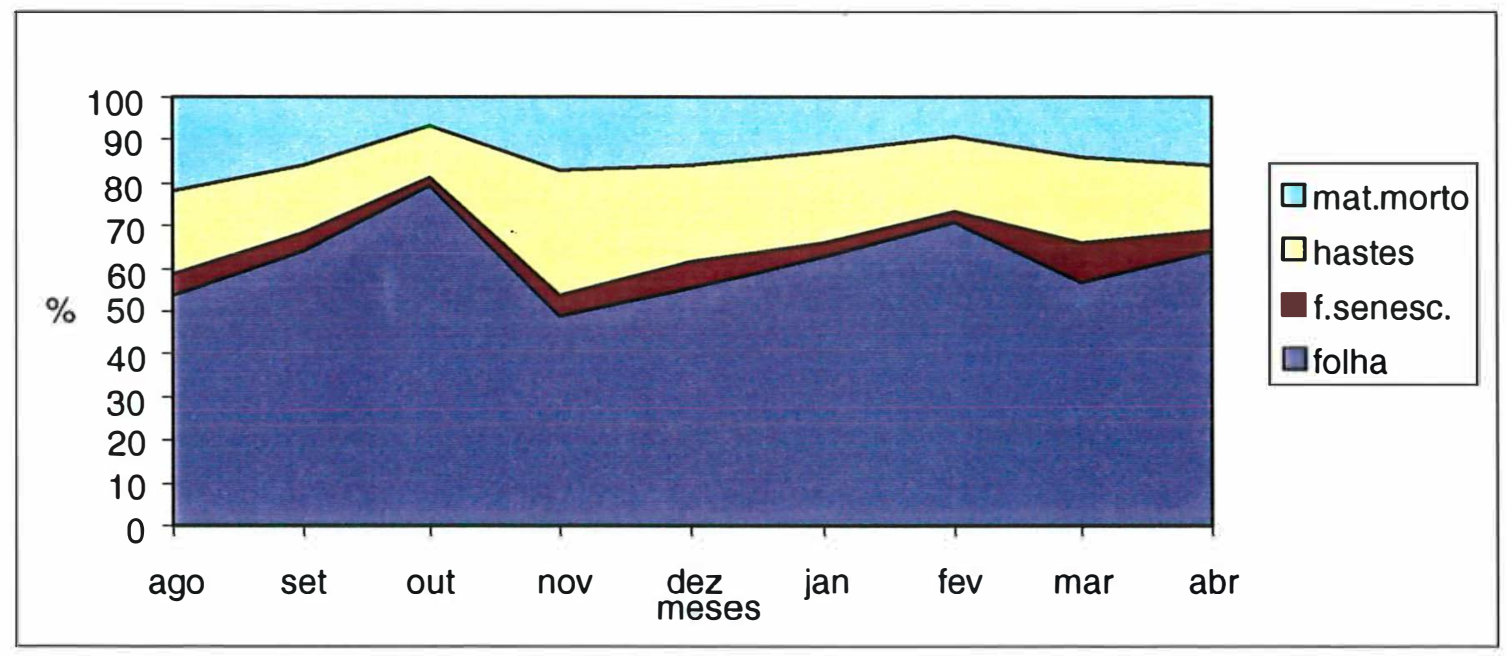

Figura 10: Composição morfológica da simulação de pastejo para a intensidade de pastejo de $150 \mathrm{~mm}$ no período experimental. 


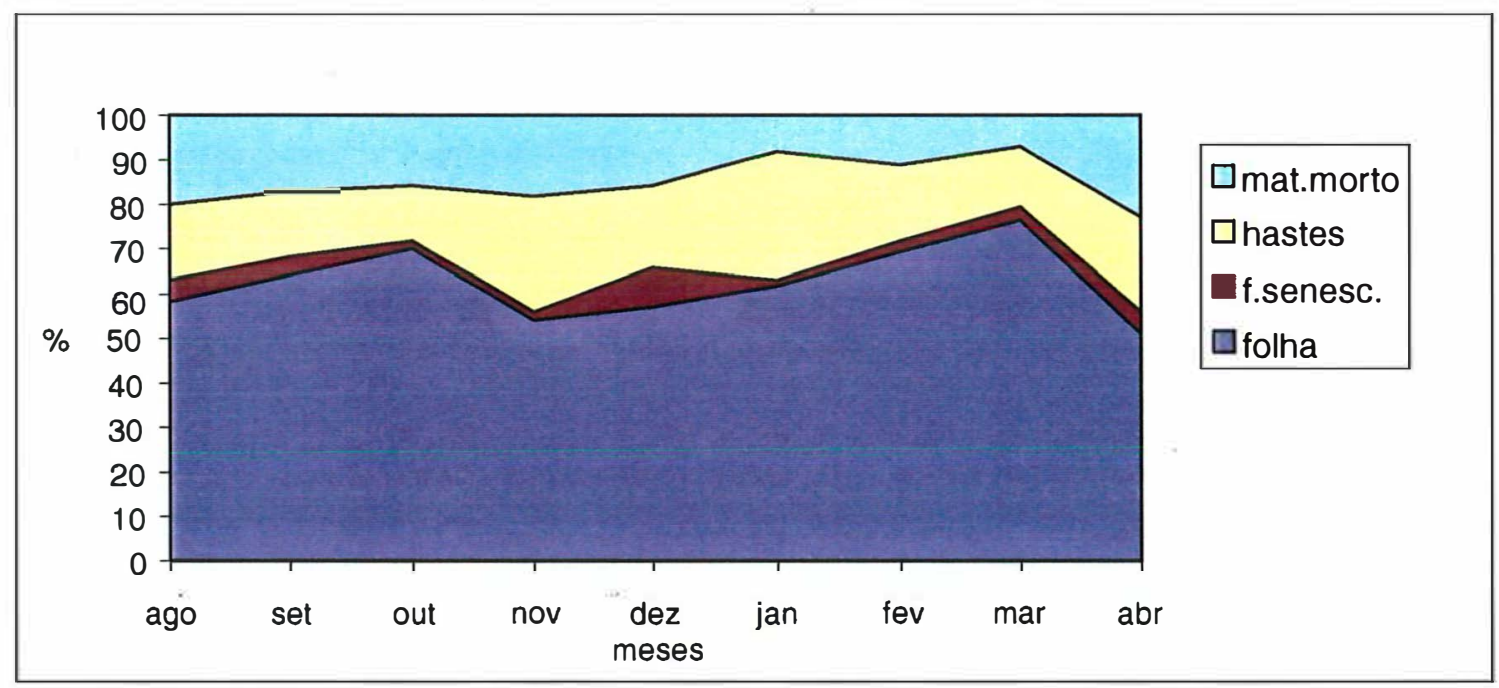

Figura 11 : Composição morfológica da simulação de pastejo para a intensidade de pastejo de $200 \mathrm{~mm}$ no período experimental

A proporção dos componentes (folhas, hastes e material morto) reflete o valor nutritivo da dieta. A Tabela 12 mostra o teor de fibra em detergente neutro (FDN) para os diferentes cultivares. Pode-se observar maior proporção de FDN para Tifton-85 e menor proporção para Florakirk. Apesar de estatisticamente serem diferentes $(P<0,05)$, biologicamente essas diferenças não são muito expressivas. Para FDN houve efeito de tempo, cultivar, bloco e altura e interações tempo $x$ cultivar, tempo $x$ bloco, tempo $x$ cultivar $x$ bloco e tempo $x$ altura $(P<0,05)$. Para FDA houve efeito de tempo, cultivar e bloco e interações entre tempo $x$ cultivar, tempo $x$ bloco e cultivar $x$ bloco $(P<0,05)$. Para lignina houve efeito de tempo e cultivar e interação tempo $x$ bloco. 
Tabela 12: Porcentagem de fibra em detergente neutro para os cultivares de Cynodon durante o periodo experimental.

\begin{tabular}{ccccc}
\hline Mês & Tifton-85 & Florakirk & Coastcross & EPM \\
\hline Agosto & $68,4 \mathrm{a}$ & $65,3 \mathrm{~b}$ & $67,3 \mathrm{ab}$ & 0,8 \\
Setembro & $70,0 \mathrm{a}$ & $67,9 \mathrm{~b}$ & $69,9 \mathrm{a}$ & 0,5 \\
Outubro & $64,6 \mathrm{a}$ & $59,9 \mathrm{~b}$ & $63,9 \mathrm{a}$ & 0,7 \\
Novembro & $66,1 \mathrm{a}$ & $62,0 \mathrm{c}$ & $64,5 \mathrm{~b}$ & 0,5 \\
Dezembro & $67,2 \mathrm{a}$ & $64,9 \mathrm{~b}$ & $66,7 \mathrm{a}$ & 0,6 \\
Janeiro & $70,1 \mathrm{a}$ & $67,6 \mathrm{~b}$ & $67,6 \mathrm{~b}$ & 0,5 \\
Fevereiro & $66,0 \mathrm{a}$ & $62,6 \mathrm{~b}$ & $61,6 \mathrm{~b}$ & 0,7 \\
Março & $67,6 \mathrm{a}$ & $64,5 \mathrm{~b}$ & $66,9 \mathrm{a}$ & 0,7 \\
Abril & $63,3 \mathrm{a}$ & $60,6 \mathrm{~b}$ & $61,5 \mathrm{ab}$ & 0,7 \\
\hline
\end{tabular}

Médias seguidas de letras diferentes na mesma linha são diferentes $(P<0,05)$.

EPM- Erro padrão da média.

Em relação às alturas, a maior proporção de folhas nos pastos mais baixos possibilitou menores porcentagens de FDN e, consequentemente, maior proporção de conteúdo celular (Tabela 12). Esses valores ainda foram menores aos obtidos por Pedreira (1995) e Hill et al. (1993) em estudos realizados na Flórida, porém bastante semelhantes aos obtidos por Resende \& Alvim (1996) em estudos realizados no Brasil. 
Tabela 13: Porcentagem de fibra em detergente neutro nas quatro intensidades de pastejo $(50,100,150$ e $200 \mathrm{~mm})$ durante o período experimental.

\begin{tabular}{cccccc}
\hline Mês & 50 & 100 & 150 & 200 & EPM \\
\hline Agosto & $66,0 \mathrm{a}$ & $66,9 \mathrm{a}$ & $68,6 \mathrm{a}$ & $66,4 \mathrm{a}$ & 1,0 \\
Setembro & $68,3 \mathrm{a}$ & $69,3 \mathrm{a}$ & $69,1 \mathrm{a}$ & $70,3 \mathrm{a}$ & 0,6 \\
Outubro & $60,4 \mathrm{c}$ & $62,0 \mathrm{bc}$ & $63,5 \mathrm{ab}$ & $65,4 \mathrm{a}$ & 0,8 \\
Novembro & $61,9 \mathrm{c}$ & $64,5 \mathrm{~b}$ & $65,1 \mathrm{ab}$ & $65,2 \mathrm{a}$ & 0,6 \\
Dezembro & $63,5 \mathrm{~b}$ & $66,4 \mathrm{a}$ & $67,3 \mathrm{a}$ & $67,8 \mathrm{a}$ & 0,7 \\
Janeiro & $63,9 \mathrm{c}$ & $69,0 \mathrm{~b}$ & $69,5 \mathrm{~b}$ & $71,2 \mathrm{a}$ & 0,6 \\
Fevereiro & $60,2 \mathrm{c}$ & $64,2 \mathrm{~b}$ & $64,7 \mathrm{a}$ & $64,6 \mathrm{a}$ & 0,8 \\
Março & $64,7 \mathrm{~b}$ & $65,9 \mathrm{ab}$ & $66,8 \mathrm{ab}$ & $67,9 \mathrm{a}$ & 0,8 \\
\multicolumn{7}{c}{ Abril } & $60,1 \mathrm{~b}$ & $60,6 \mathrm{~b}$ & $61,6 \mathrm{~b}$ & $64,9 \mathrm{a}$ & 0,8 \\
\hline Médias seguidas de letras diferentes na mesma linha são diferentes $(\mathrm{P}<0,05)$. & \\
EPM- Erro padrão da média. & & & &
\end{tabular}

Seguindo a mesma tendência do FDN, a fibra em detergente ácido (FDA) foi menor no cultivar Florakirk (Tabela 14). Resende \& Alvim (1996) obtiveram valores de FDA para Coastcross de $35 \%$. Os pastos mais baixos apresentaram valores de FDA mais baixos (Tabela 15). 
Tabela 14 : Porcentagem de fibra em detergente ácido para os cultivares de Cynodon durante o período experimental.

\begin{tabular}{ccccc}
\hline Mês & Tifton-85 & Florakirk & Coastcross & EPM \\
\hline Agosto & $28,9 a$ & $27,6 a$ & $29,9 a$ & 0,9 \\
Setembro & $26,3 a b$ & $25,3 b$ & $27,2 a$ & 0,4 \\
Outubro & $26,3 b$ & $24,4 c$ & $27,7 a$ & 0,5 \\
Novembro & $26,8 a$ & $24,1 c$ & $25,6 b$ & 0,4 \\
Dezembro & $29,2 a$ & $27,8 b$ & $29,4 a$ & 0,4 \\
Janeiro & $29,1 a$ & $28,1 b$ & $28,2 b$ & 0,3 \\
Fevereiro & $26,9 a$ & $24,5 b$ & $24,7 b$ & 0,5 \\
Março & $27,5 a b$ & $26,4 b$ & $27,8 a$ & 0,4 \\
Abril & $25,7 a$ & $24,3 b$ & $24,7 a b$ & 0,5 \\
\hline
\end{tabular}

Médias seguidas de letras diferentes na mesma linha são diferentes $(P<0,05)$.

EPM- Erro padrão cla média.

Tabela 15: Porcentagem de fibra em detergente ácido nas quatro intensidades de pastejo $(50,100,150$ e $200 \mathrm{~mm})$ durante o período experimental.

\begin{tabular}{cccccc}
\hline Mês & 50 & 100 & 150 & 200 & EPM \\
\hline Agosto & $27,1 \mathrm{~b}$ & $28,3 \mathrm{ab}$ & $31,1 \mathrm{a}$ & $28,7 \mathrm{ab}$ & 1,1 \\
Setembro & $25,4 \mathrm{~b}$ & $26,2 \mathrm{ab}$ & $26,5 \mathrm{ab}$ & $26,8 \mathrm{a}$ & 0,5 \\
Outubro & $24,5 \mathrm{~b}$ & $25,3 \mathrm{~b}$ & $26,4 \mathrm{~b}$ & $28,3 \mathrm{a}$ & 0,6 \\
Novembro & $23,6 \mathrm{~b}$ & $25,5 \mathrm{a}$ & $26,2 \mathrm{a}$ & $26,6 \mathrm{a}$ & 0,4 \\
Dezembro & $26,9 \mathrm{c}$ & $28,6 \mathrm{~b}$ & $29,6 \mathrm{a}$ & $30,1 \mathrm{a}$ & 0,4 \\
Janeiro & $25,4 \mathrm{c}$ & $28,5 \mathrm{~b}$ & $29,4 \mathrm{~b}$ & $30,5 \mathrm{a}$ & 0,4 \\
Fevereiro & $23,1 \mathrm{~b}$ & $25,9 \mathrm{a}$ & $26,1 \mathrm{a}$ & $26,3 \mathrm{a}$ & 0,5 \\
Março & $25,8 \mathrm{~b}$ & $27,4 \mathrm{a}$ & $27,8 \mathrm{a}$ & $28,0 \mathrm{a}$ & 0,5 \\
Abril & $23,4 \mathrm{~b}$ & $24,1 \mathrm{~b}$ & $24,6 \mathrm{~b}$ & $27,3 \mathrm{a}$ & 0,6 \\
\hline
\end{tabular}

Médias seguidas de: letras diferentes na mesma linha são diferentes $(P<0,05)$.

EPM- Erro padrão cla média.

A proporção de lignina não apresentou diferença estatística para cultivar (Tabela 16) e para altura (Tabela 17) $(P>0,05)$. Nota-se um aumento na proporção de 
lignina nos meses de outubro e novembro devido a redução de folhas e aumento considerável dos outros componentes. Depois, esses teores diminuíram novamente. Esse fato pode ser facilmente visualizado nas Figuras 12, 13 e 14.

Tabela 16: Porcentagem de lignina para os cultivares de Cynodon durante o período experimental.

\begin{tabular}{ccccc}
\hline Mês & Tifton-85 & Florakirk & Coastcross & EPM \\
\hline Agosto & $4,4 a$ & $4,0 a$ & $3,4 a$ & 0,4 \\
Setembro & $4,7 a$ & $2,3 b$ & $2,8 b$ & 0,5 \\
Outubro & $8,3 a$ & $6,7 a$ & $7,2 a$ & 1,0 \\
Novembro & $8,2 a$ & $7,0 a$ & $7,9 a$ & 0,5 \\
Dezembro & $6,1 a$ & $5,4 a$ & $5,3 a$ & 0,5 \\
Janeiro & $3,2 a$ & $2,4 b$ & $2,5 a b$ & 0,3 \\
Fevereiro & $4,5 a$ & $3,9 a$ & $3,4 a$ & 0,6 \\
Março & $4,3 a$ & $4,4 a$ & $4,7 a$ & 0,3 \\
Abril & $2,7 a$ & $3,3 a$ & $2,7 a$ & 0,2 \\
\hline
\end{tabular}

Médias seguidels de letras diferentes na mesma linha são diferentes $(P<0,05)$.

EPM- Erro padrão da média. 
Tabela 17: Porcentagem de lignina nas quatro intensidades de pastejo $(50,100,150$ e $200 \mathrm{~mm}$ ) durante o periodo experimental.

\begin{tabular}{cccccc}
\hline Mês & 50 & 100 & 150 & 200 & EPM \\
\hline Agosto & $3,4 a$ & $3,8 a$ & $4,2 a$ & $4,1 a$ & 0,5 \\
Setembro & $3,2 a$ & $3,0 a$ & $3,5 a$ & $3,4 a$ & 0,6 \\
Outubro & $7,6 a$ & $7,2 a$ & $7,9 a$ & $6,9 a$ & 1,2 \\
Novembro & $7,3 a$ & $8,0 a$ & $7,4 a$ & $8,1 a$ & 0,6 \\
Dezembro & $5,1 a$ & $5,1 a$ & $5,8 a$ & $6,4 a$ & 0,6 \\
Janeiro & $2,5 a$ & $3,0 a$ & $2,9 a$ & $2,5 a$ & 0,3 \\
Fevereiro & $4,4 a$ & $4,0 a$ & $3,2 a$ & $4,3 a$ & 0,7 \\
Março & $4,5 a$ & $4,4 a$ & $4,1 a$ & $4,9 a$ & 0,4 \\
Abril & $3,0 a$ & $2,6 a$ & $2,8 a$ & $3,1 a$ & 0,3 \\
\hline
\end{tabular}

Médias seguidas de letras diferentes na mesma linha são diferentes $(P<0,05$ EPM- Erro padrão da média.

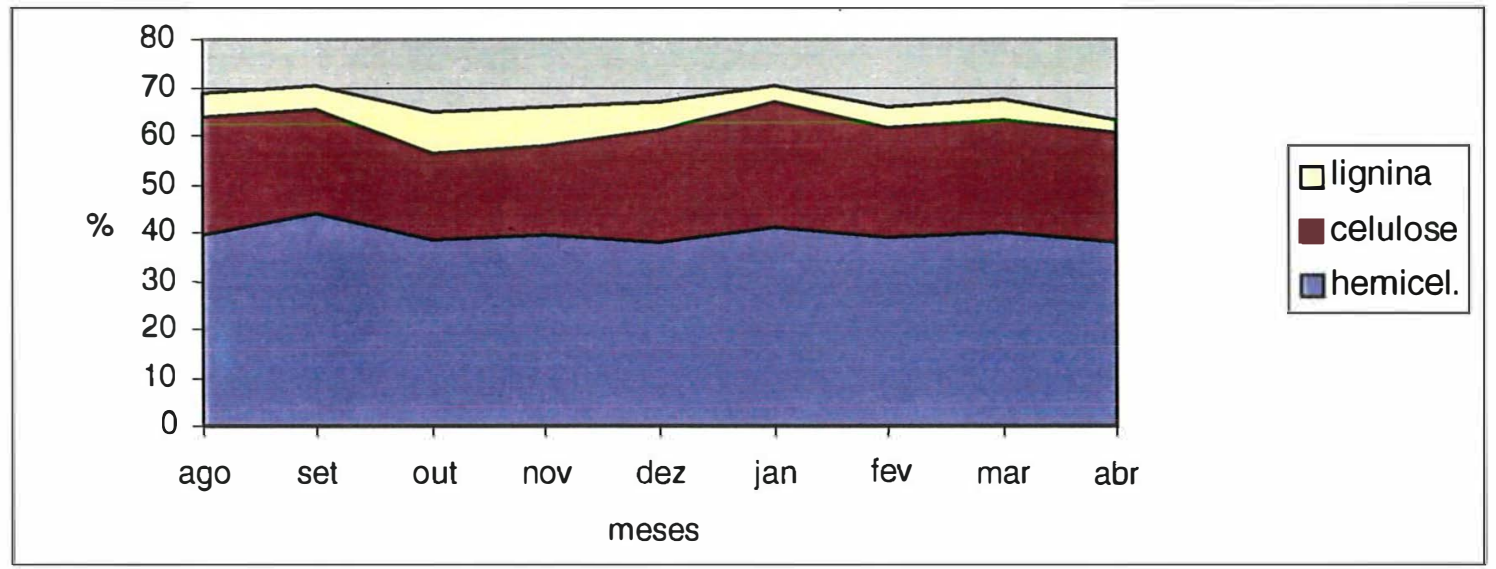

Figura 12: Composição da parede celular (hemicelulose, celulose e lignina) para Tifton-85 no período experimental. 


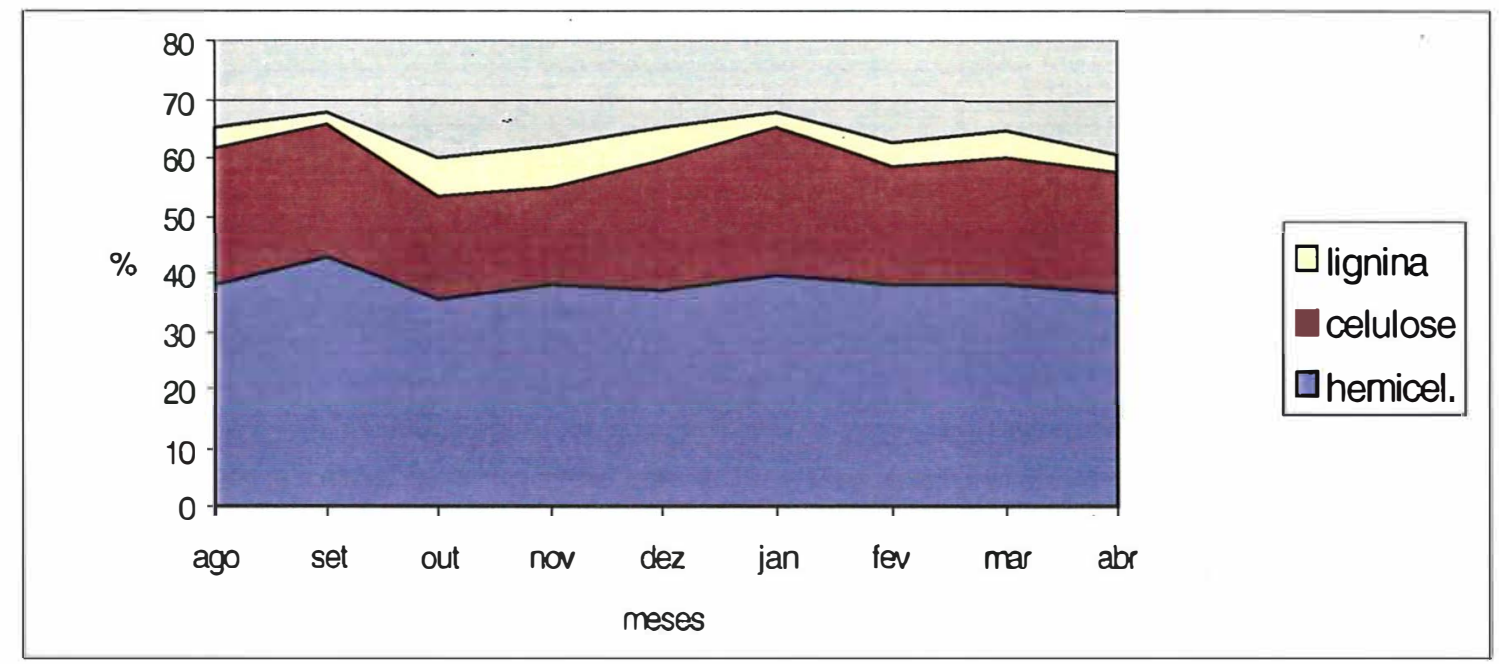

Figura 13: Composição da parede celular (hemicelulose, celulose e lignina) para Florakirk no período experimental.

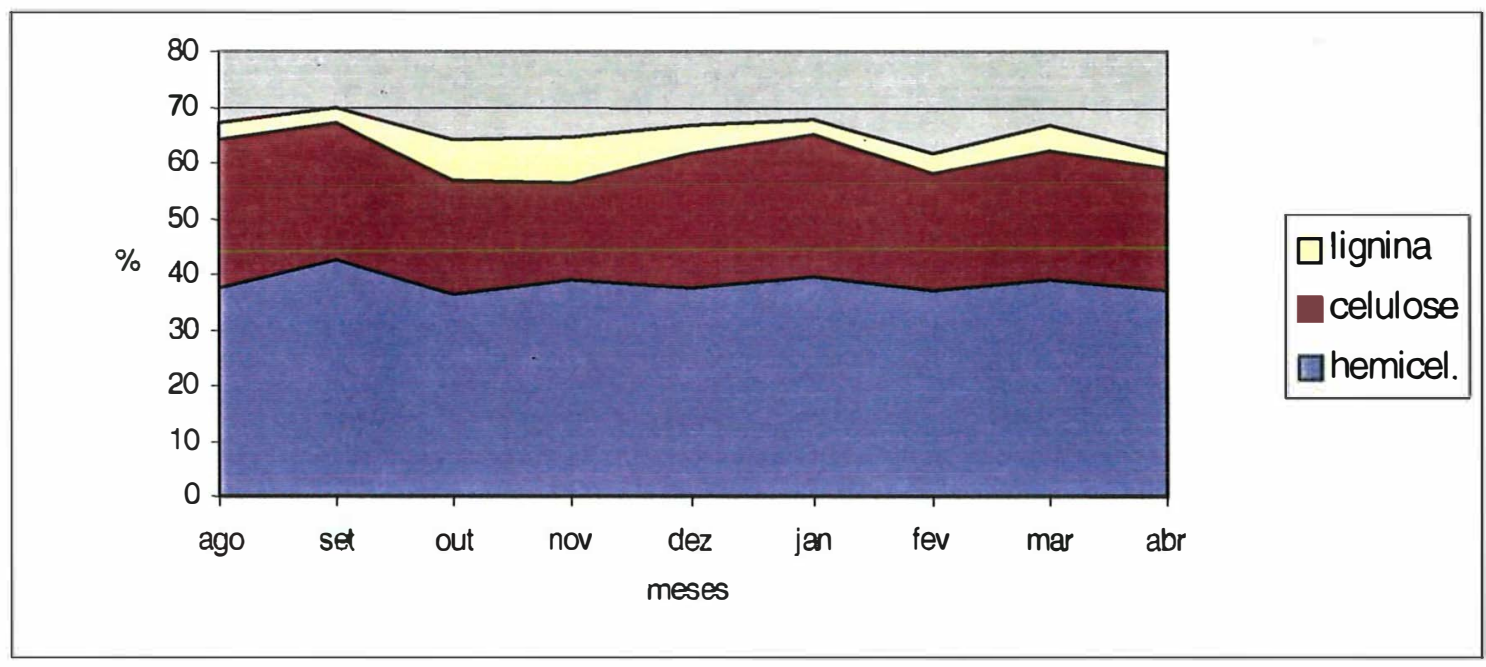

Figura 14: Composição da parede celular (hemicelulose, celulose e lignina) para Coastcross no período experimental. 
Nas Figuras 15, 16, 17 e 18 pode-se observar que a proporção dos componentes da parede celular se manteve ao longo do tempo para as diferentes alturas de pastejo estudadas. O que mudou foi a proporção de parede celular em relação à conteúdo celular. Para os pastos mais baixos, a proporção de parede celular foi menor.

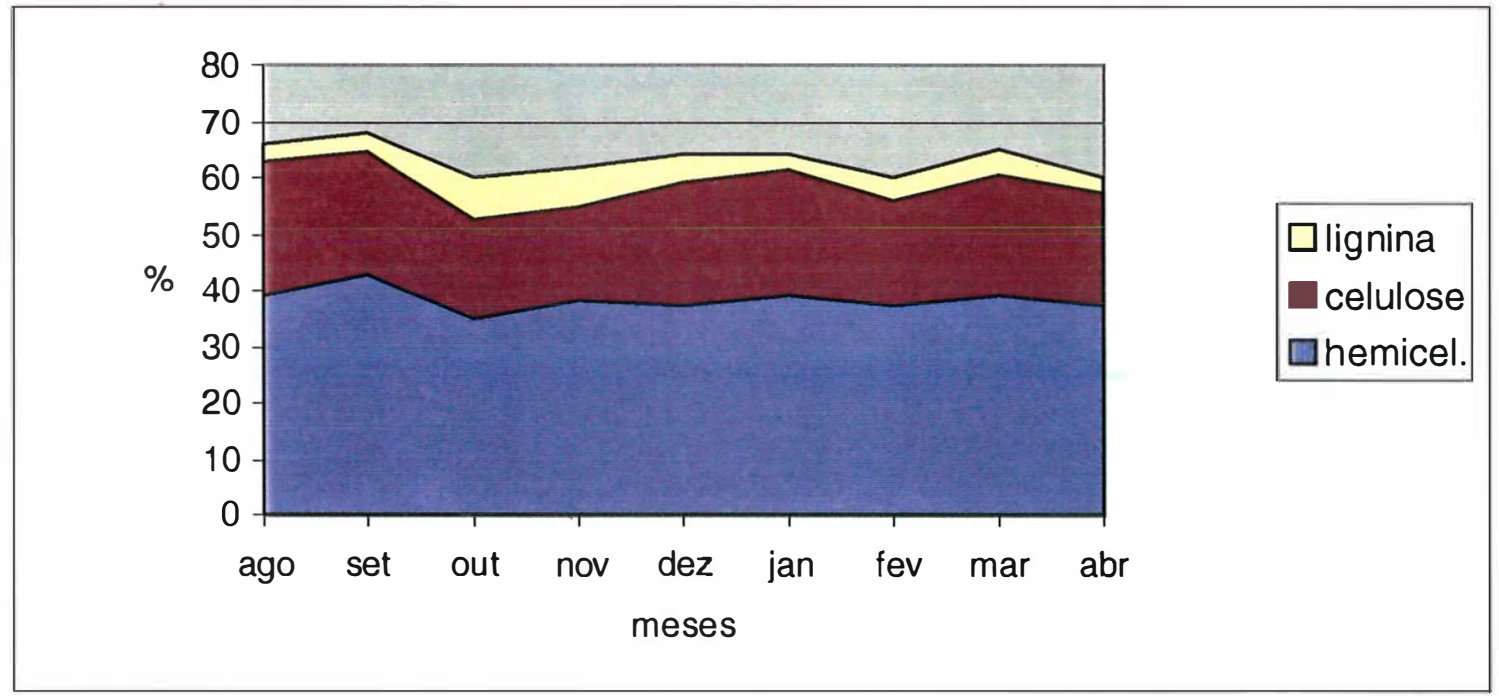

Figura 15: Composição da parede celular (hemicelulose, celulose e lignina) para $50 \mathrm{~mm}$ de altura no periodo experimental.

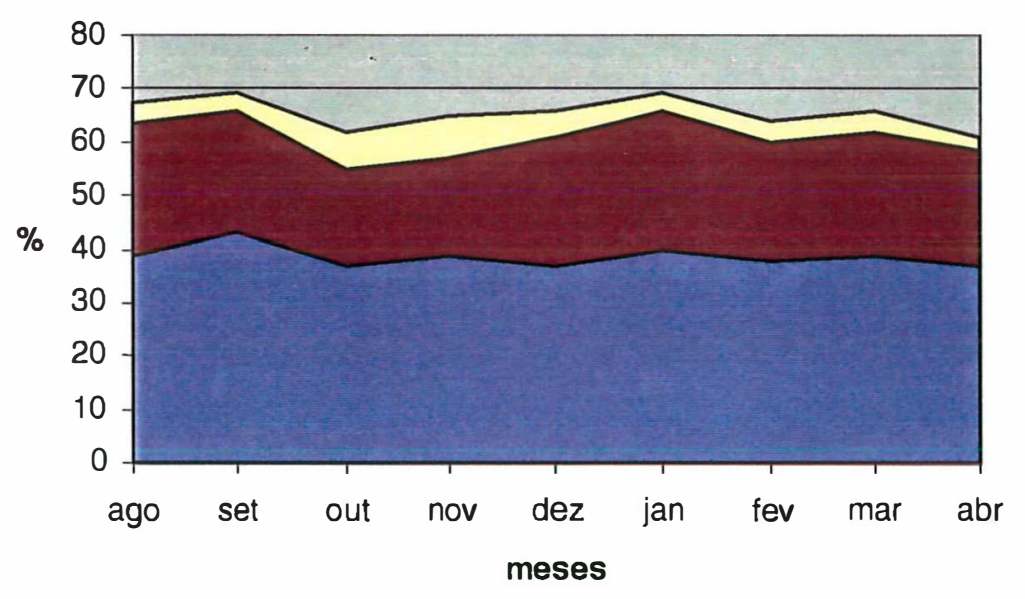

Figura 16: Composição da parede celular (hemicelulose, celulose e lignina) para $100 \mathrm{~mm}$ de altura no período experimental. 


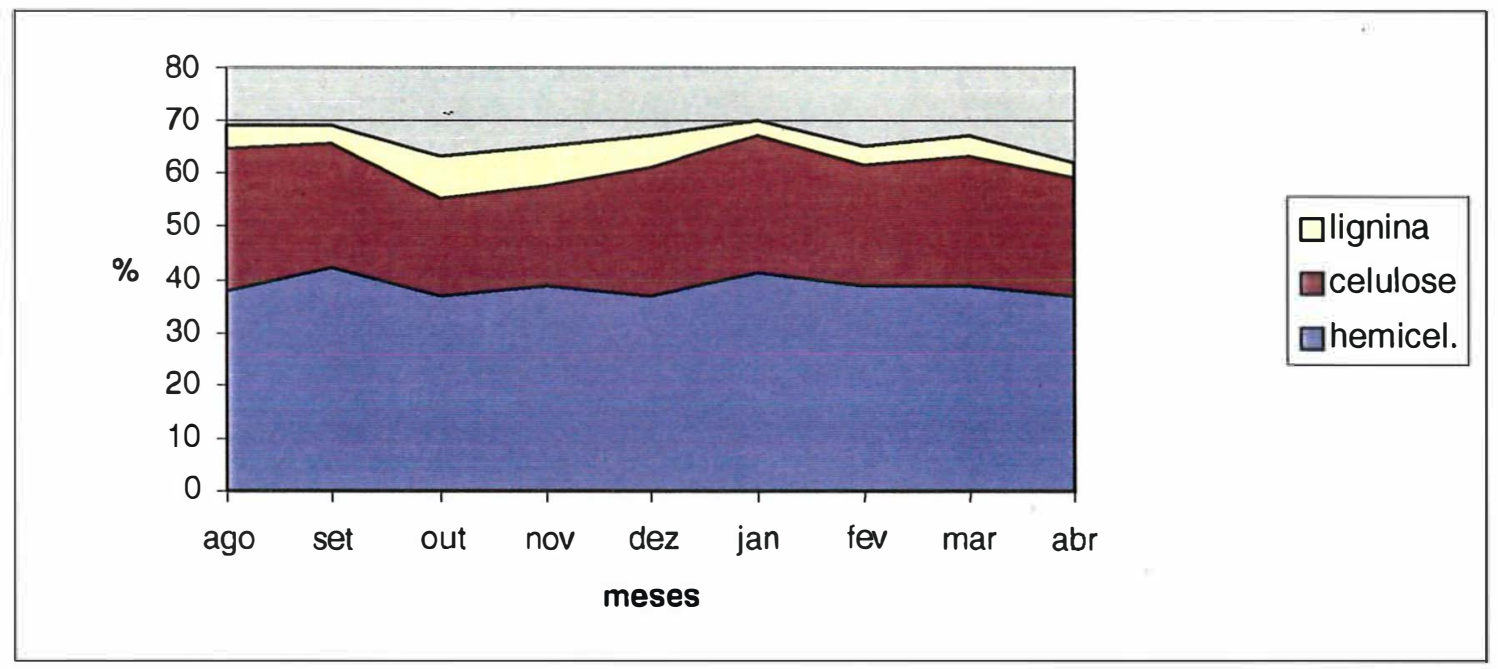

Figura 17: Composição da parede celular (hemicelulose, celulose e lignina) para $150 \mathrm{~mm}$ de altura no período experimental.

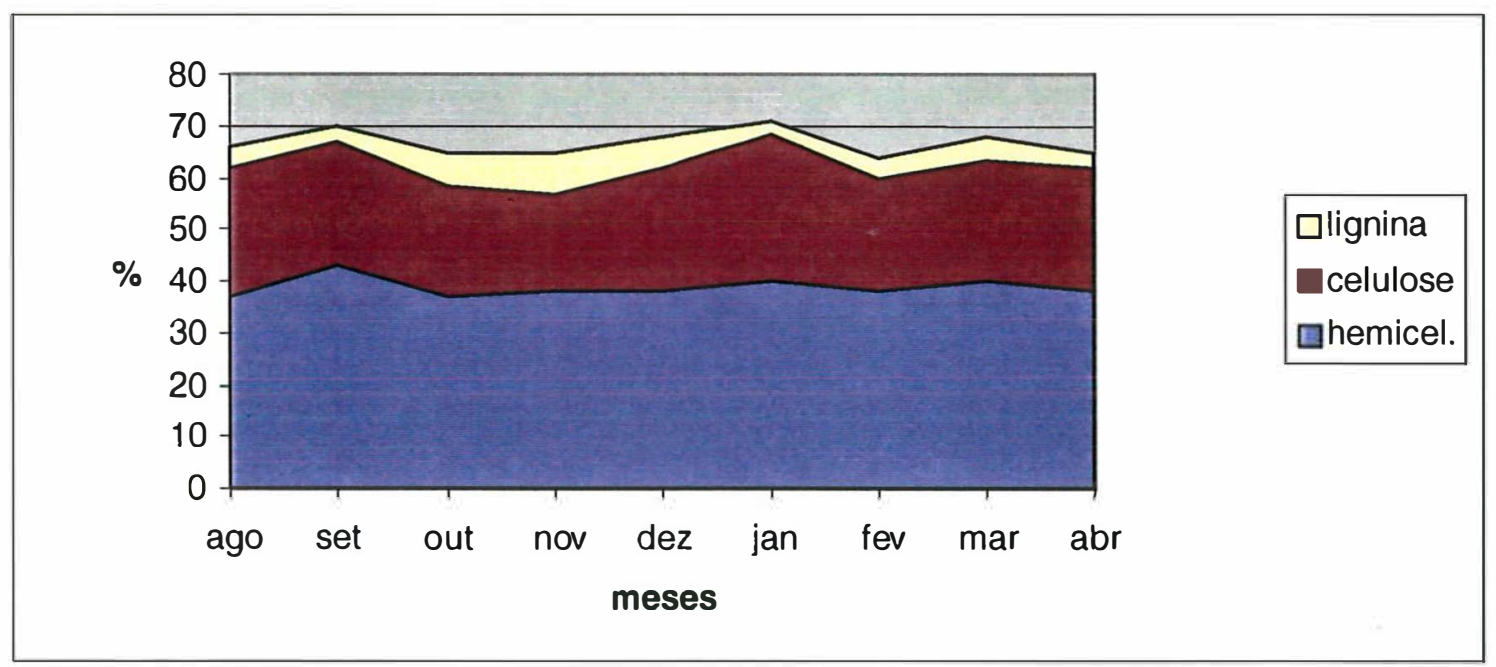

Figura 18: Composição da parede celular (hemicelulose, celulose e lignina) para $200 \mathrm{~mm}$ de altura no período experimental. 
O teor de nutrientes digestiveis totais (NDT), calculado em função dos valores de FDA, atingiu valores relativamente altos para pastagens tropicais. Foi observado efeito de tempo, cultivar, bloco e altura e interações entre tempo $x$ cultivar, tempo $x$ bloco e cultivar $x$ bloco $(P<0,05)$. Esses valores podem ser visualizados na Tabela 18 para os cultivares e Tabela 19 para as alturas. Os maiores valores foram atingidos pela Florakirk, seguido do Coastcross. Os niveis mais baixos de NDT foram atingidos por Tifton-85, apesar das diferenças não serem biologicamente tão importantes. Os pastos de $50 \mathrm{~mm}$ apresentaram maiores niveis de NDT que os demais.

Tabela18: Porcentagem de nutrientes digestiveis totais em amostras de forragem dos cultivares de Cynodon durante o periodo experimental.

\begin{tabular}{ccccc}
\hline Mês & Tifton-85 & Florakirk & Coastcross & EPM \\
\hline Agosto & $66,9 a$ & $68,8 a$ & $65,4 a$ & 1,3 \\
Setembro & $70,8 \mathrm{ab}$ & $72,2 \mathrm{a}$ & $69,4 \mathrm{~b}$ & 0,6 \\
Outubro & $70,8 \mathrm{~b}$ & $73,6 \mathrm{a}$ & $68,6 \mathrm{c}$ & 0,7 \\
Novembro & $70,0 \mathrm{c}$ & $74,1 \mathrm{a}$ & $71,8 \mathrm{~b}$ & 0,6 \\
Dezembro & $66,4 \mathrm{~b}$ & $68,6 \mathrm{a}$ & $66,2 \mathrm{~b}$ & 0,5 \\
Janeiro & $66,5 \mathrm{~b}$ & $68,1 \mathrm{a}$ & $68,0 \mathrm{a}$ & 0,4 \\
Fevereiro & $69,8 \mathrm{~b}$ & $73,4 \mathrm{a}$ & $73,1 \mathrm{a}$ & 0,7 \\
Março & $69,0 \mathrm{a}$ & $70,5 \mathrm{a}$ & $68,5 \mathrm{~b}$ & 0,7 \\
Abril & $71,7 \mathrm{~b}$ & $73,8 \mathrm{a}$ & $73,2 \mathrm{ab}$ & 0,7 \\
\hline
\end{tabular}

Médias seguidas de letras diferentes na mesma linha são diferentes $(P<0,05)$.

EPM- Erro padrão da média. 
Tabela 19: Porcentagem de nutrientes digestiveis totais em amostras de forragem nas quatro intensidades de pastejo $(50,100,150$ e $200 \mathrm{~mm})$ durante o periodo experimental.

\begin{tabular}{cccccc}
\hline Mês & 50 & 100 & 150 & 200 & EPM \\
\hline Agosto & $69,6 \mathrm{a}$ & $67,8 \mathrm{ab}$ & $63,6 \mathrm{~b}$ & $67,1 \mathrm{~b}$ & 1,6 \\
Setembro & $72,0 \mathrm{a}$ & $70,9 \mathrm{ab}$ & $70,5 \mathrm{ab}$ & $69,9 \mathrm{~b}$ & 0,7 \\
Outubro & $73,4 \mathrm{a}$ & $72,2 \mathrm{ab}$ & $70,6 \mathrm{~b}$ & $67,7 \mathrm{c}$ & 0,8 \\
Novembro & $74,8 \mathrm{a}$ & $71,9 \mathrm{~b}$ & $70,9 \mathrm{~b}$ & $70,2 \mathrm{~b}$ & 0,7 \\
Dezembro & $69,9 \mathrm{a}$ & $67,4 \mathrm{~b}$ & $65,8 \mathrm{~b}$ & $65,2 \mathrm{~b}$ & 0,6 \\
Janeiro & $72,0 \mathrm{a}$ & $67,5 \mathrm{~b}$ & $66,1 \mathrm{~b}$ & $64,6 \mathrm{c}$ & 0,5 \\
Fevereiro & $75,4 \mathrm{a}$ & $71,3 \mathrm{~b}$ & $71,0 \mathrm{~b}$ & $70,7 \mathrm{~b}$ & 0,8 \\
Março & $71,5 \mathrm{a}$ & $69,2 \mathrm{~b}$ & $68,5 \mathrm{~b}$ & $68,2 \mathrm{~b}$ & 0,8 \\
Abril & $75,0 \mathrm{a}$ & $74,0 \mathrm{a}$ & $73,3 \mathrm{a}$ & $69,2 \mathrm{~b}$ & 0,8
\end{tabular}

Médias seguidas de letras diferentes na mesma linha são diferentes $(P<0,05)$.

EPM- Erro padrão da média.

Em relação ao teor de proteina bruta, Florakirk e Coastcross apresentaram os maiores valores. Para proteina bruta houve efeito de tempo, bloco e altura e interações entre tempo $x$ cultivar, tempo $x$ bloco e cultivar $x$ bloco $(P<0,05)$. Contudo, apesar de, geralmente, Tifton- 85 ter apresentado os menores teores de proteina bruta, estes ainda são bastante elevados considerando que trata-se de uma gramínea tropical (Tabela 20 e Figura 19). Os valores obtidos neste experimento são superiores àqueles obtidos por Hill et al.(1993). 
Tabela 20: Porcentagem de proteína bruta em amostras de forragem dos cultivares de Cynodon durante o período experimental.

\begin{tabular}{ccccc}
\hline Mês & Tifton-85 & Florakirk & Coastcross & EPM \\
\hline Agosto & $16,4 \mathrm{a}$ & $14,6 \mathrm{ab}$ & $13,5 \mathrm{~b}$ & 0,7 \\
Setembro & $14,1 \mathrm{a}$ & $15,5 \mathrm{a}$ & $15,2 \mathrm{a}$ & 0,7 \\
Outubro & $18,7 \mathrm{a}$ & $17,6 \mathrm{a}$ & $18,9 \mathrm{a}$ & 1,9 \\
Novembro & $15,7 \mathrm{~b}$ & $20,2 \mathrm{a}$ & $16,7 \mathrm{ab}$ & 1,3 \\
Dezembro & $16,1 \mathrm{a}$ & $17,9 \mathrm{a}$ & $16,2 \mathrm{a}$ & 0,7 \\
Janeiro & $17,1 \mathrm{a}$ & $17,2 \mathrm{a}$ & $17,2 \mathrm{a}$ & 0,6 \\
Fevereiro & $18,5 \mathrm{~b}$ & $20,4 \mathrm{a}$ & $21,2 \mathrm{a}$ & 0,6 \\
Março & $18,4 \mathrm{~b}$ & $20,5 \mathrm{a}$ & $18,2 \mathrm{~b}$ & 0,7 \\
Abril & $19,5 \mathrm{a}$ & $20,0 \mathrm{a}$ & $20,9 \mathrm{a}$ & 0,8 \\
\hline
\end{tabular}

Médias seguidas de letras diferentes na mesma linha são diferentes $(P<0,05)$. EPM- Erro padrão da média.

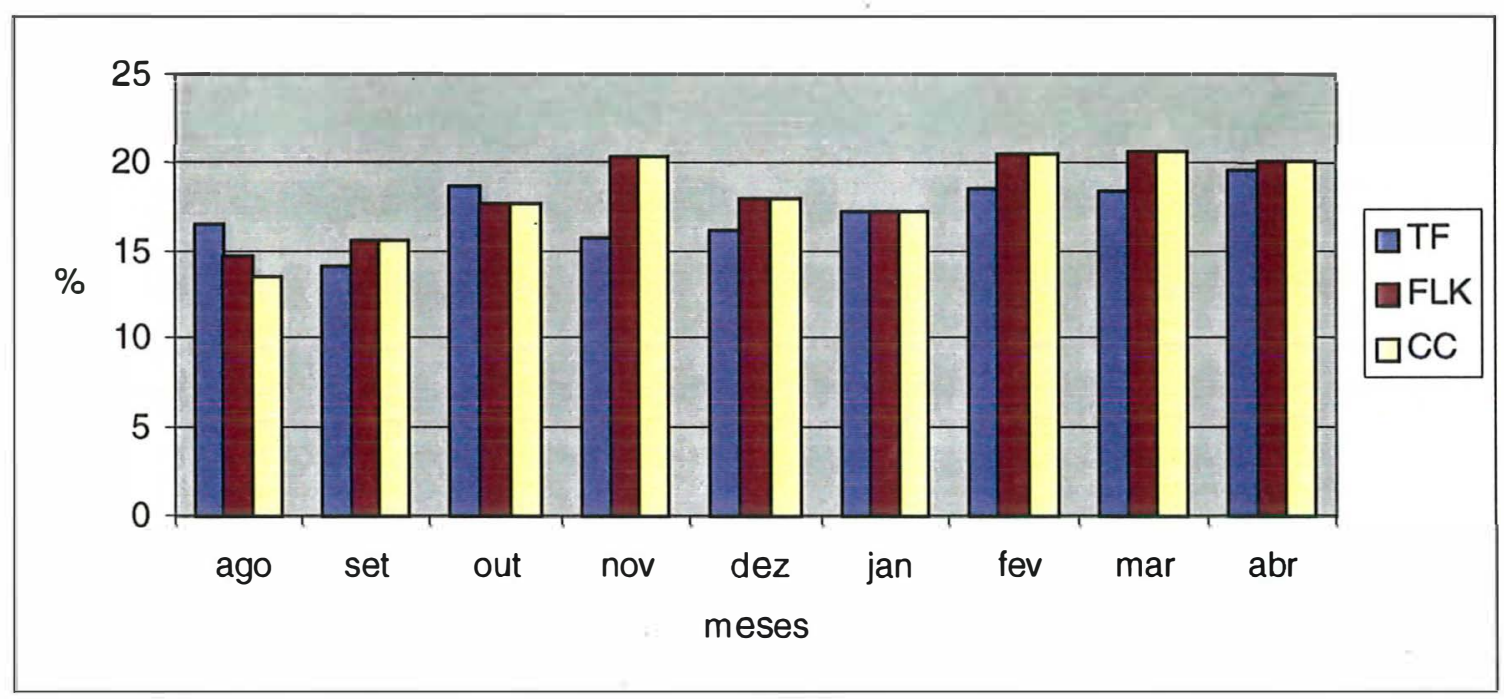

Figura 19: Teor de proteína bruta (\%) em amostras de forragem de simulação de pastejo para os três cultivares de Cynodon no período experimental. 
Na Tabela 21 pode-se observar a maior a proporção de proteina nos pastos de $50 \mathrm{~mm}$, mantendo uma tendência de queda com a elevação da altura do pasto. Essas diferenças são facilmente visualizadas na Figura 20.

Tabela 21: Porcentagem de proteina bruta em amostras de forragem nas quatro intensidades de pastejo $(50,100,150$ e $200 \mathrm{~mm})$ durante o periodo experimental.

\begin{tabular}{cccccc}
\hline Mês & 50 & 100 & 150 & 200 & EPM \\
\hline Agosto & $16,9 a$ & $14,5 b$ & $14,2 b$ & $13,9 b$ & 0,8 \\
Setembro & $18,0 a$ & $14,5 b$ & $13,7 b$ & $13,6 b$ & 0,8 \\
Outubro & $22,1 \mathrm{a}$ & $16,6 \mathrm{a}$ & $17,8 \mathrm{a}$ & $17,0 \mathrm{a}$ & 2,2 \\
Novembro & $21,9 \mathrm{a}$ & $17,0 \mathrm{~b}$ & $15,8 \mathrm{~b}$ & $15,5 \mathrm{~b}$ & 1,5 \\
Dezembro & $19,8 \mathrm{a}$ & $16,9 \mathrm{~b}$ & $15,2 \mathrm{~b}$ & $15,0 \mathrm{~b}$ & 0,8 \\
Janeiro & $21,3 \mathrm{a}$ & $17,1 \mathrm{~b}$ & $15,7 \mathrm{bc}$ & $14,5 \mathrm{c}$ & 0,7 \\
Fevereiro & $22,2 \mathrm{a}$ & $19,7 \mathrm{~b}$ & $19,6 \mathrm{~b}$ & $18,6 \mathrm{~b}$ & 0,7 \\
Março & $22,0 \mathrm{a}$ & $19,3 \mathrm{~b}$ & $18,1 \mathrm{bc}$ & $16,7 \mathrm{c}$ & 0,8 \\
Abril & $22,0 \mathrm{a}$ & $21,5 \mathrm{a}$ & $20,2 \mathrm{a}$ & $16,8 \mathrm{~b}$ & 0,9 \\
\hline
\end{tabular}

Médias seguidas de letras diferentes na mesma linha são diferentes $(P<0,05)$.

EPM- Erro padrão da média. 


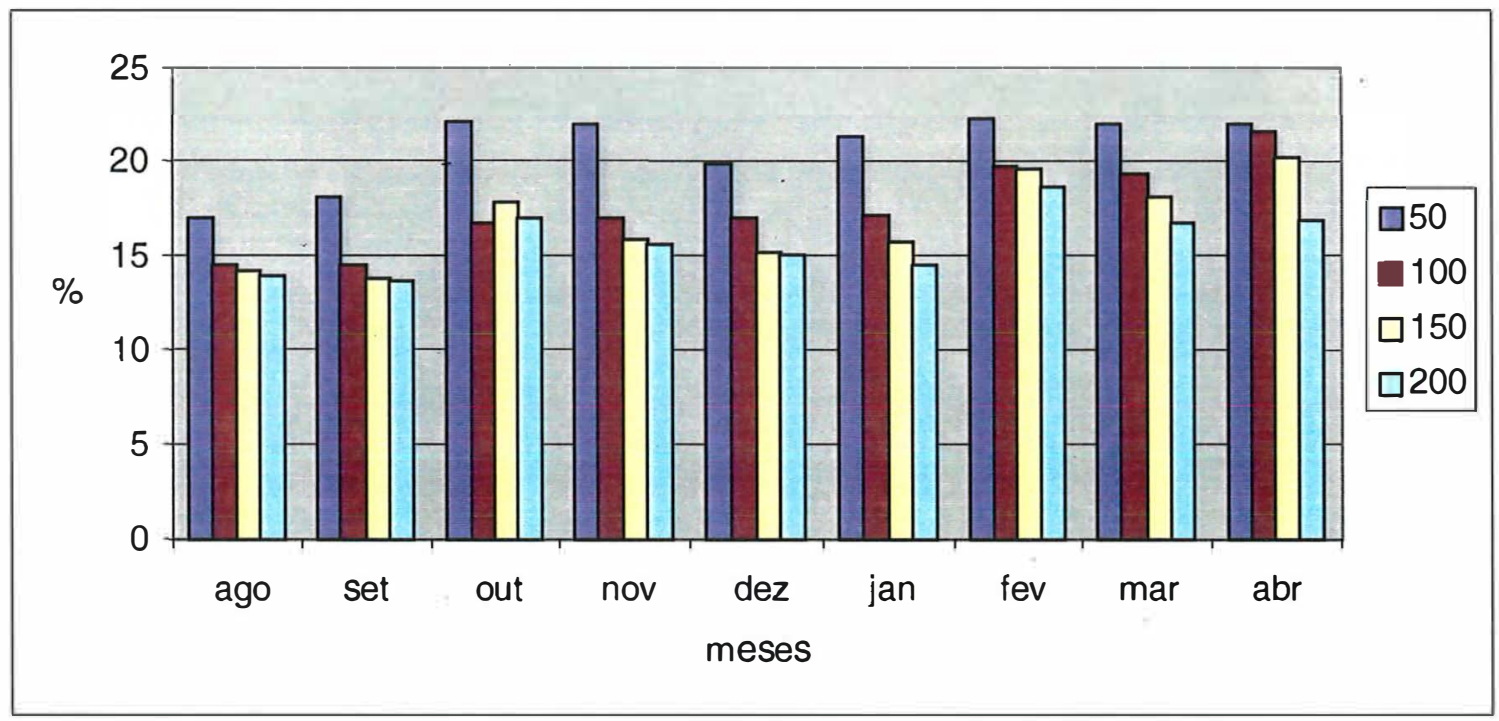

Figura 20: Teor de proteína bruta (\%) em amostras de forragem de simulação de pastejo para as quatro intensidades de pastejo no período experimental.

Os valores de digestibilidade foram altos e seguiram a mesma tendência dos teores de proteína bruta e \% de folhas ao longo dos meses. Os tratamentos de $50 \mathrm{~mm}$ destacaram-se dos demais pelos maiores valores de digestibilidade. Houve efeito de tempo e interações tempo $\times$ cultivar, tempo $\times$ bloco e tempo $\times$ cultivar $\mathrm{x}$ altura para esta variável $(P<0,05)$. Os valores são mostrados na Tabela 22 e ilustrados nas Figuras 21, 22 e 23. O comportamento da digestibilidade do Tifton-85 deve estar relacionado com a proporção de folhas. Ocorreu uma inversão nos valores a partir de novembro. Até novembro, Tifton-85 apresentava os maiores valores de DIVMO, depois assumiu uma posição intermediária e, no final do período experimental, já apresentava os menores valores de digestibilidade. 
Tabela 22: Porcentagem de digestibilidade 'in vitro' da matéria orgânica em amostras de forragem dos cultivares de Cynodon submetidos a quatro intensidades de pastejo durante o periodo experimental.

\begin{tabular}{|c|c|c|c|c|}
\hline Agosto & TF & FLK & $\mathrm{CC}$ & EPM \\
\hline 50 & $81,2 a A$ & $76,2 a A$ & $75,6 a A$ & 1,6 \\
\hline 100 & $77,9 a A$ & $79,8 a A$ & $75,7 a A$ & 1,5 \\
\hline 150 & $77,7 \mathrm{aA}$ & $73,3 \mathrm{bAB}$ & $70,2 \mathrm{bB}$ & 1,5 \\
\hline 200 & $81,3 a A$ & $73,9 \mathrm{bB}$ & $64,0 \mathrm{bB}$ & 1,5 \\
\hline EPM & 1,3 & 1,3 & 1,3 & \\
\hline Setembro & TF & FLK & $\mathrm{CC}$ & EPM \\
\hline 50 & $78,7 a A$ & $81,1 a$ & $76,7 a$ & 1,5 \\
\hline 100 & $77,6 a A$ & $73,7 \mathrm{bA}$ & $71,4 a A$ & 1,4 \\
\hline 150 & $74,3 a A$ & $76,9 \mathrm{abA}$ & $74,8 a A$ & 1,4 \\
\hline 200 & $73,2 a A$ & $72,7 \mathrm{bA}$ & $76,1 \mathrm{aA}$ & 1,4 \\
\hline EPM & 1,2 & 1,2 & 1,3 & \\
\hline Outubro & TF & FLK & $\mathrm{CC}$ & EPM \\
\hline 50 & $86,3 \mathrm{aA}$ & $82,8 a A$ & $83,2 a A$ & 3,8 \\
\hline 100 & $82,9 a A$ & $78,7 a A$ & $77,0 \mathrm{abA}$ & 3,6 \\
\hline 150 & $79,7 a A$ & $78,6 a A$ & $57,0 \mathrm{bA}$ & 3,6 \\
\hline 200 & $79,6 a A$ & $73,9 a A$ & $76,3 a b A$ & 3,6 \\
\hline EPM & 3,1 & 3,1 & 3,2 & \\
\hline Novembro & TF & FLK & $\mathrm{CC}$ & EPM \\
\hline 50 & $78,7 a A B$ & $74,7 \mathrm{aB}$ & $81,8 a A$ & 1,3 \\
\hline 100 & $73,7 \mathrm{bA}$ & $74,8 \mathrm{aA}$ & $77,5 \mathrm{abA}$ & 1,2 \\
\hline 150 & $74,4 \mathrm{bA}$ & $72,6 a A$ & $73,7 \mathrm{bA}$ & 1,2 \\
\hline 200 & $71,7 \mathrm{bA}$ & $73,3 a A$ & $75,4 a b A$ & 1,2 \\
\hline EPM & 1,0 & 1,0 & 1,1 & \\
\hline
\end{tabular}




\begin{tabular}{|c|c|c|c|c|}
\hline Dezembro & TF & FLK & $\mathrm{CC}$ & EPM \\
\hline 50 & $85,5 a A$ & $82,0 a A$ & $78,4 a A$ & 1,4 \\
\hline 100 & $80,8 a b A$ & $77,3 \mathrm{bA}$ & $73,9 a A$ & 1,3 \\
\hline 150 & $74,9 \mathrm{bA}$ & $72,7 \mathrm{bA}$ & $76,2 \mathrm{aA}$ & 1,3 \\
\hline 200 & $77,5 \mathrm{bA}$ & $72,2 \mathrm{bA}$ & $73,7 a A$ & 1,3 \\
\hline EPM & 1,1 & 1,1 & 1,2 & \\
\hline Janeiro & TF & FLK & $\mathrm{CC}$ & EPM \\
\hline 50 & $83,8 a A$ & $79,9 a b A$ & $78,9 a A$ & 2,7 \\
\hline 100 & $78,0 \mathrm{aB}$ & $90,1 \mathrm{aA}$ & $76,1 \mathrm{aB}$ & 2,5 \\
\hline 150 & $74,9 a A$ & $73,3 \mathrm{bA}$ & $77,4 a A$ & 2,5 \\
\hline 200 & $76,2 \mathrm{aA}$ & $72,6 \mathrm{bA}$ & $77,2 \mathrm{aA}$ & 2,5 \\
\hline EPM & 2,2 & 2,2 & 2,3 & \\
\hline Fevereiro & TF & FLK & $\mathrm{CC}$ & EPM \\
\hline 50 & $85,9 a A$ & $81,4 a A$ & $81,4 a A$ & 1,0 \\
\hline 100 & $82,1 \mathrm{abB}$ & $76,7 a b B$ & $85,1 \mathrm{Aa}$ & 1,0 \\
\hline 150 & $78,4 b$ & $77,9 b$ & $82,5 a A$ & 1,0 \\
\hline 200 & $78,9 \mathrm{bAB}$ & $74,6 \mathrm{Bb}$ & $81,3 \mathrm{aA}$ & 1,0 \\
\hline EPM & 0,8 & 0,8 & 0,9 & \\
\hline Março & TF & FLK & $\mathrm{CC}$ & EPM \\
\hline 50 & $84,3 a A$ & $79,0 a b A$ & $80,3 a b A$ & 1,0 \\
\hline 100 & $80,1 \mathrm{abA}$ & $77,2 \mathrm{bA}$ & $76,4 \mathrm{bA}$ & 1,0 \\
\hline 150 & $74,0 \mathrm{bAB}$ & $72,1 \mathrm{cB}$ & $79,1 a b A$ & 1,0 \\
\hline 200 & $76,4 \mathrm{bB}$ & $77,4 \mathrm{bAB}$ & $83,0 \mathrm{aA}$ & 1,0 \\
\hline EPM & 1,0 & 1,0 & 1,1 & \\
\hline
\end{tabular}




\begin{tabular}{ccccc}
\hline Abril & TF & FLK & CC & EPM \\
\hline 50 & $69,8 \mathrm{abB}$ & $70,0 \mathrm{aB}$ & $77,5 \mathrm{aA}$ & 2,3 \\
100 & $71,6 \mathrm{aAB}$ & $68,7 \mathrm{aB}$ & $75,6 \mathrm{aA}$ & 2,1 \\
150 & $61,3 \mathrm{aAB}$ & $69,1 \mathrm{aA}$ & $70,5 \mathrm{bA}$ & 2,1 \\
200 & $60,1 \mathrm{bA}$ & $67,7 \mathrm{aA}$ & $61,7 \mathrm{bA}$ & 2,1 \\
EPM & 1,9 & 1,9 & 2,0 & \\
\hline
\end{tabular}

Médias seguidas de letras maiúsculas diferentes na mesma linha são diferentes $(P<0,05)$ Médias seguidas de letras minúsculas diferentes na mesma coluna são diferentes $(P<0,05)$ EPM - Erro Padrão da Média.

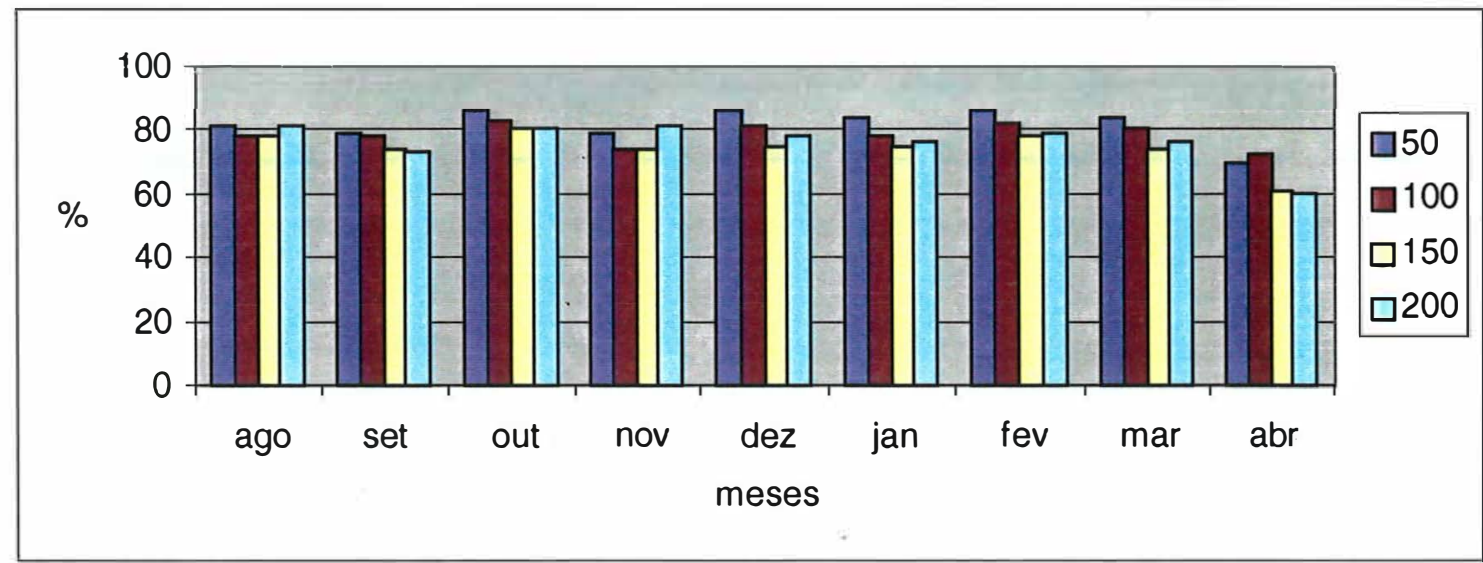

Figura 21: Digestibilidade 'in vitro' da matéria orgânica em amostras de Tifton-85 nas quatro intensidades de pastejo no período experimental.

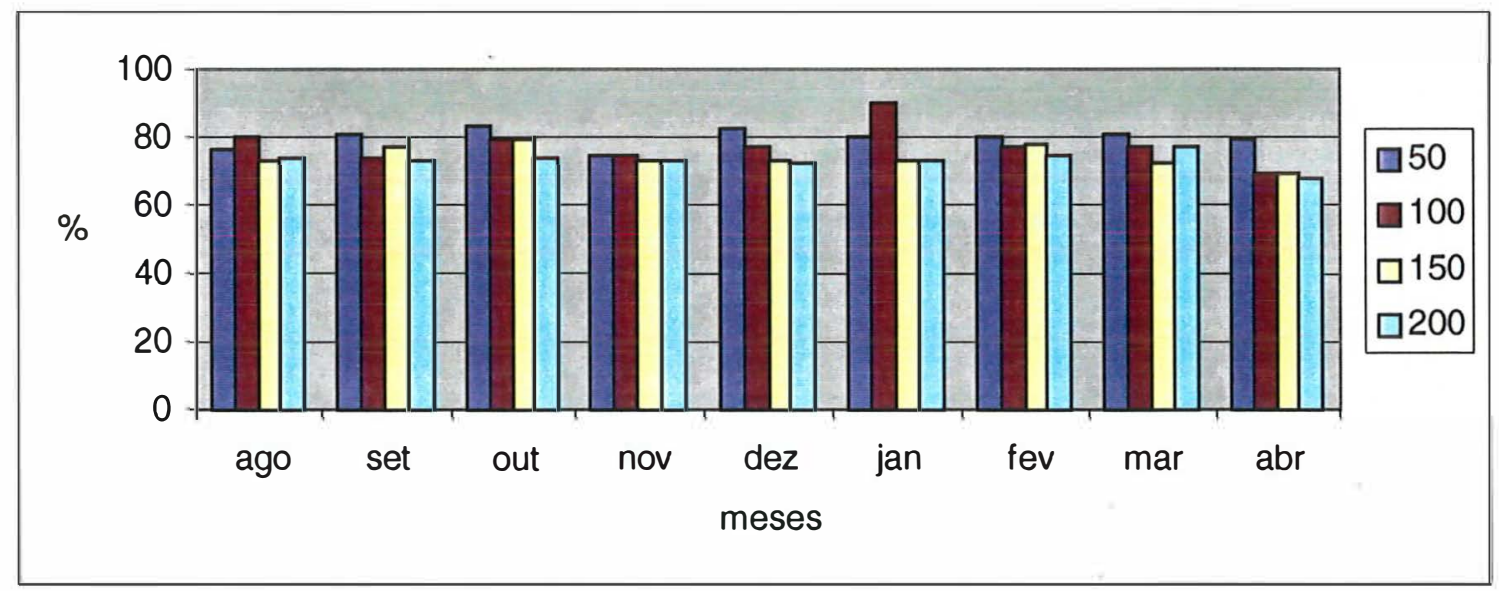

Figura 22: Digestibilidade 'in vitro' da matéria orgânica em amostras de Florakirk nas quatro intensidades de pastejo no período experimental. 


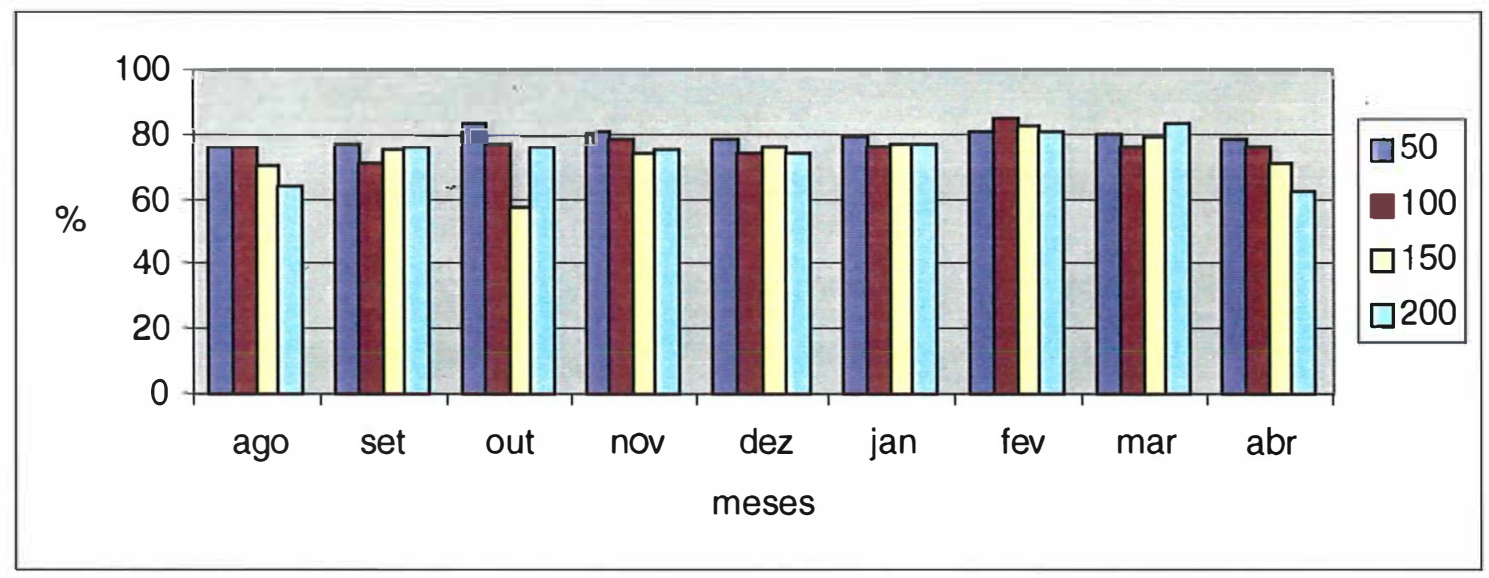

Figura 23: Digestibilidade 'in vitro' da matéria orgânica em amostras de Coastcross nas quatro intensidades de pastejo no período experimental.

A partir dos teores de proteína e digestibilidade da forragem foram calculadas as concentrações de Energia Metabolizável. Na tabela 23 pode-se observar valores altos variando de 11 a $13 \mathrm{MJ} / \mathrm{kg}$ de matéria seca. Valores para azevém perene (planta toda) são da ordem de 10 a $11 \mathrm{MJ} / \mathrm{kg}$ MS e são considerados elevados (Le Du \& Penning, 1982). Para esta variável houve efeito de tempo, bloco e altura e interação tempo $\mathrm{x}$ bloco $(\mathrm{P}<0,05)$.

Tabela 23: Quantidade de Energia Metabolizável MJ/kg de MS em amostras de forragem dos cultivares de Cynodon durante o período experimental.

\begin{tabular}{ccccc}
\hline Mês & Tifton-85 & Florakirk & Coastcross & EPM \\
\hline Agosto & $12,9 a$ & $12,3 \mathrm{~b}$ & $11,4 \mathrm{c}$ & 0,2 \\
Setembro & $12,3 \mathrm{a}$ & $12,4 \mathrm{a}$ & $12,2 \mathrm{a}$ & 0,2 \\
Outubro & $13,5 \mathrm{a}$ & $12,9 \mathrm{a}$ & $13,0 \mathrm{a}$ & 0,3 \\
Novembro & $12,0 \mathrm{a}$ & $12,7 \mathrm{a}$ & $12,5 \mathrm{a}$ & 0,2 \\
Dezembro & $12,8 \mathrm{a}$ & $12,6 \mathrm{a}$ & $12,4 \mathrm{a}$ & 0,2 \\
Janeiro & $12,8 \mathrm{a}$ & $13,4 \mathrm{a}$ & $12,7 \mathrm{a}$ & 0,6 \\
Fevereiro & $13,5 \mathrm{ab}$ & $13,2 \mathrm{~b}$ & $13,9 \mathrm{a}$ & 0,2 \\
Março & $13,0 \mathrm{a}$ & $13,0 \mathrm{a}$ & $13,0 \mathrm{a}$ & 0,2 \\
Abril & $11,2 \mathrm{a}$ & $12,1 \mathrm{a}$ & $12,3 \mathrm{a}$ & 0,4 \\
\hline
\end{tabular}

Médias seguidas de letras diferentes na mesma linha são diferentes $(P<0,05)$.

EPM- Erro padrão da média. 
Os tratamentos de $50 \mathrm{~mm}$ apresentaram, em geral, as maiores quantidades de energia por $\mathrm{kg}$ de forragem $(P<0,05)$ (Tabela 24).

Tabela 24: Quantidade de Energia Metabolizável em MJ/kg de MS em amostras de forragem nas quatro intensidades de pastejo (50, 100, 150 e $200 \mathrm{~mm}$ ) durante o periodo experimental.

\begin{tabular}{cccccc}
\hline Mês & 50 & 100 & 150 & 200 & EPM \\
\hline Agosto & $12,8 \mathrm{a}$ & $12,4 \mathrm{ab}$ & $11,8 \mathrm{~b}$ & $11,8 \mathrm{~b}$ & 0,3 \\
Setembro & $13,0 \mathrm{a}$ & $12,0 \mathrm{~b}$ & $12,2 \mathrm{~b}$ & $12,0 \mathrm{~b}$ & 0,3 \\
Outubro & $14,1 \mathrm{a}$ & $12,9 \mathrm{~b}$ & $13,0 \mathrm{~b}$ & $12,6 \mathrm{~b}$ & 0,4 \\
Novembro & $13,4 \mathrm{a}$ & $12,3 \mathrm{~b}$ & $11,9 \mathrm{~b}$ & $12,0 \mathrm{~b}$ & 0,3 \\
Dezembro & $13,6 \mathrm{a}$ & $12,6 \mathrm{~b}$ & $12,2 \mathrm{~b}$ & $12,1 \mathrm{~b}$ & 0,3 \\
Janeiro & $13,6 \mathrm{a}$ & $13,8 \mathrm{a}$ & $12,3 \mathrm{a}$ & $12,2 \mathrm{a}$ & 0,7 \\
Fevereiro & $14,1 \mathrm{a}$ & $13,6 \mathrm{ab}$ & $13,3 \mathrm{bc}$ & $13,0 \mathrm{c}$ & 0,2 \\
Março & $13,8 \mathrm{a}$ & $12,9 \mathrm{~b}$ & $12,4 \mathrm{~b}$ & $12,8 \mathrm{~b}$ & 0,3 \\
Abril & $12,5 \mathrm{a}$ & $12,1 \mathrm{ab}$ & $11,8 \mathrm{ab}$ & $11,0 \mathrm{~b}$ & 0,5 \\
\hline
\end{tabular}

Médias seguidas de letras diferentes na mesma linha são diferentes $(P<0,05)$.

EPM- Erro padrão da média.

\subsection{Densidade "bulk" e estrutura do pasto}

A avaliação geral dos dados de análise química e composição bromatológica revela um alto valor nutritivo da forragem "consumida". Contudo, aspectos estruturais e quantidade de alimento disponível no pasto também interferem no consumo de maneira decisiva. Entre os principais fatores estruturais está a densidade de forragem. Houve efeito de tempo, cultivar e altura e interações entre tempo $x$ cultivar, tempo $x$ bloco, tempo $x$ altura e tempo $x$ cultivar $x$ altura para essa variável $(P<0,05)$. Os dados são encontrados na Tabela 25.

A densidade seguiu a mesma tendência para todos os cultivares. Quanto maior a altura do pasto, menor a densidade de forragem. Tifton-85 apresentou, em média, as maiores densidades, seguido de Florakirk e Coastcross. Houve uma tendência de 
aumento na densidade até novembro/dezembro e a partir daí houve uma tendência de queda, independentemente da altura ou cultivar.

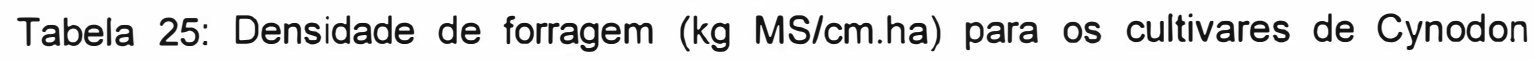
durante o período experimental.

\begin{tabular}{|c|c|c|c|c|}
\hline Agosto & TF & FLK & $\mathrm{CC}$ & EPM \\
\hline 50 & $591 a A$ & $532 a B$ & $360 a C$ & 11,3 \\
\hline 100 & $452 \mathrm{bA}$ & $370 \mathrm{bA}$ & $316 a B$ & 10,5 \\
\hline 150 & $369 c A$ & $329 \mathrm{bcA}$ & $255 \mathrm{bB}$ & 10,5 \\
\hline 200 & $352 \mathrm{cA}$ & $290 \mathrm{cB}$ & $236 b C$ & 10,5 \\
\hline EPM & 9,6 & 9,1 & 9,1 & \\
\hline Setembro & TF & FLK & $\mathrm{CC}$ & EPM \\
\hline 50 & $638 a A$ & $585 a B$ & $381 \mathrm{aC}$ & 8,9 \\
\hline 100 & $465 \mathrm{bA}$ & $399 \mathrm{bB}$ & $310 b C$ & 8,3 \\
\hline 150 & $378 \mathrm{cA}$ & $347 c A$ & $272 c B$ & 8,3 \\
\hline 200 & $332 d A$ & $300 A$ & $234 c B$ & 8,3 \\
\hline EPM & 7,6 & 7,2 & 7,2 & \\
\hline Outubro & TF & FLK & $\mathrm{CC}$ & EPM \\
\hline 50 & $580 a A$ & $486 a \mathrm{~B}$ & $333 a C$ & 7,8 \\
\hline 100 & $485 \mathrm{bA}$ & $368 \mathrm{bB}$ & $279 a b c$ & 7,3 \\
\hline 150 & $440 \mathrm{cA}$ & $302 \mathrm{cB}$ & $246 b c B$ & 7,3 \\
\hline 200 & $379 d A$ & $276 d A$ & $230 \mathrm{cB}$ & 7,3 \\
\hline EPM & 6,7 & 6,3 & 6,3 & \\
\hline Novembro & TF & FLK & $\mathrm{CC}$ & EPM \\
\hline 50 & $626 a B$ & $691 \mathrm{aA}$ & $472 \mathrm{aC}$ & 5,5 \\
\hline 100 & $471 \mathrm{bA}$ & $467 \mathrm{bA}$ & $345 b B$ & 5,2 \\
\hline 150 & $417 c A$ & $381 \mathrm{cB}$ & $298 c C$ & 5,2 \\
\hline 200 & $394 c A$ & $335 \mathrm{~dB}$ & $283 c C$ & 5,2 \\
\hline EPM & 4,7 & 4,5 & 4,5 & \\
\hline
\end{tabular}




\begin{tabular}{ccccc}
\hline Dezembro & TF & FLK & CC & EPM \\
\hline 50 & $608 \mathrm{aA}$ & $549 \mathrm{aB}$ & $425 \mathrm{aC}$ & 6,3 \\
100 & $489 \mathrm{bA}$ & $435 \mathrm{bB}$ & $353 \mathrm{bC}$ & 5,8 \\
150 & $419 \mathrm{cA}$ & $377 \mathrm{cB}$ & $310 \mathrm{cC}$ & 5,8 \\
200 & $398 \mathrm{cA}$ & $346 \mathrm{~dB}$ & $282 \mathrm{cC}$ & 5,8 \\
EPM & 5,3 & 5,1 & 5,1 & \\
\hline Janeiro & $\mathrm{TF}$ & $\mathrm{FLK}$ & $\mathrm{CC}$ & EPM \\
\hline 50 & $430 \mathrm{aB}$ & $481 \mathrm{aA}$ & $321 \mathrm{aC}$ & 4,1 \\
100 & $347 \mathrm{bB}$ & $380 \mathrm{bA}$ & $269 \mathrm{bC}$ & 3,8 \\
150 & $313 \mathrm{cA}$ & $300 \mathrm{cA}$ & $263 \mathrm{bB}$ & 3,8 \\
200 & $292 \mathrm{dA}$ & $265 \mathrm{~dB}$ & $253 \mathrm{bB}$ & 3,8 \\
EPM & 3,5 & 3,3 & 3,3 & \\
\hline Fevereiro & TF & FLK & CC & EPM \\
\hline 50 & $325 \mathrm{aB}$ & $393 \mathrm{aA}$ & $287 \mathrm{aC}$ & 3,0 \\
100 & $312 \mathrm{abA}$ & $290 \mathrm{bB}$ & $269 \mathrm{bC}$ & 2,8 \\
150 & $308 \mathrm{bA}$ & $261 \mathrm{cB}$ & $263 \mathrm{bB}$ & 2,8 \\
200 & $306 \mathrm{bA}$ & $242 \mathrm{dC}$ & $258 \mathrm{bB}$ & 2,8 \\
EPM & 2,6 & 2,5 & 2,5 & \\
\hline MarçO & TF & FLK & CC & EPM \\
\hline 50 & $456 \mathrm{aA}$ & $442 \mathrm{aB}$ & $395 \mathrm{aC}$ & 3,6 \\
100 & $360 \mathrm{bA}$ & $343 \mathrm{bB}$ & $289 \mathrm{bC}$ & 3,4 \\
150 & $336 \mathrm{cA}$ & $315 \mathrm{cB}$ & $261 \mathrm{cC}$ & 3,4 \\
200 & $330 \mathrm{cA}$ & $297 \mathrm{~dB}$ & $244 \mathrm{cC}$ & 3,4 \\
EPM & 3,1 & 3,0 & 3,0 & \\
\hline & & & &
\end{tabular}




\begin{tabular}{ccccc}
\hline Abril & TF & FLK & CC & EPM \\
\hline 50 & $466 \mathrm{abB}$ & $548 \mathrm{aA}$ & $251 \mathrm{aC}$ & 17,6 \\
100 & $390 \mathrm{bcA}$ & $379 \mathrm{bA}$ & $296 \mathrm{aB}$ & 16,4 \\
150 & $353 \mathrm{cA}$ & $329 \mathrm{bcAB}$ & $268 \mathrm{aB}$ & 16,4 \\
200 & $330 \mathrm{cA}$ & $271 \mathrm{cA}$ & $248 \mathrm{aA}$ & 16,4 \\
EPM & 15,0 & 14,2 & 14,2 & \\
\hline
\end{tabular}

Médias seguidas de letras maiúsculas diferentes na mesma linha são diferentes $(P<0,05)$ Médias seguidas de letras minúsculas diferentes na mesma coluna são diferentes $(P<0,05)$ EPM - Erro Padrão da Média.

O comportamento da densidade de forragem deve estar relacionado com a quantidade de material morto no perfil do pasto, que foi gradativamente menor depois do mês de novembro. Para \% de folhas houve efeito de tempo, cultivar e bloco e interações entre tempo $x$ cultivar, tempo $x$ bloco, tempo $x$ cultivar $x$ bloco e tempo $x$ altura $(P<0,05)$. Para \% de hastes houve efeito de tempo, cultivar, bloco e altura e interação entre tempo $x$ cultivar $(P<0,05)$. Para \% de material morto houve efeito de tempo, cultivar e bloco e interação entre tempo $x$ cultivar $(P<0,05)$.

A maior proporção de folhas foi observada para o Coastcross (exceção feita aos meses de agosto a setembro), seguido pelo Tifton-85 e Florakirk $(P<0,05)$ (Tabela 26). Apesar dos valores absolutos serem diferentes, o comportamento das proporções dos componentes da simulação de pastejo foi bastante semelhante ao que existia no perfil total do pasto (Tabelas 5 e 10). Isso mostra a grande influência que a composição do pasto pode exercer sobre a seleção final do animal. Os dados de porcentagem de folhas nos diferentes cultivares estão na Tabela 26 , hastes na Tabela 27 e material morto na Tabela 28. 
Tabela 26: Porcentagem de folhas no perfil total dos três cultivares de Cynodon durante o período experimental.

\begin{tabular}{ccccc}
\hline Mês & Tifton-85 & Florakirk & Coastcross & EPM \\
\hline Agosto & $26,5 \mathrm{a}$ & $18,3 \mathrm{~b}$ & $17,5 \mathrm{~b}$ & 1,5 \\
Setembro & $16,4 \mathrm{a}$ & $10,4 \mathrm{~b}$ & $10,8 \mathrm{~b}$ & 1,0 \\
Outubro & $22,6 \mathrm{ab}$ & $19,5 \mathrm{~b}$ & $23,3 \mathrm{a}$ & 1,3 \\
Novembro & $15,3 \mathrm{ab}$ & $13,9 \mathrm{~b}$ & $17,9 \mathrm{a}$ & 1,1 \\
Dezembro & $12,5 \mathrm{~b}$ & $12,1 \mathrm{~b}$ & $17,1 \mathrm{a}$ & 0,8 \\
Janeiro & $16,8 \mathrm{~b}$ & $18,4 \mathrm{ab}$ & $19,8 \mathrm{a}$ & 0,8 \\
Fevereiro & $20,3 \mathrm{ab}$ & $17,4 \mathrm{~b}$ & $21,2 \mathrm{a}$ & 1,3 \\
Março & $17,7 \mathrm{~b}$ & $20,7 \mathrm{~b}$ & $28,0 \mathrm{a}$ & 1,5 \\
\hline
\end{tabular}

Médias seguidas de letras diferentes na mesma linha são diferentes $(P<0,05)$.

EPM- Erro padrão da média.

Tabela 27: Porcentagem de hastes no perfil total dos três cultivares de Cynodon durante o período experimental.

\begin{tabular}{ccccc}
\hline Mês & Tifton-85 & Florakirk & Coastcross & EPM \\
\hline Agosto & $37,8 \mathrm{ab}$ & $36,9 \mathrm{~b}$ & $42,5 \mathrm{a}$ & 1,7 \\
Setembro & $44,5 \mathrm{a}$ & $36,9 \mathrm{~b}$ & $31,8 \mathrm{~b}$ & 2,0 \\
Outubro & $41,5 \mathrm{a}$ & $41,6 \mathrm{a}$ & $39,6 \mathrm{a}$ & 2,0 \\
Novembro & $46,7 \mathrm{a}$ & $45,0 \mathrm{a}$ & $49,0 \mathrm{a}$ & 1,7 \\
Dezembro & $47,5 \mathrm{a}$ & $42,2 \mathrm{a}$ & $41,2 \mathrm{a}$ & 2,5 \\
Janeiro & $40,7 \mathrm{ab}$ & $45,6 \mathrm{a}$ & $39,7 \mathrm{~b}$ & 1,8 \\
Fevereiro & $50,1 \mathrm{a}$ & $44,2 \mathrm{~b}$ & $44,7 \mathrm{~b}$ & 1,2 \\
Março & $54,8 \mathrm{a}$ & $45,5 \mathrm{~b}$ & $42,0 \mathrm{~b}$ & 2,6
\end{tabular}

Médias seguidas de letras diferentes na mesma linha são diferentes $(P<0,05)$.

EPM- Erro padrão da média. 
Tabela 28: Porcentagem de material morto no perfil total dos três cultivares de Cynodon durante o período experimental.

\begin{tabular}{ccccc}
\hline Mês & Tifton-85 & Florakirk & Coastcross & EPM \\
\hline Agosto & $35,6 \mathrm{a}$ & $43,2 \mathrm{a}$ & $40,0 \mathrm{a}$ & 1,9 \\
Setembro & $39,1 \mathrm{~b}$ & $52,6 \mathrm{a}$ & $57,4 \mathrm{a}$ & 2,1 \\
Outubro & $35,9 \mathrm{a}$ & $37,7 \mathrm{a}$ & $37,1 \mathrm{a}$ & 2,1 \\
Novembro & $38,0 \mathrm{ab}$ & $40,3 \mathrm{a}$ & $33,1 \mathrm{~b}$ & 2,2 \\
Dezembro & $40,0 \mathrm{a}$ & $44,6 \mathrm{a}$ & $41,7 \mathrm{a}$ & 2,6 \\
Janeiro & $42,6 \mathrm{a}$ & $35,1 \mathrm{~b}$ & $40,4 \mathrm{ab}$ & 1,9 \\
Fevereiro & $29,6 \mathrm{~b}$ & $37,3 \mathrm{a}$ & $34,1 \mathrm{ab}$ & 1,7 \\
Março & $27,5 \mathrm{a}$ & $31,7 \mathrm{a}$ & $29,9 \mathrm{a}$ & 2,7 \\
\hline
\end{tabular}

Médias seguidas de letras diferentes na mesma linha são diferentes $(P<0,05)$.

EPM- Erro padrão da média.

A tendência de redução do material morto e o comportamento da proporção de folhas podem ser melhor visualizados nas Figuras 24,25 e 26 a seguir.

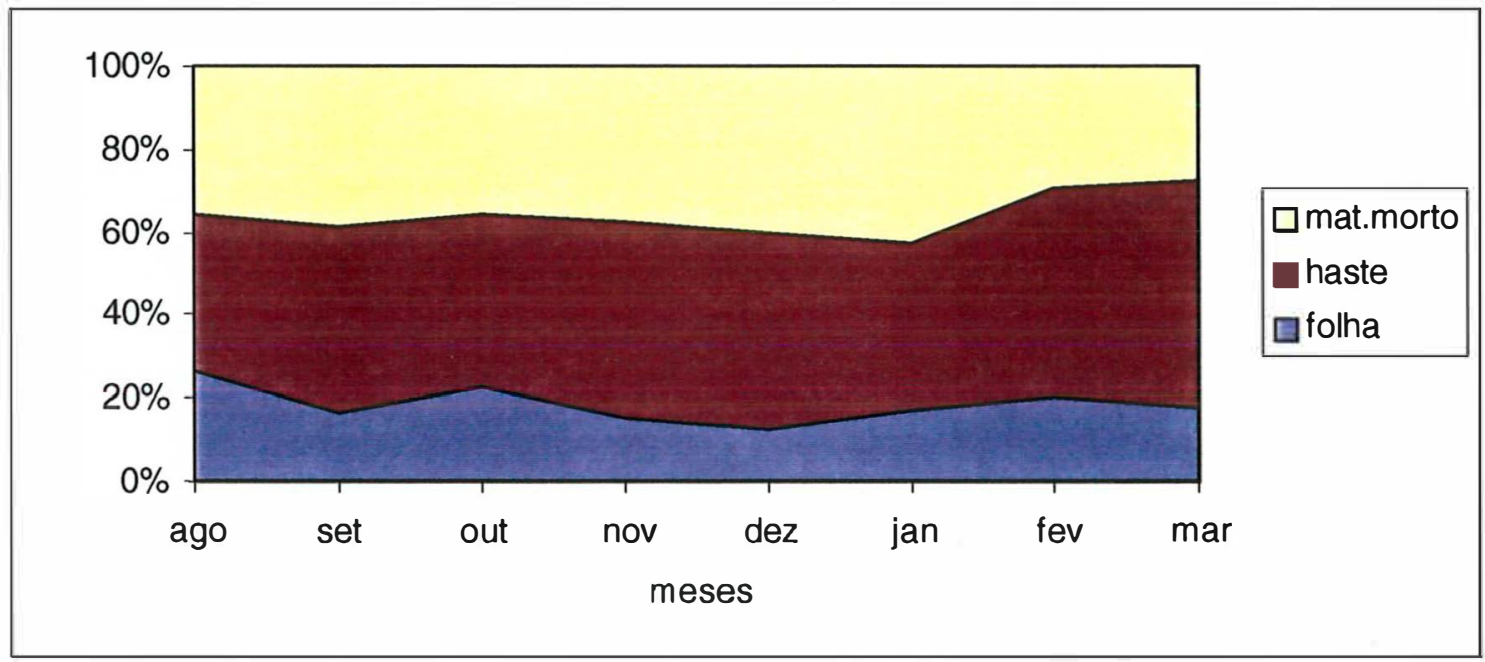

Figura 24: Composição morfológica do perfil total do pasto de Tifton-85 durante o período experimental. 


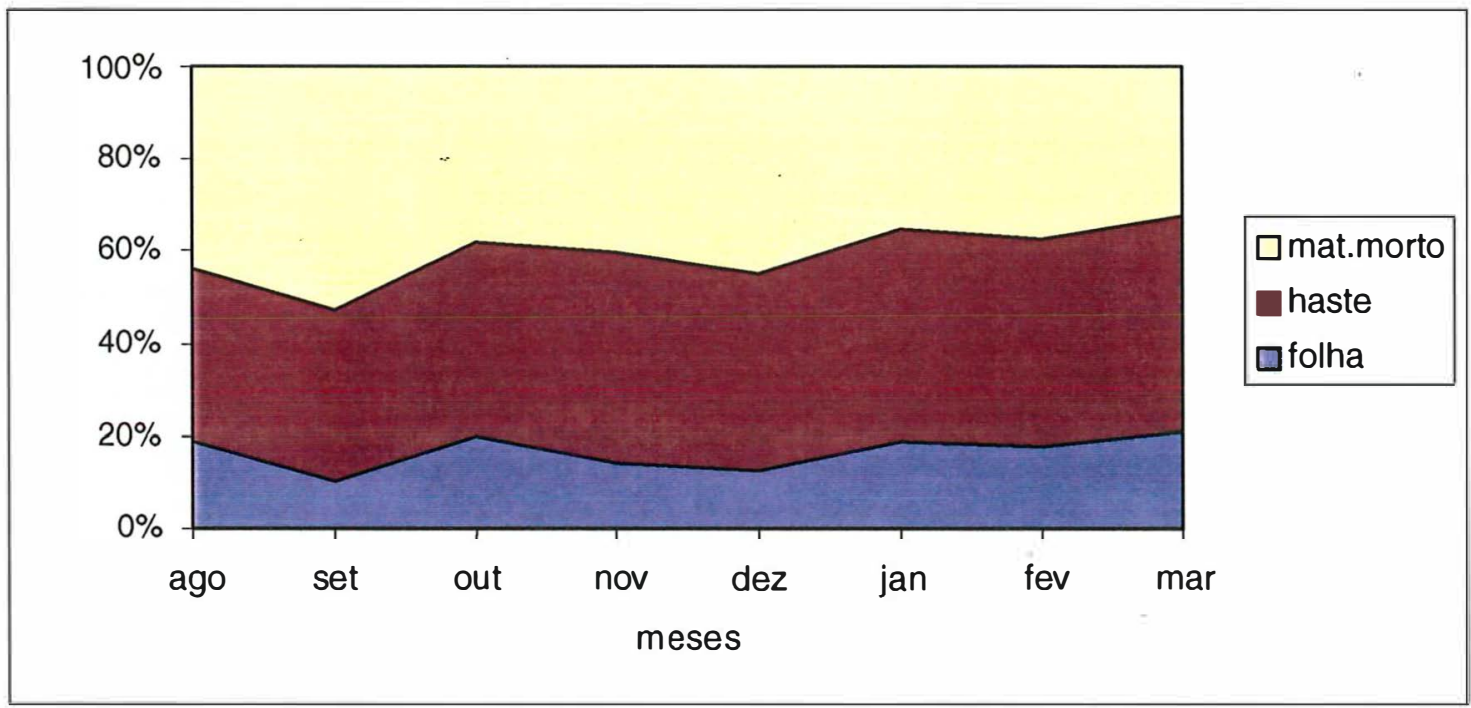

Figura 25: Composição morfológica do perfil total do pasto de Florakirk durante o período experimental.

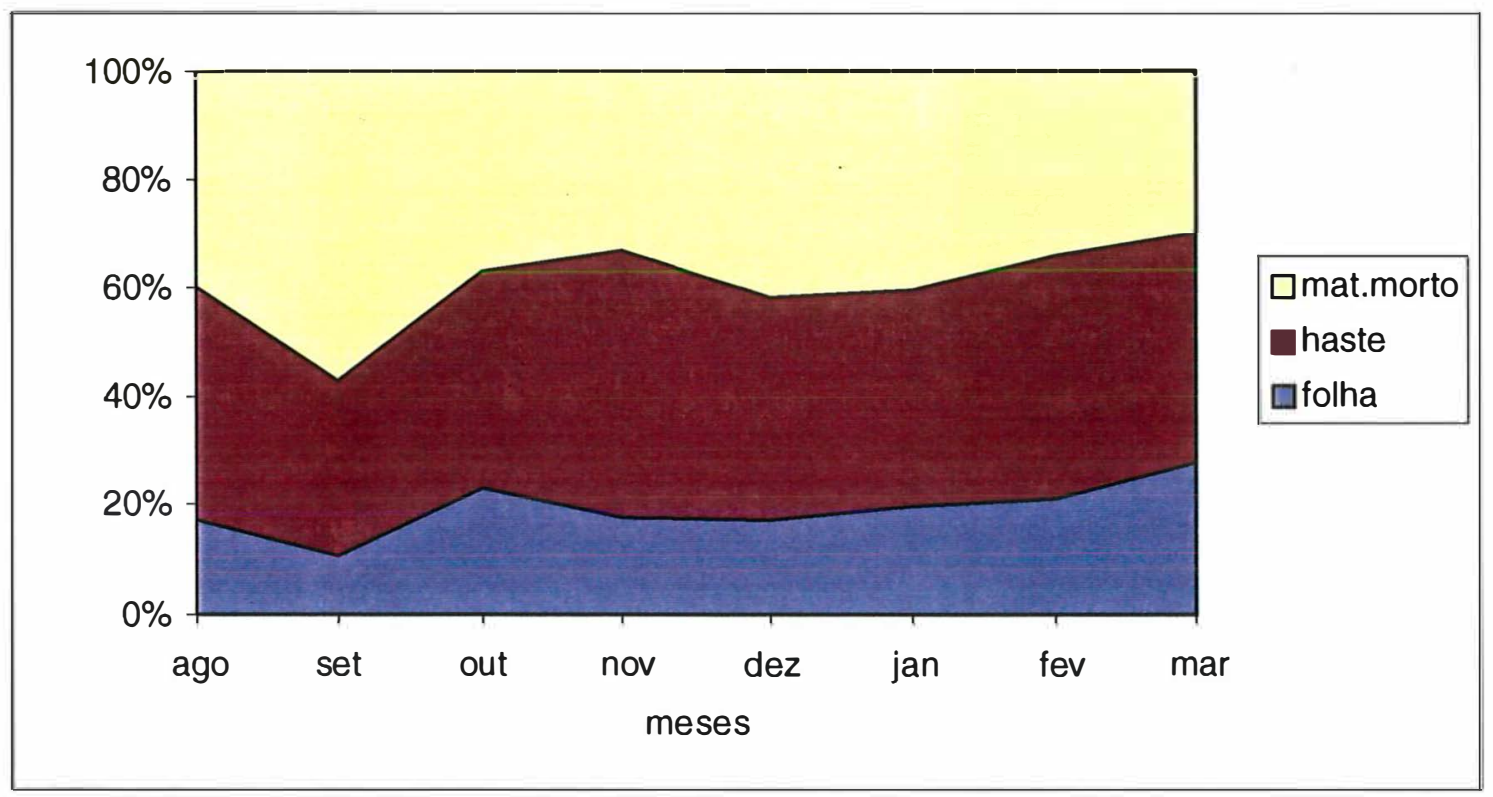

Figura 26: Composição morfológica do perfil total do pasto de Coastcross durante o período experimental. 
Em relação às alturas, não foram observadas diferenças $(P>0,05)$. Os dados são apresentados nas Tabelas 29 (folhas), 30 (hastes) e 31 (material morto).

Tabela 29: Forcentagem de folhas no perfil total para as quatro intensidades de pastejo $(50,100,150$ e $200 \mathrm{~mm})$ durante o período experimental.

\begin{tabular}{cccccc}
\hline Mês & 50 & 100 & 150 & 200 & EPM \\
\hline Agosto & $19,5 a$ & $22,6 a$ & $19,4 a$ & $21,4 a$ & 1,8 \\
Setembro & $11,8 b$ & $10,6 b$ & $12,1 b$ & $15,4 a$ & 1,1 \\
Outubro & $21,7 a$ & $22,9 a$ & $20,9 a$ & $21,7 a$ & 1,5 \\
Novembro & $19,4 a$ & $16,4 a b$ & $13,8 b$ & $13,4 b$ & 1,3 \\
Dezembro & $15,0 a$ & $14,6 a b$ & $13,7 a b$ & $12,3 b$ & 0,9 \\
Janeiro & $17,6 a$ & $19,9 a$ & $18,1 a$ & $17,8 a$ & 1,0 \\
Fevereiro & $19,1 a b$ & $22,5 a$ & $19,2 a b$ & $17,7 b$ & 1,5 \\
Março & $22,7 a b$ & $24,8 a$ & $22,7 a b$ & $18,4 b$ & 1,7 \\
\hline
\end{tabular}

Médias seguidas de letras diferentes na mesma linha são diferentes $(P<0,05)$.

EPM- Erro padrão da média.

Tabela 30: Porcentagem de hastes no perfil total para as quatro intensidades de pastejo $(50,100,150$ e $200 \mathrm{~mm})$ durante o periodo experimental.

\begin{tabular}{cccccc}
\hline Mês & 50 & 100 & 150 & 200 & EPM \\
\hline Agosto & $38,1 \mathrm{a}$ & $39,2 \mathrm{a}$ & $38,3 \mathrm{a}$ & $40,7 \mathrm{a}$ & 2,0 \\
Setembro & $36,6 \mathrm{a}$ & $37,8 \mathrm{a}$ & $36,0 \mathrm{a}$ & $40,7 \mathrm{a}$ & 2,4 \\
Outubro & $44,0 \mathrm{a}$ & $41,3 \mathrm{a}$ & $38,7 \mathrm{a}$ & $39,7 \mathrm{a}$ & 2,3 \\
Novembro & $47,1 \mathrm{a}$ & $47,5 \mathrm{a}$ & $47,7 \mathrm{a}$ & $45,2 \mathrm{a}$ & 2,0 \\
Dezembro & $47,8 \mathrm{a}$ & $42,8 \mathrm{a}$ & $43,4 \mathrm{a}$ & $40,4 \mathrm{a}$ & 2,8 \\
Janeiro & $46,8 \mathrm{a}$ & $39,3 \mathrm{~b}$ & $40,6 \mathrm{~b}$ & $41,3 \mathrm{ab}$ & 2,1 \\
Fevereiro & $47,3 \mathrm{a}$ & $45,1 \mathrm{a}$ & $46,5 \mathrm{a}$ & $46,5 \mathrm{a}$ & 1,4 \\
Março & $48,9 \mathrm{ab}$ & $46,4 \mathrm{ab}$ & $40,2 \mathrm{~b}$ & $54,2 \mathrm{a}$ & 3,0 \\
\hline
\end{tabular}

Médias seguidas de letras diferentes na mesma linha são diferentes $(P<0,05)$.

EPM- Erro padrão da média. 
Tabela 31: Porcentagem de material morto no perfil total para as quatro intensidades de pastejo $(50,100,150$ e $200 \mathrm{~mm})$ durante o período experimental.

\begin{tabular}{cccccc}
\hline Mês & 50 & 100 & 150 & 200 & EPM \\
\hline Agosto & $42,6 a b$ & $37,1 a b c$ & $43,0 a$ & $35,7 c$ & 2,2 \\
Setembro & $51,6 a$ & $51,6 a$ & $51,9 a$ & $43,8 b$ & 2,4 \\
Outubro & $34,8 a$ & $35,2 a$ & $40,2 a$ & $37,2 a$ & 2,4 \\
Novembro & $34,0 a$ & $35,9 a$ & $38,5 a$ & $40,1 a$ & 2,5 \\
Dezembro & $38,4 a$ & $41,5 a$ & $42,9 a$ & $45,6 a$ & 3,1 \\
Janeiro & $36,0 a$ & $41,1 a$ & $40,6 a$ & $39,7 a$ & 2,2 \\
Fevereiro & $33,0 a$ & $32,6 a$ & $34,0 a$ & $34,9 a$ & 2,0 \\
Março & $27,5 b$ & $27,8 b$ & $38,3 a$ & $25,3 b$ & 2,0 \\
\hline
\end{tabular}

Médias seguidas de letras diferentes na mesma linha são diferentes $(P<0,05)$.

EPM- Erro padrão da média.

Apesar das proporções dos diferentes componentes não terem diferido entre si com relação à altura do pasto, vale ressaltar que pastos mantidos mais altos tinham maiores massas de forragem e, consequentemente, maior produção de cada uma das frações.

\subsection{Desempenho Animal}

A primeira variável a ser considerada é a capacidade de suporte obtida no período experimental. Foram observados efeitos de tempo, cultivar, bloco e altura e interações entre tempo $x$ bloco, tempo $x$ altura e bloco $x$ altura $(P<0,05)$. Na Tabela 32 e Figura 27 são apresentados dados de capacidade de suporte dos diferentes cultivares. Pode-se observar uma maior capacidade de suporte para o Tifton-85, consequência das maiores taxas de acúmulo de forragem observadas na Tabela 1. 
Tabela 32: Capacidade de Suporte (kg PV/ha.dia) para os cultivares de Cynodon durante o período experimental.

\begin{tabular}{ccccc}
\hline & Tifton-85 & Florakirk & Coastcross & EPM \\
\hline Agosto & $1110 a$ & $1000 a$ & $1090 a$ & 89,2 \\
Setembro & $1550 a$ & $1370 a$ & $1535 a$ & 111,4 \\
Outubro & $1770 a$ & $1330 b$ & $1150 b$ & 87,4 \\
Novembro & $1870 a$ & $1300 b$ & $1015 b$ & 102,1 \\
Dezembro & $1810 a$ & $1290 b$ & $1485 b$ & 87,8 \\
Janeiro & $2035 a$ & $1720 b$ & $1735 b$ & 99,7 \\
Fevereiro & $2035 a$ & $1905 a$ & $1660 a$ & 149,7 \\
Março & $1965 a$ & $1520 b$ & $1415 b$ & 101,6 \\
Abril & $1505 a$ & $1225 a b$ & $1125 b$ & 114,5 \\
\hline
\end{tabular}

Médias seguidas de letras diferentes na mesma linha são diferentes $(P<0,05)$.

EPM- Erro padrão da média.

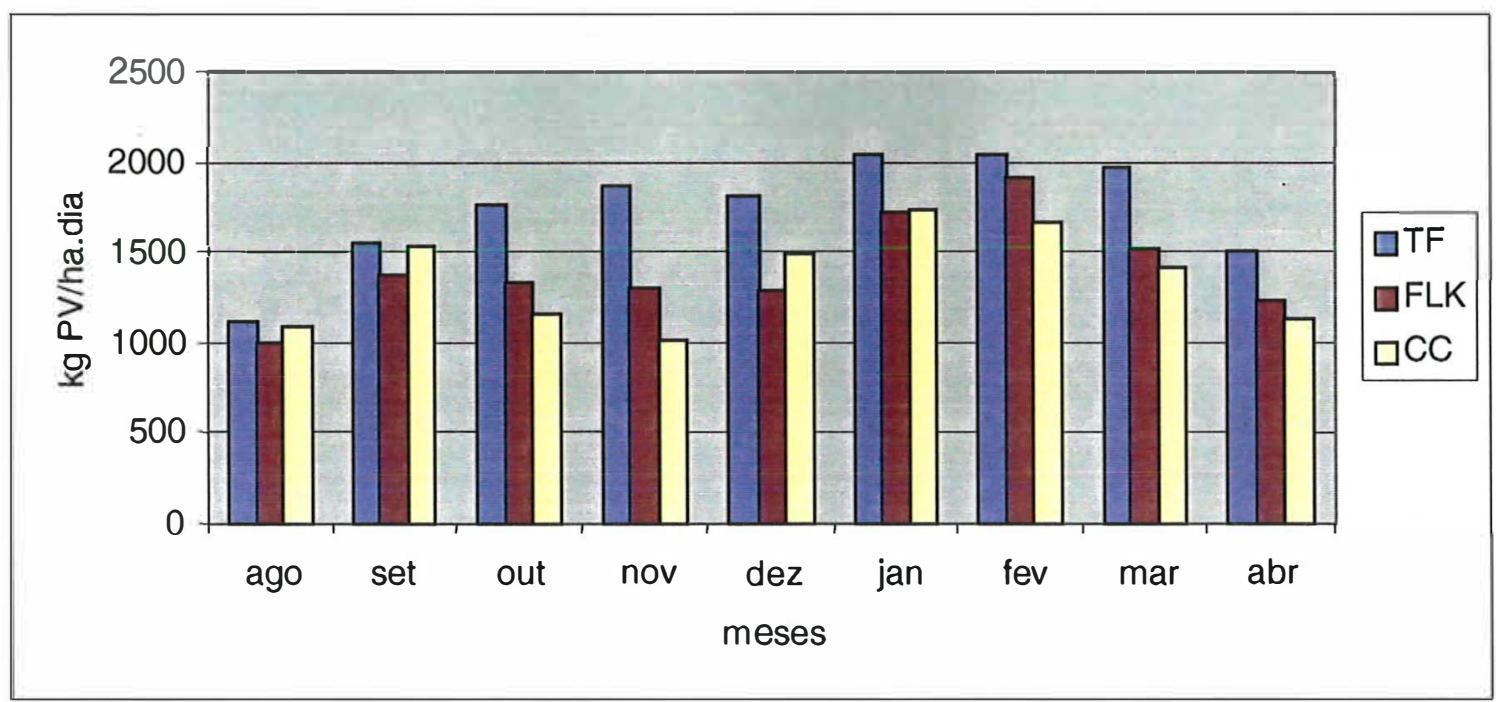

Figura 27: Capacidade de Suporte (kg PV/ha.dia) para os três cultivares de Cynodon no período experimental. 
A tabela 33 mostra a tendência de redução da capacidade de suporte com o aumento da altura do pasto. Isso acontece devido ao menor nível de utilização da pastagem nos pastos mais altos.

Tabela 33: Capacidade de Suporte (kg PV/ha.dia) nas quatro intensidades de pastejo $(50,100,150$ e $200 \mathrm{~mm})$ durante o período experimental.

\begin{tabular}{cccccc}
\hline & 50 & 100 & 150 & 200 & EPM \\
\hline Agosto & $1295 a$ & $885 b$ & $1095 a b$ & $985 b$ & 103,0 \\
Setembro & $1990 a$ & $1460 b$ & $1350 b$ & $1130 b$ & 128,6 \\
Outubro & $2030 a$ & $1450 b$ & $1170 b c$ & $1020 c$ & 101,0 \\
Novembro & $2025 a$ & $1435 b$ & $1100 b c$ & $1014 c$ & 117,9 \\
Dezembro & $2030 a$ & $1490 b$ & $1430 b c$ & $1170 c$ & 101,4 \\
Janeiro & $2330 a$ & $1710 b$ & $1680 b$ & $1605 b$ & 115,1 \\
Fevereiro & $2050 a$ & $1710 a$ & $1750 a$ & $1950 a$ & 172,9 \\
Março & $1500 b c$ & $1790 a b$ & $1845 a$ & $1390 c$ & 117,3 \\
Abril & $1235 a$ & $1225 a$ & $1300 a$ & $1380 a$ & 132,2 \\
\hline
\end{tabular}

Médias seguidas de letras diferentes na mesma linha são diferentes $(P<0,05)$.

EPM- Erro padrão da média.

$\mathrm{Na}$ figura 28 destaca-se a maior capacidade de suporte na altura de $50 \mathrm{~mm}$ em relação as outras alturas, fato este que será explorado mais detalhadamente junto com os dados de ganho de peso. 


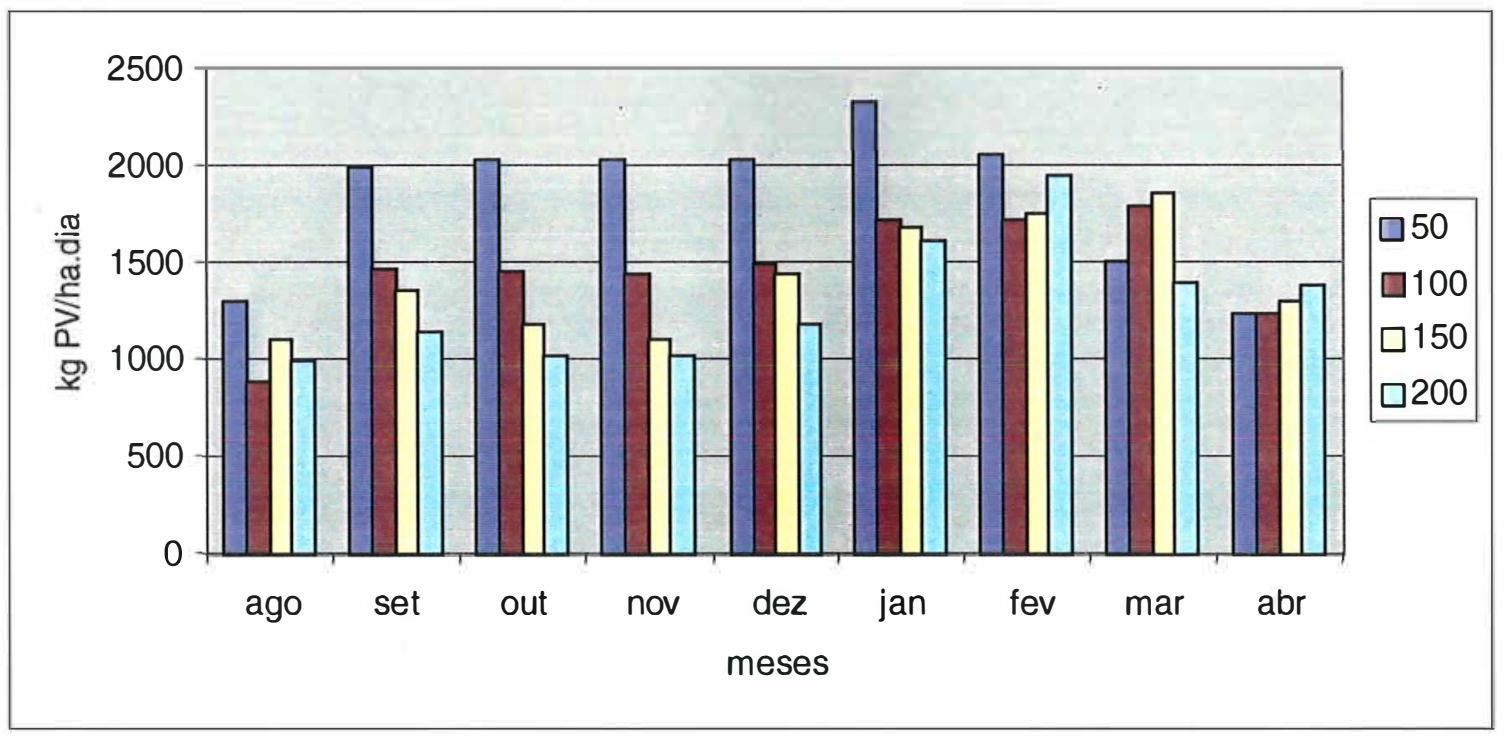

Figura 28: Capacidade de Suporte (kg PV/ha.dia) para as quatro intensidades de pastejo no período experimental.

Os ganhos de peso individuais obtidos foram baixos em relação aos ganhos esperados em função do valor nutritivo da forragem "consumida" (Tabela 34 e Figura. 29). Para ganho individual houve efeito de tempo, bloco e altura $(P<0,05)$. Os ganhos aumentaram nos meses de verão. Esse fato pode ter sido devido à troca dos animais nessa época. Contudo, um fator que está altamente relacionado com esse fato é a disponibilidade de forragem que será discutida a seguir. 
Tabela 34: Ganho de peso individual de ovinos em crescimento (g/animal.dia) para os cultivares de Cynodon durante o período experimental.

\begin{tabular}{ccccc}
\hline Mês & Tifton-85 & Florakirk & Coastcross & EPM \\
\hline Agosto & $50,3 \mathrm{a}$ & $60,1 \mathrm{a}$ & $39,1 \mathrm{a}$ & 16,0 \\
Setembro & $20,9 \mathrm{a}$ & $11,8 \mathrm{a}$ & $14,4 \mathrm{a}$ & 6,7 \\
Outubro & $16,4 \mathrm{a}$ & $-5,2 \mathrm{~b}$ & $16,4 \mathrm{a}$ & 7,0 \\
Novembro & $12,8 \mathrm{~b}$ & $28,3 \mathrm{a}$ & $9,1 \mathrm{~b}$ & 0,1 \\
Dezembro & $9,1 \mathrm{~b}$ & $28,8 \mathrm{a}$ & $12,8 \mathrm{~b}$ & 5,3 \\
Janeiro & $45,2 \mathrm{a}$ & $47,9 \mathrm{a}$ & $37,9 \mathrm{a}$ & 5,2 \\
Fevereiro & $30,5 \mathrm{a}$ & $29,5 \mathrm{a}$ & $35,2 \mathrm{a}$ & 5,4 \\
Março & $68,1 \mathrm{a}$ & $51,4 \mathrm{a}$ & $89,1 \mathrm{a}$ & 13,0 \\
Abril & $33,6 \mathrm{a}$ & $47,0 \mathrm{a}$ & $46,3 \mathrm{a}$ & 11,0 \\
\hline
\end{tabular}

Médias seguidas de letras diferentes na mesma linha são diferentes $(P<0,05)$.

EPM- Erro padrão da média.

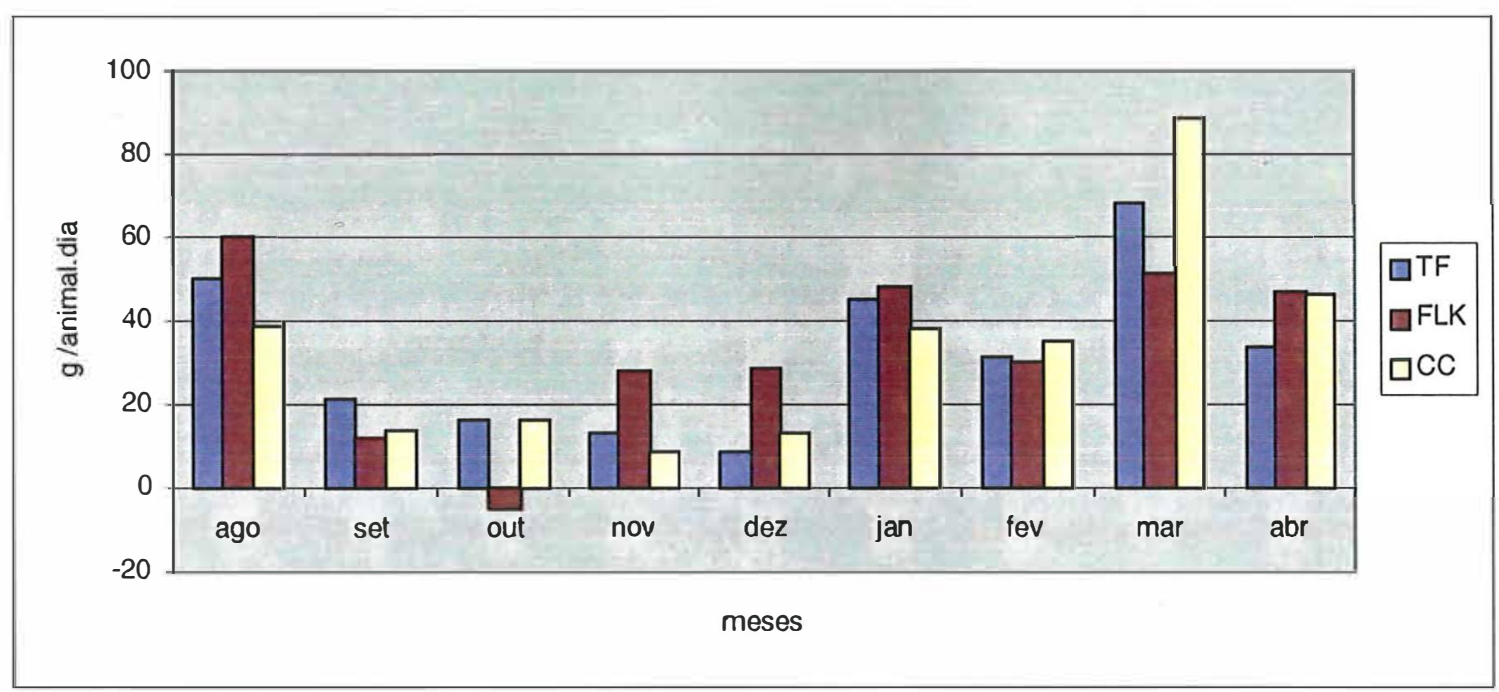

Figura 29: Ganho de peso individual de ovinos em crescimento para os três cultivares de Cynodon no período experimental. 
As diferenças mais evidentes de ganho de peso ocorreram em função da altura do pasto. Os pastos mais baixos, que anteriormente mostrados tiveram as maiores capacidades de suporte, tiveram os menores ganhos de peso (Tabela 35 e Figura 30). Contudo, se forem observados os meses de setembro e outubro para a altura de 50 $\mathrm{mm}$, a lotação foi mantida alta em relação à forragem acumulada no período, o que pode ter resultado em perda de peso dos animais devido à baixa disponibilidade. Essa lotação tão diferenciada pode ser justificada através das alturas médias mantidas nas parcelas. As figuras 31,32 e 33 mostram que houve uma grande dificuldade em se manter as alturas das parcelas em $50 \mathrm{~mm}$ até dezembro. Na tentativa de sempre abaixar a altura real, eram colocados mais animais e o ganho de cada animal era prejudicado. A partir de dezembro conseguiu-se chegar muito próximo da altura meta de $50 \mathrm{~mm}$ e o ganho individual aumentou.

Tabela 35: Ganho de peso individual de ovinos em crescimento (g/animal.dia) nas quatro intensidades de pastejo $(50,100,150$ e $200 \mathrm{~mm})$ durante o periodo experimental.

\begin{tabular}{cccccc}
\hline Mês & 50 & 100 & 150 & 200 & EPM \\
\hline Agosto & $37,3 a$ & $52,4 a$ & $51,8 a$ & $57,8 a$ & 18,8 \\
Setembro & $-9,9 b$ & $29,3 a$ & $6,9 b$ & $36,5 a$ & 7,8 \\
Outubro & $-25,3 c$ & $22,0 a$ & $4,1 b$ & $36,0 a$ & 8,7 \\
Novembro & $8,4 a$ & $10,5 a$ & $22,3 a$ & $26,3 a$ & 6,6 \\
Dezembro & $8,4 a$ & $10,5 a$ & $22,3 a$ & $26,3 a$ & 6,6 \\
Janeiro & $33,5 b$ & $45,3 a b$ & $52,1 a$ & $43,9 a b$ & 6,5 \\
Fevereiro & $31,9 a$ & $28,3 a$ & $40,9 a$ & $25,7 a$ & 6,8 \\
Março & $71,2 a$ & $68,3 a$ & $55,3 a$ & $83,2 a$ & 16,3 \\
Abril & $49,4 a$ & $33,5 a$ & $37,9 a$ & $48,4 a$ & 13,8 \\
\hline
\end{tabular}

Médias seguidas de letras diferentes na mesma linha são diferentes $(P<0,05)$.

EPM- Erro padrão da média. 


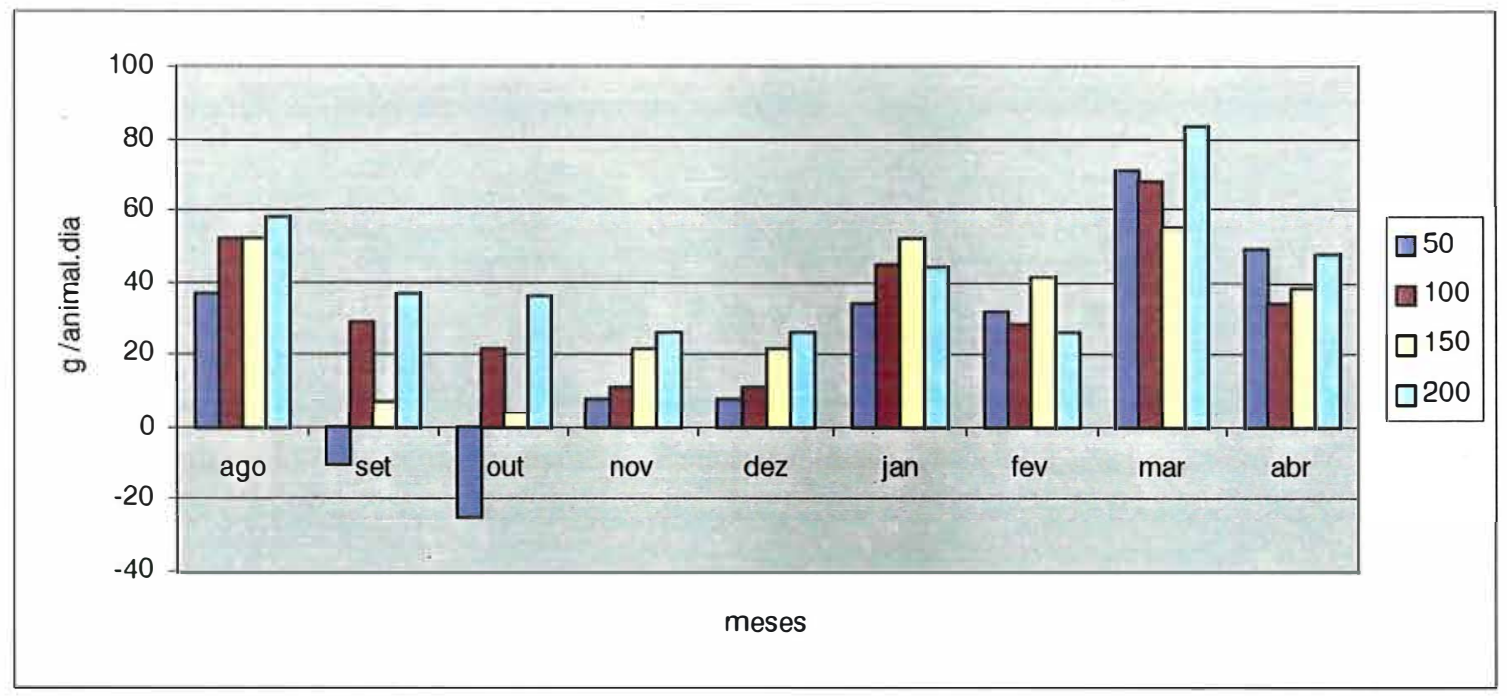

Figura 30: Ganho de peso individual de ovinos em crescimento para as quatro intensidades de pastejo no período experimental.

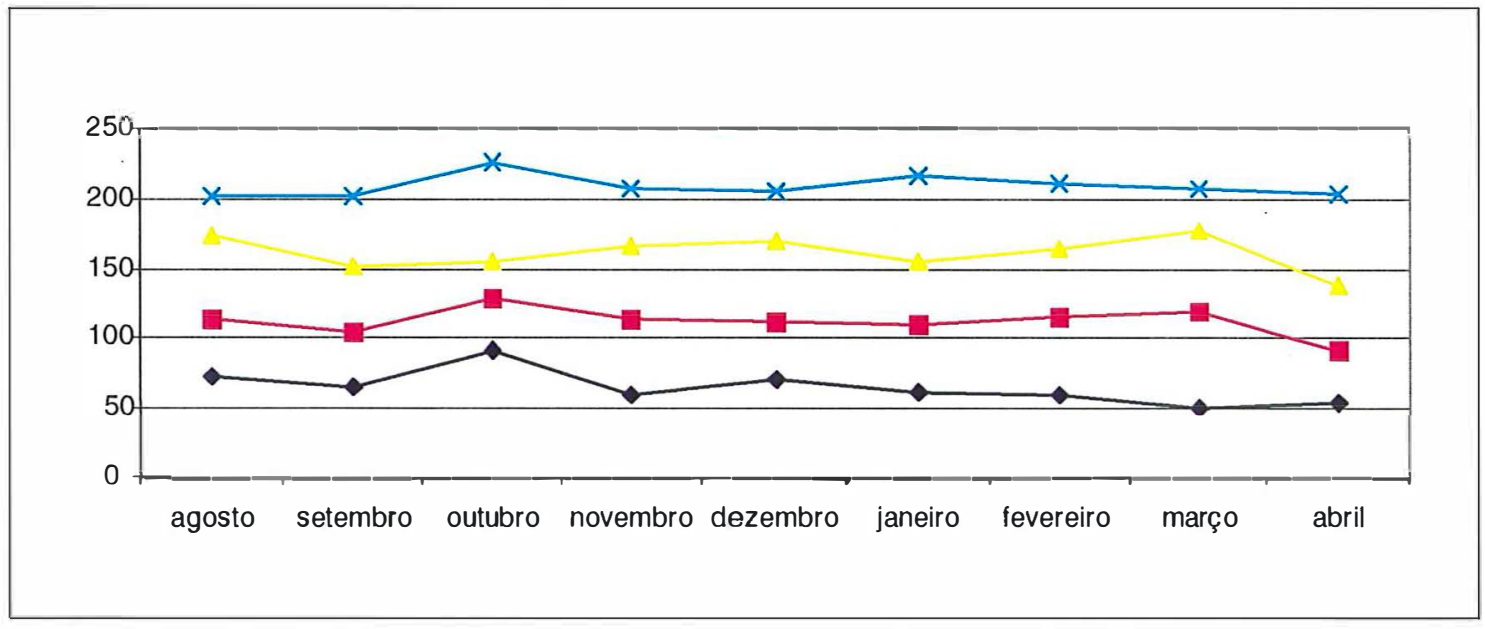

Figura 31: Flutuação da altura média mensal em torno da altura meta de tratamento para Tifton-85 no período experimental. 


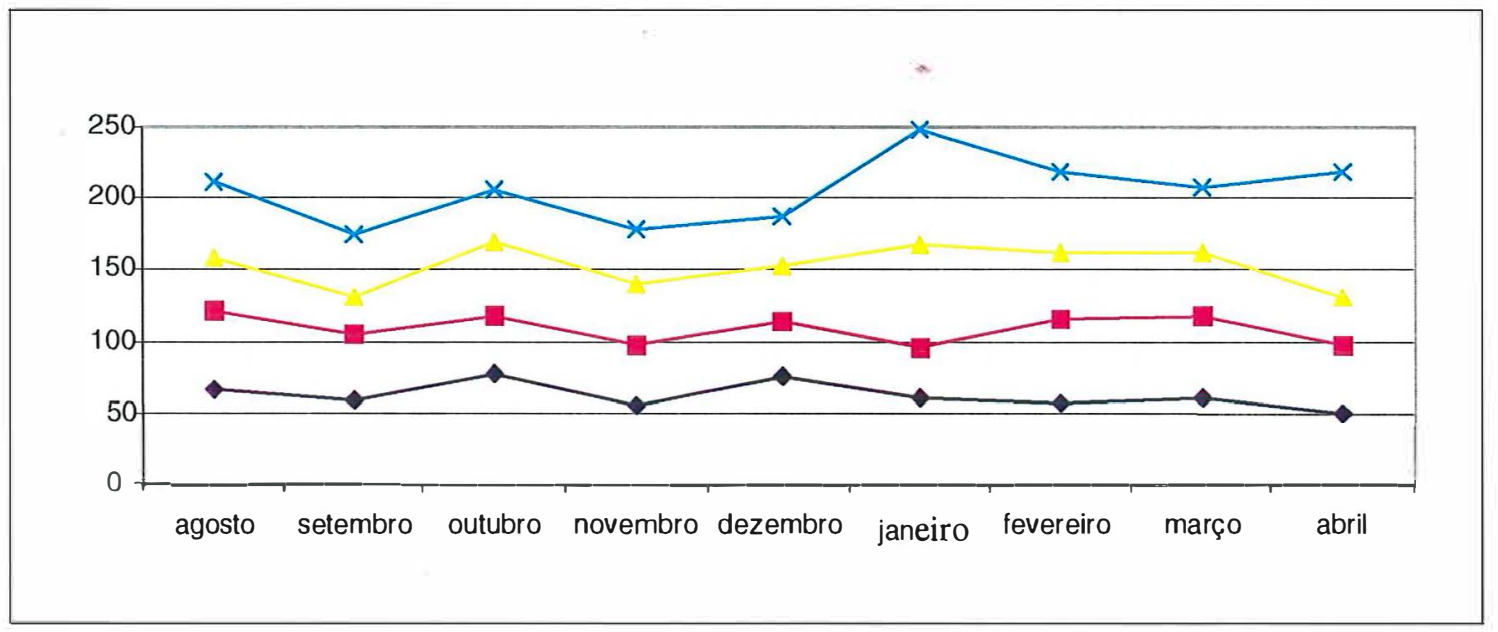

Figura 32 : Flutuação da altura média mensal em torno da altura meta de tratamento para Florakirk no período experimental.

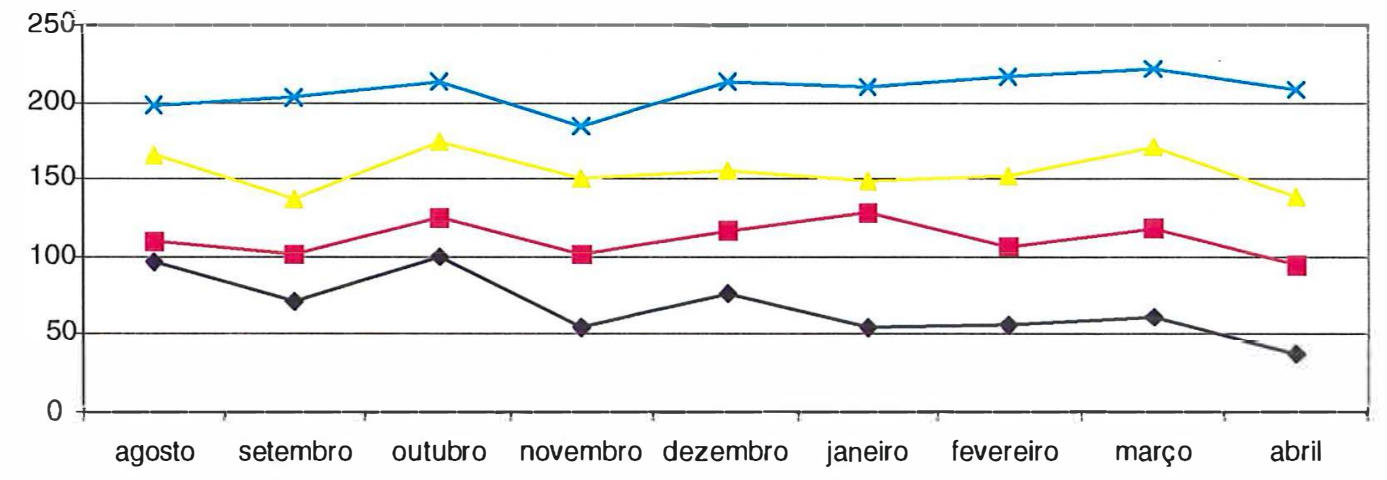

Figura 33: Flutuação da altura média mensal em torno da altura meta de tratamento para Coastcross no período experimental. 
Os menores ganhos podem ser justificados pelos dados de disponibilidade de forragem, os quais também foram baixos para esse periodo. Na tabela 36 e figura 34 são apresentados os valores de disponibilidade para os cultivares. Houve efeito de tempo e altura e interações entre tempo $x$ bloco e tempo $x$ altura $(P<0,05)$. Observa-se que mesmo tendo a maior taxa de acúmulo, Tifton-85 foi o cultivar que apresentou menor disponibilidade de forragem, isso devido a alta capacidade de suporte mantida nesses pastos. Valores de disponibilidade em torno de 6 a $7 \%$ PV foram os que propiciaram os maiores ganhos individuais.

Tabela 36: Disponibilidade de forragem ( $\mathrm{kg} \mathrm{MS} / 100 \mathrm{Kg}$ PV.dia) para os cultivares de Cynodon durante o período experimental.

\begin{tabular}{ccccc}
\hline Mês & Tifton-85 & Florakirk & Coastcross & EPM \\
\hline Agosto & $3,4 \mathrm{~b}$ & $4,3 \mathrm{a}$ & $3,7 \mathrm{a}$ & 0,6 \\
Setembro & $2,2 \mathrm{~b}$ & $1,8 \mathrm{~b}$ & $2,7 \mathrm{a}$ & 0,3 \\
Outubro & $4,6 \mathrm{~b}$ & $4,4 \mathrm{a}$ & $5,8 \mathrm{a}$ & 0,6 \\
Novembro & $3,7 \mathrm{~b}$ & $3,6 \mathrm{a}$ & $5,0 \mathrm{a}$ & 0,6 \\
Dezembro & $6,2 \mathrm{~b}$ & $6,5 \mathrm{a}$ & $6,3 \mathrm{a}$ & 0,6 \\
Janeiro & $5,4 \mathrm{~b}$ & $5,4 \mathrm{a}$ & $5,7 \mathrm{a}$ & 0,4 \\
Fevereiro & $6,2 \mathrm{a}$ & $4,2 \mathrm{a}$ & $6,1 \mathrm{a}$ & 1,0 \\
Março & $5,0 \mathrm{a}$ & $6,5 \mathrm{ab}$ & $7,4 \mathrm{a}$ & 0,7 \\
Abril & $1,8 \mathrm{a}$ & $4,1 \mathrm{a}$ & $3,4 \mathrm{a}$ & 0,4 \\
\hline
\end{tabular}

Médias seguidas de letras diferentes na mesma linha são diferentes $(P<0,05)$.

EPM- Erro padrão da média. 


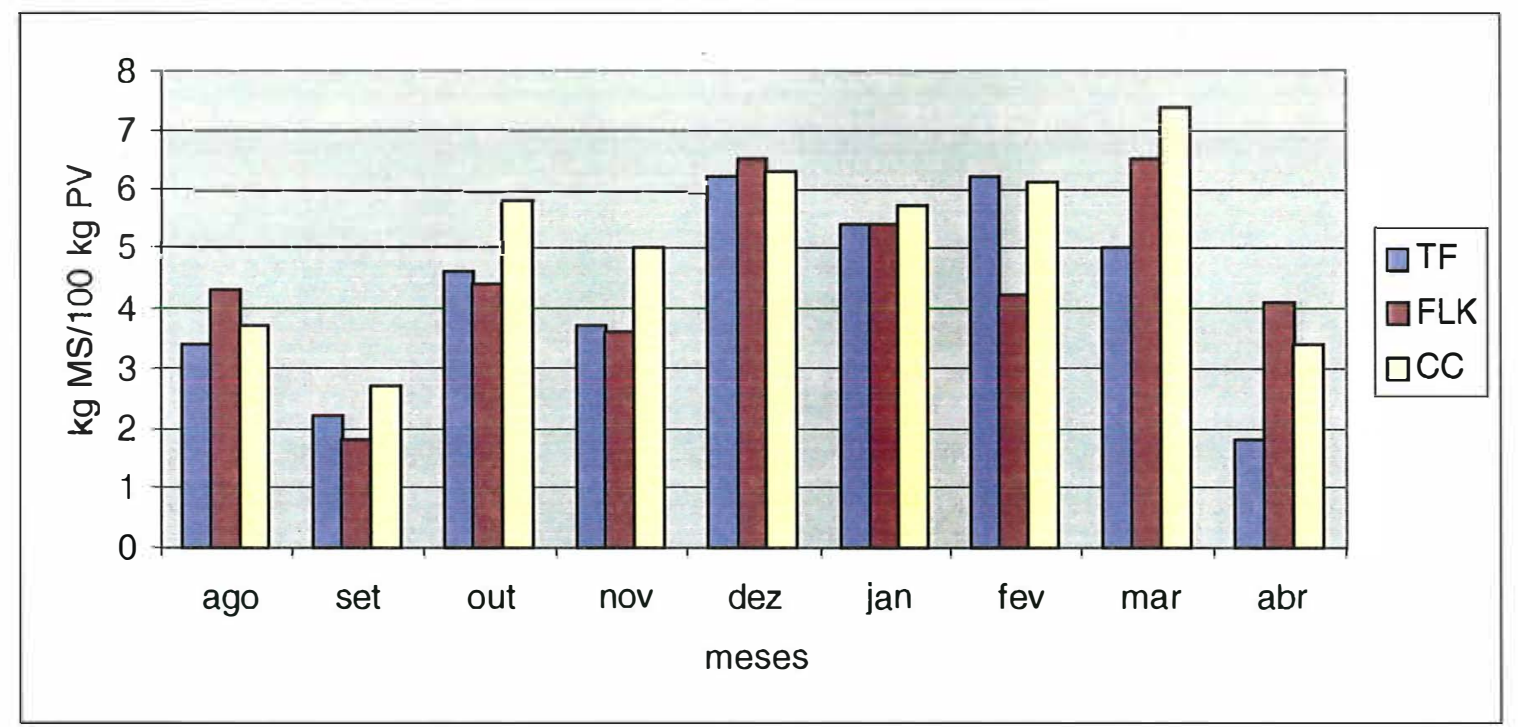

Figura 34: Disponibilidade de forragem (kg MS/100 kg PV.dia) para os três cultivares de Cynodon no período experimental.

As maiores disponibilidades foram obtidas nos pastos mais altos e as menores nos pastos mais baixos (Tabela 37). Valores menores que 3\% PV são extremamente limitantes para o ganho de ovinos em pastejo de Cynodon. Isso acontece porque nesse nível não se tem disponível a quantidade mínima necessária para ingestão diária, compatível com desempenho satisfatório. Além disso, deve-se considerar que em pastejo existe uma seleção feita pelos animais e as partes rejeitadas são perdidas. 
Tabela 37: Disponibilidade de forragem (kg MS/100Kg PV.dia) nas quatro intensidades de pastejo $(50,100,150$ e $200 \mathrm{~mm}$ ) durante o período experimental.

\begin{tabular}{cccccc}
\hline Mês & 50 & 100 & 150 & 200 & EPM \\
\hline Agosto & $2,4 \mathrm{~b}$ & $4,8 \mathrm{a}$ & $2,8 \mathrm{~b}$ & $5,2 \mathrm{a}$ & 0,7 \\
Setembro & $1,9 \mathrm{~b}$ & $1,9 \mathrm{~b}$ & $2,0 \mathrm{~b}$ & $3,1 \mathrm{a}$ & 0,3 \\
Outubro & $4,1 \mathrm{~b}$ & $4,6 \mathrm{ab}$ & $4,8 \mathrm{ab}$ & $6,1 \mathrm{a}$ & 0,6 \\
Novembro & $2,6 \mathrm{~b}$ & $2,8 \mathrm{~b}$ & $4,3 \mathrm{~b}$ & $6,8 \mathrm{a}$ & 0,6 \\
Dezembro & $4,6 \mathrm{~b}$ & $6,4 \mathrm{~b}$ & $5,7 \mathrm{~b}$ & $8,5 \mathrm{a}$ & 0,7 \\
Janeiro & $4,6 \mathrm{~b}$ & $5,7 \mathrm{ab}$ & $5,6 \mathrm{ab}$ & $6,2 \mathrm{a}$ & 0,4 \\
Fevereiro & $4,9 \mathrm{a}$ & $7,0 \mathrm{a}$ & $6,1 \mathrm{a}$ & $4,1 \mathrm{a}$ & 1,1 \\
Março & $6,9 \mathrm{a}$ & $6,1 \mathrm{a}$ & $5,3 \mathrm{a}$ & $7,0 \mathrm{a}$ & 0,8 \\
Abril & $3,6 \mathrm{a}$ & $2,9 \mathrm{ab}$ & $3,3 \mathrm{ab}$ & $2,4 \mathrm{~b}$ & 0,4 \\
\hline
\end{tabular}

Médias seguidas de letras diferentes na mesma linha são diferentes $(P<0,05)$.

EPM- Erro padrão da média.

Na figura 35 observa-se que a disponibilidade, assim como a taxa de acúmulo, segue o padrão estacional de produção de forragem. Considerando que a disponibilidade de forragem é dependente da taxa de acúmulo e da capacidade de suporte, qualquer aumento em produção de forragem com uma adubação nitrogenada, por exemplo, pode resultar em um aumento na disponibilidade, proporcionando maiores ganhos individuais. Contudo, esse benefício é momentâneo, uma vez que um ajuste em lotação se fará imediatamente necessário para que o estado do pasto (altura) seja mantido sob controle. 


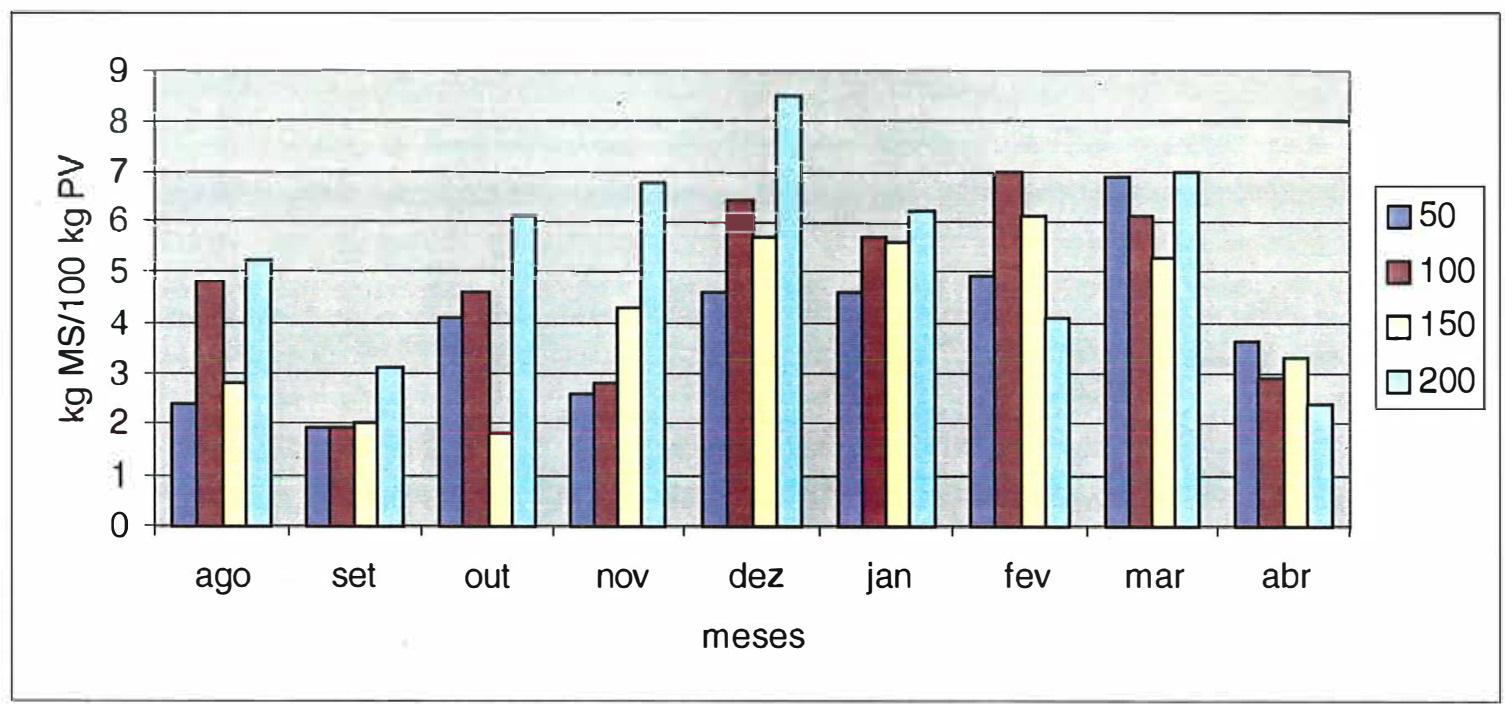

Figura 35: Disponibilidade de forragem (kg MS/kg PV.dia) para as quatro intensidades de pastejo no período experimental.

Em pastos tropicais, provavelmente não se atinja o potencial genético de ganho dos animais sem se perder o controle da estrutura do pasto e sem nenhum tipo de suplementação. Pode ser bastante vantajoso trabalhar com alta lotação diminuindo ao máximo as perdas, desde que se obtenha ganhos por área satisfatórios. Na Tabela 38 são encontrados os ganhos de peso por área obtidos no período. Houve efeito de tempo e bloco e interação entre tempo $x$ altura $(P<0,05)$. Nota-se que a maior variação foi no tempo. Nos meses de primavera os ganhos foram baixos. Contudo, no verão esses valores aumentaram bastante atingindo um máximo em março (Figura 36). 
Tabela 38: Ganho de peso por área (kg PV/ha.dia) para os cultivares de Cynodon durante o período experimental.

\begin{tabular}{ccccc}
\hline Mês & Tifton-85 & Florakirk & Coastcross & EPM \\
\hline Agosto & $2,4 a$ & $2,4 a$ & $0,8 a$ & 0,7 \\
Setembro & $0,9 a$ & $0,5 a$ & $0,2 a$ & 0,5 \\
Outubro & $0,1 a$ & $-1,0 a$ & $0,6 a$ & 0,6 \\
Novembro & $0,5 a$ & $2,3 a$ & $1,5 a$ & 0,6 \\
Dezembro & $0,5 a$ & $2,3 a$ & $1,5 a$ & 0,6 \\
Janeiro & $4,5 a$ & $4,1 a$ & $3,8 a$ & 0,6 \\
Fevereiro & $2,5 a$ & $2,8 a$ & $2,7 a$ & 0,7 \\
Março & $5,0 a$ & $5,4 a$ & $5,6 a$ & 2,4 \\
Abril & $2,8 a$ & $2,2 a$ & $2,2 a$ & 0,6 \\
\hline
\end{tabular}

Médias seguidas de letras diferentes na mesma linha são diferentes $(P<0,05)$. EPM- Erro padrão da média.

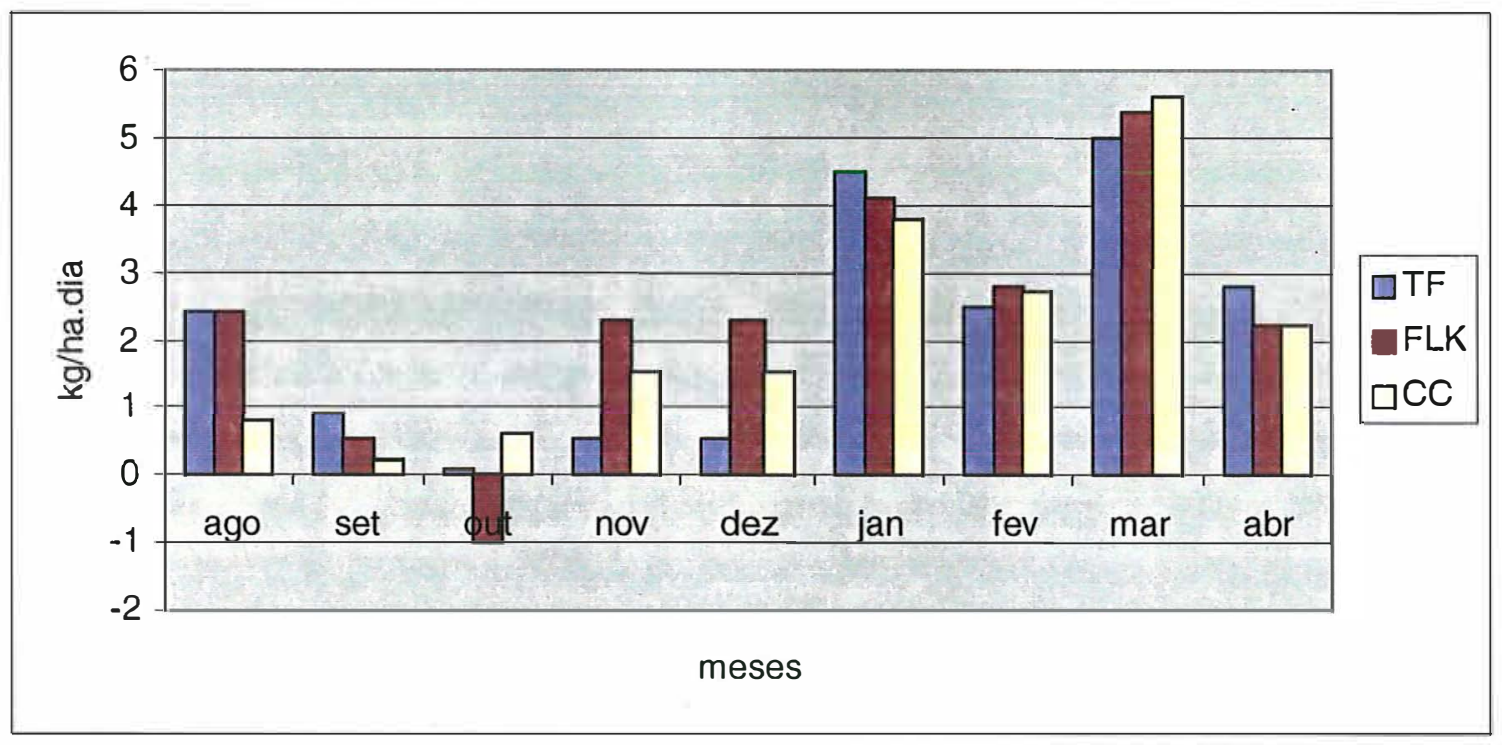

Figura 36: Ganho de peso por área (kg/ha.dia) para os três cultivares de Cynodon no período experimental.

Os ganhos de peso por área dos ovinos foram inferiores àqueles observados com os mesmos cultivares, pastejados por bovinos, por Pedreira (1995) e Hill et al. 
(1997), apesar do menor período de pastejo possivel durante o ano na Flórida em relação ao Brasil. Entre as alturas também não foram observadas diferenças $(P>0,05)$. Isso pode significar que existe uma flexibilidade de utilização da pastagem onde é possivel explorar ganho individual ou lotação sem haver diferença no ganho por área. Os ganhos dos meses de verão superaram aqueles dos meses de primavera (Tabela 39 e Figura 37).

Tabela 39: Ganho de peso por área (kg PV/ha.dia) nas quatro intensidades de pastejo $(50,100,150$ e $200 \mathrm{~mm})$ durante o período experimental.

\begin{tabular}{cccccc}
\hline Mês & 50 & 100 & 150 & 200 & Sem \\
\hline Agosto & $2,1 \mathrm{a}$ & $1,4 \mathrm{a}$ & $1,3 \mathrm{a}$ & $2,7 \mathrm{a}$ & 0,8 \\
Setembro & $-1,4 \mathrm{~b}$ & $1,7 \mathrm{a}$ & $0,1 \mathrm{a}$ & $1,7 \mathrm{a}$ & 0,6 \\
Outubro & $-3,8 \mathrm{~b}$ & $1,7 \mathrm{a}$ & $0,0 \mathrm{a}$ & $1,7 \mathrm{a}$ & 0,7 \\
Novembro & $1,3 \mathrm{a}$ & $1,3 \mathrm{a}$ & $1,8 \mathrm{a}$ & $1,3 \mathrm{a}$ & 0,7 \\
Dezembro & $1,3 \mathrm{a}$ & $1,3 \mathrm{a}$ & $1,8 \mathrm{a}$ & $1,3 \mathrm{a}$ & 0,7 \\
Janeiro & $5,0 \mathrm{a}$ & $4,0 \mathrm{a}$ & $4,4 \mathrm{a}$ & $3,1 \mathrm{a}$ & 0,7 \\
Fevereiro & $3,0 \mathrm{a}$ & $1,8 \mathrm{a}$ & $3,6 \mathrm{a}$ & $2,2 \mathrm{a}$ & 0,8 \\
Março & $3,8 \mathrm{a}$ & $9,8 \mathrm{a}$ & $4,4 \mathrm{a}$ & $3,3 \mathrm{a}$ & 2,8 \\
Abril & $3,3 \mathrm{a}$ & $1,8 \mathrm{a}$ & $2,1 \mathrm{a}$ & $2,4 \mathrm{a}$ & 0,7 \\
\hline
\end{tabular}

Médias seguidas de letras diferentes na mesma linha são diferentes $(P<0,05)$.

EPM- Erro padrāo da média. 


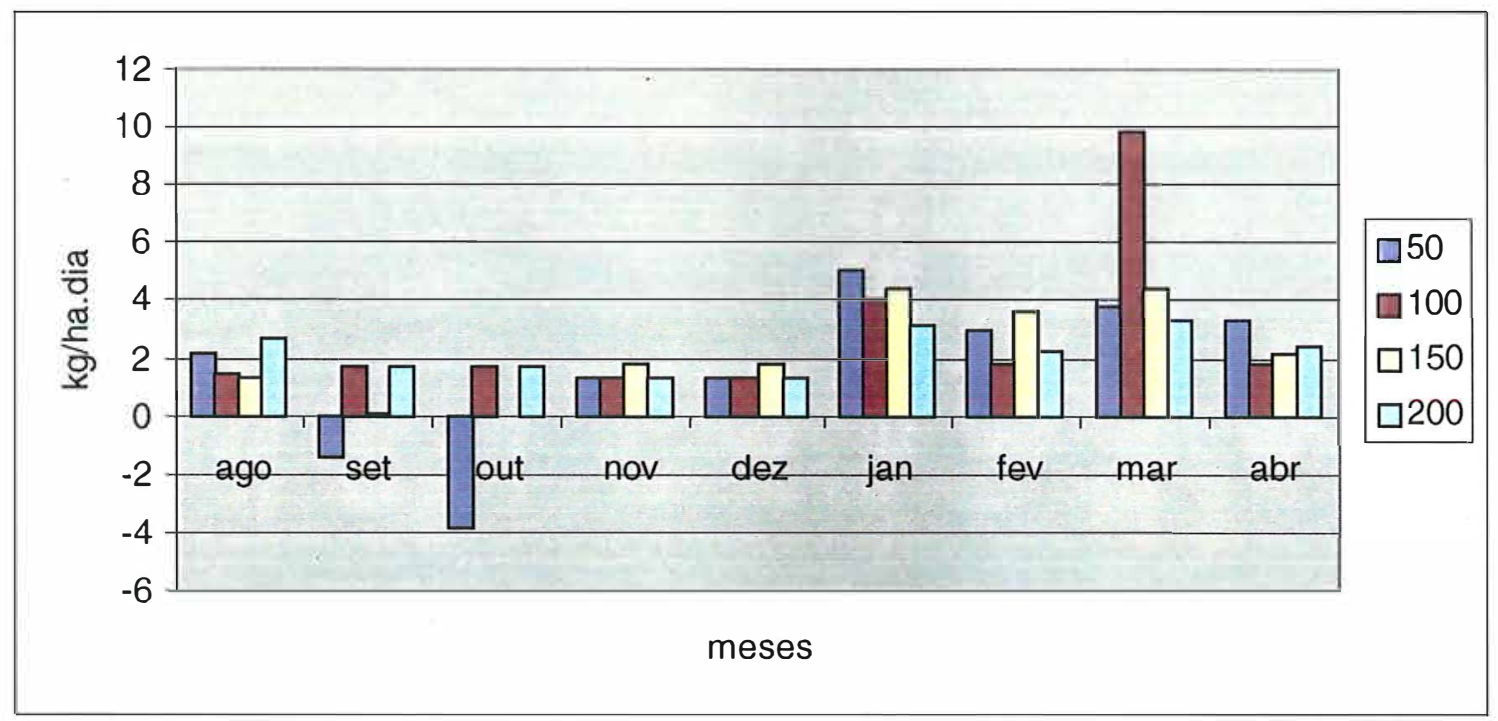

Figura 37: Ganho de peso por área (kg/ha.dia) para as quatro intensidades de pastejo no período experimental.

A título de ilustração foram calculados os consumos individuais e por área em função do valor nutritivo, peso médio e ganho de peso dos animais. Na tabela 40 são apresentados os dados de consumo individual para os cultivares. Um máximo de $550 \mathrm{~g}$ por animal foi obtido para Florakirk. Para esta variável houve efeito de tempo e altura e interações entre tempo $x$ cultivar, tempo $x$ bloco e tempo $x$ altura $(P<0,05)$. 
Tabela 40: Estimativas de consumo diário (g MS/animal dia) para os cultivares de Cynodon durante o periodo experimental.

\begin{tabular}{ccccc}
\hline & Tifton-85 & Florakirk & Coastcross & Sem \\
\hline Agosto & $466 a$ & $549 a$ & $493 a$ & 56,0 \\
Setembro & $413 a$ & $352 a$ & $279 a$ & 51,6 \\
Outubro & $348 a$ & $215 a$ & $309 a$ & 61,0 \\
Novembro & $268 a$ & $194 b$ & $252 a b$ & 56,0 \\
Dezembro & $188 b$ & $350 a$ & $321 a$ & 38,9 \\
Janeiro & $428 a$ & $431 a$ & $418 a$ & 28,0 \\
Fevereiro & $376 a$ & $372 a$ & $307 a$ & 31,3 \\
Março & $470 a$ & $428 a$ & $513 a$ & 54,0 \\
Abril & $504 a$ & $433 a$ & $493 a$ & 66,3 \\
\hline
\end{tabular}

Médias seguidas de letras diferentes na mesma linha são diferentes $(P<0,05)$.

EPM- Erro padrão da média.

$\mathrm{Na}$ tabela 41 estão os valores de consumo individual para as diferentes intensidades de pastejo. Nessa tabela destaca-se o baixo consumo obtido nos meses de setembro a dezembro para os tratamentos de $50 \mathrm{~mm}$ e os mais altos valores de consumo para os tratamentos de $200 \mathrm{~mm}$. 
Tabela 41: Estimativas de consumo diário (g MS/animal dia) nas quatro intensidades de pastejo $(50,100,150$ e $200 \mathrm{~mm})$ durante o periodo experimental.

\begin{tabular}{cccccc}
\hline Mês & 50 & 100 & 150 & 200 & EPM \\
\hline Agosto & $420 a$ & $526 a$ & $558 a$ & $508 a$ & 64,5 \\
Setembro & $147 b$ & $488 a$ & $289 b$ & $468 a$ & 59,6 \\
Outubro & $32 b$ & $434 a$ & $304 a$ & $394 a$ & 70,4 \\
Novembro & $26 b$ & $332 a$ & $258 a$ & $336 a$ & 64,6 \\
Dezembro & $171 b$ & $240 b$ & $332 a b$ & $401 a$ & 44,9 \\
Janeiro & $333 b$ & $415 a b$ & $465 a$ & $490 a$ & 32,4 \\
Fevereiro & $336 a$ & $362 a$ & $391 a$ & $318 a$ & 36,2 \\
Março & $426 a$ & $504 a$ & $501 a$ & $448 a$ & 62,4 \\
Abril & $477 a$ & $378 a$ & $418 a$ & $633 a$ & 76,6 \\
\hline
\end{tabular}

Médias seguidas de letras diferentes na mesma linha são diferentes $(P<0,05)$.

EPM- Erro padrão da média.

Na tabela 42 estão os valores de consumo por área para os cultivares. Para consumo por área houve efeito de tempo e bloco e interações entre tempo $x$ bloco e tempo $x$ altura $(P<0,05)$. Nessa tabela é possivel verificar um tendência de maior consumo por área para o Tifton-85, principalmente nos meses da primavera onde 0 consumo de todos os cultivares foi mais baixo. Houve diferença $(P<0,05)$ entre as alturas para os meses de primavera (Tabela 43). 
Tabela 42: Estimativas de consumo por área (kg MS/ha.dia) para os cultivares de Cynodon durante o período experimental.

\begin{tabular}{ccccc}
\hline Mês & Tifton-85 & Florakirk & Coastcross & EPM \\
\hline Agosto & $20,6 a$ & $22,1 a$ & $19,0 a$ & 3,2 \\
Setembro & $22,6 a$ & $18,6 a$ & $14,4 a$ & 2,9 \\
Outubro & $19,8 a$ & $7,9 c$ & $12,6 b$ & 2,5 \\
Novembro & $20,0 a$ & $8,9 b$ & $12,5 a b$ & 3,1 \\
Dezembro & $18,0 a$ & $22,8 a$ & $27,6 a$ & 3,7 \\
Janeiro & $45,3 a$ & $39,6 a b$ & $36,6 b$ & 2,8 \\
Fevereiro & $36,7 a$ & $36,0 a$ & $34,2 a$ & 5,6 \\
Março & $41,8 a$ & $30,7 a$ & $35,7 a$ & 4,3 \\
Abril & $33,3 a$ & $22,3 a$ & $27,5 a$ & 4,3 \\
\hline
\end{tabular}

Médias seguidas de letras diferentes na mesma linha são diferentes $(P<0,05)$.

EPM- Erro padrão da média.

Tabela 43: Estimativas de consumo por área (kg MS/ha.dia) nas quatro intensidades de pastejo $(50,100,150$ e $200 \mathrm{~mm})$ durante o período experimental.

\begin{tabular}{cccccc}
\hline Mês & 50 & 100 & 150 & 200 & EPM \\
\hline Agosto & $21,3 a$ & $16,5 a$ & $23,2 a$ & $21,2 a$ & 3,7 \\
Setembro & $11,6 b$ & $27,0 a$ & $14,4 b$ & $21,1 a$ & 3,4 \\
Outubro & $1,9 c$ & $22,4 a$ & $12,6 b$ & $16,8 a$ & 2,9 \\
Novembro & $1,9 c$ & $24,7 a$ & $12,6 b$ & $16,0 a b$ & 3,5 \\
Dezembro & $19,9 a$ & $21,0 a$ & $26,6 a$ & $23,7 a$ & 4,3 \\
Janeiro & $44,4 a$ & $38,0 a$ & $41,5 a$ & $38,3 a$ & 3,3 \\
Fevereiro & $49,1 a$ & $28,3 b$ & $34,9 a$ & $30,3 a$ & 6,4 \\
Março & $32,8 a b$ & $41,9 a$ & $43,5 a$ & $26,1 a$ & 4,9 \\
Abril & $29,2 a$ & $21,5 a$ & $26,8 a$ & $33,5 a$ & 4,9 \\
\hline
\end{tabular}

Médias seguidas de letras diferentes na mesma linha são diferentes $(P<0,05)$.

EPM- Erro padrão da média. 
Observando os valores de consumo por área e comparando-os às taxas de acúmulo de forragem ( que teoricamente é o que está disponivel para o consumo em lotação continua), há uma grande diferença em termos de valores absolutos. Contudo, não é possivel afirmar que trata-se exclusivamente de perdas de pastejo, pois o consumo aqui descrito vem de estimativas e não de medições diretas.

Na tabela 44 são encontrados os dias de pastejo de cada cultivar para cada altura. Houve interação entre cultivar $x$ altura para esta variável. Tifton-85 mantido a 50 $\mathrm{mm}$ foi o tratamento que permaneceu o maior número de dias com animais ( $95 \%$ do periodo) e Coastcross $150 \mathrm{~mm}$ foi o qual suportou menor número de dias $(79 \%$ do periodo). Nota-se que apesar do experimento não ter a duração de um ano, o número de dias de pastejo foi muito superior àquele encontrado na maioria dos trabalhos da literatura (Pedreira, 1995; Hill et al. 1997).

Tabela 44: Número de dias de pastejo* de três cultivares de Cynodon e quatro intensidades de pastejo durante o periodo experimental.

\begin{tabular}{cccccc}
\hline \multicolumn{7}{c}{ Cultivar } \\
\hline Altura & TF & FLK & CC & Média & EPM \\
\hline 50 & $258 \mathrm{aA}$ & $253 \mathrm{bA}$ & $238 \mathrm{bA}$ & 249,7 & 5,6 \\
100 & $230 \mathrm{aA}$ & $227 \mathrm{aAB}$ & $231 \mathrm{aA}$ & 229,3 & 5,6 \\
150 & $248 \mathrm{aA}$ & $220 \mathrm{aB}$ & $215 \mathrm{aA}$ & 227,7 & 5,6 \\
200 & $235 \mathrm{aA}$ & $219 \mathrm{aB}$ & $227 \mathrm{aA}$ & 227,0 & 5,6 \\
\hline Média & 242,8 & 229,8 & 227,8 & & \\
\hline EPM & 4,9 & 4,9 & 4,9 & & \\
\hline
\end{tabular}

*em 273 dias de pastejo considerados. TF -Tifton-85; FLK - Florakirk; CC - Coastcross. Médias seguidas de letras maiúsculas diferentes na mesma linha são diferentes $(P<0,05)$ Médias seguidas de letras minúsculas diferentes na mesma coluna são diferentes $(P<0,05)$ EPM - Erro Padrão da Média.

De uma forma geral, pastos mantidos mais baixos apresentaram uma maior número de dias de pastejo. Tifton-85 apresentou-se superior a Florakirk e a Coastcross, provavelmente por Ter permanecido vegetativo a maior parte do tempo. 


\section{Conclusões}

Os dados de capacidade de suporte mostram existir diferença entre acúmulo para as diferentes alturas, indicando limitação da técnica de gaiolas de exclusão utilizada.

A estrutura do pasto interferiu na composição morfológica, valor nutritivo e nível de consumo da forragem dos animais.

O desempenho individual e por área foram determinados pelo nível de disponibilidade e não pelo valor nutritivo da forragem.

Os cultivares tenderam a diferir em número de dias de pastejo e isto esteve relacionado, provavelmente, com sua fenologia e características vegetativas.

Os cultivares apresentaram diferenças entre si indicando, portanto, a necessidade de cuidados específicos de manejo do pastejo . 


\section{Referências Bibliográficas}

BLASER, R. E. Pasture-animal management to evaluate plants and to develop forage systems. In: SIMPÓSIO SOBRE MANEJO DA PASTAGEM, 9., Piracicaba, 1988. Anais. Piracicaba: FEALQ, 1988, p. 1-40.

BURTON, G.W.; GATES, R.N.; HILL, G.M. Registration of Tifton-85 bermudagrass. Crop Science, v.18, p.911, 1993.

CARNEVALLI, R.A.; DA SILVA, S.C. Validação de técnicas experimentais para avaliação de características agronômicas e ecológicas de pastagens de Cynodon dactylon cv. Coastcross-1. Scientia Agrícola, v.56, n.2, p.489-499, abr./jun., 1999.

CHACON, E.A.; STOOBS, T.H.; DALE, M.B. Influence of swards characteristics on grazing behaviour and growth of hereford steers grazing tropical grass pastures. In . Australian Journal of Agricultural Research, v.29, p. 89-102, 1978.

DA SILVA, S.C. \& PEDREIRA, C.G.S. Fatores condicionantes e predisponentes da produção animal a pasto. In: Simpósio sobre Manejo da Pastagem. Anais.13., Piracicaba : FEALQ, 1996, p.97-122.

DA SILVA, S. C.; PEDREIRA, C. G. S. Princípios de ecologia aplicados ao manejo da pastagem. In: SIMPÓSIO SOBRE ECOSSISTEMAS DE PASTAGENS, 3., Jaboticabal, 1997. Anais. Jaboticabal: UNESP, 1997, p. 1-62. 
DAVIES, D.A.; FUTHERGILL, M.; MORGAM, C.T. Assessment of constrasting perenial ryegrasses with and white clover, under continuous stocking in the uplands. 5 Herbage prodution, quality and intake in years 4-6. Grass and Forage Science., v. 48, n.3, p 213-222, Sept., 1993.

EUCLIDES, V. P. B. Valor alimentício de espécies forrageiras do gênero Panicum. In: SIMPÓSIO SOBRE MANEJO DA PASTAGEM, 12., Piracicaba, 1995. Anais. Piracicaba: FEALQ, 1995, p. 245-274.

FERNANDEZ, D; GOMEZ, L.; PARRETAS, J.J. Fertilización nitrogenada en bermuda cruzada n. 1 (Cynodon dactylon) sobre suelo pardo tropical. Ciencia y Tecnica en la Agricultura, Pastos y Forrajes, v.6, n. 1, p. 45-52, 1983.

FONSECA, I.; FLORES, E.; PACHECO, O. Fertilizacion nitrogenada en bermuda cruzada n.1 (Cynodon dactylon x C. nlemfuensis) sobre suelo pardo grisaceos. Ciencia y Técnica en la Agricultura, Suelos y Agroquimica, v.7, n.3, p.55-62, 1984.

FRAME, J. Herbage mass. In : HODGSON,J.; BAKER, R.D.; DAVIES, A.; LAIDLAW, A.S.; LEAVER, J.D. (Ed.) Sward meansurement handbook. Hurley: Bristish Grassland Society, 1981, p.39-67.

HARLAN, D. W.; HOLTER, J. B.; HAYES, H. H. Detergent fiber traits to predict productive energy of forages fed free choice to nonlactating dairy cattle. Journal of Dairy Science, v.74, p.1337-1353, 1991.

HILL, G.M.; GATES, R.N.; BURTON, G.W. Forage quality and grazing steer performance from "Tifton-85" and "Tifton-78" bermudagrasses pastures. Journal of Animal Science, v.71, p.3219-3225,1993. 
HILL, G.M.; GATES, R.N.; WEST, J.W.; BURTON, G.W. Steer grazing performance and forage quality on Coastal, Tifton-78 and Tifton-85 pastures. Univ. of Georgia, College of Agric. \& Environ. Sci., Dept. of Animal \& Dairy Science Annual Report, p. 38-43, 1997.

HILL, G.M.; GATES, R.N.; WEST, J.W.; MANDEBVU, P. Pesquisa com capim bermuda cv. 'Tifton-85'em ensaios de pastejo e de digestibilidade de feno com bovinos. SIMPÓSIO SOBRE MANEJO DE PASTAGEM, 15., Piracicaba. Anais. Piracicaba: FEALQ, p. 7-22, 1998.

HODGSON, J. Herbage production and utilization. In: HODGSON, J. Grazing Management: Science into Pratice. New York: John Wiley, 1990.

HODGSON, J.; JAMIESON, W.S. Variations in herbage mass and digestibility and grazing behaviour and herbage intake of adult cattle and weaned calves. Grass Forage Science. v. 36, p.39-48, 1981.

LE DU, Y.L.P.; PENNING, P.D. Animal based tecniques for estimating herbage intake. In: LEAVE, J.D.. Herbage Intake Handbook. British Grassland Society, 1982 p. $37-76$.

MATCHES, A. G. Pasture Research Methods 1. In: Proceeding of the National Conference on Forage Quality Evaluation and Utilization. Sept. v.3-4, p.1-32, 1969.

MATTHEWS, P.N. Study guide and readings Pasture Production and Grazing Management. In Agricultural Plant Production. Massey University, 1994.

MATTOS, W. R. S. Alimentos para Ruminantes: Noções Básicas e Valor Nutritivo. In: PEIXOTO, A.M. Curso de Alimentação de Bovinos, Piracicaba, p. 53-70, 1992.

MAYNARD, L. A. Nutrição animal. 3. ed. Rio de Janeiro, 1984. 
MERTENS, D.R. Regulation of forage intake. In: FAHEY, C.G.; COLLINS, M.; MERTENS, D.R. ; MOSER, L.E. (ed). Forage Quality Evaluation and Utilization. ASA, CSSA, SSSA, Madison, WL, 1994, p.450-493.

PARSONS, A. J. The effects of season ang management on the growth of grass swards. In: JONES, M.B. ; LAZENBY, A. (ed). The Grass Crop: the physiological basis of production, London Chapman and Hall, p. 129-177, 1988.

PEDREIRA, C.G.S. Plant and animal responses on grazed pastures of "Florakirk" and "Tifton-85" bermudagrasses. Florida, 1995. Thesis Ph.D., University of Florida, $153 p$.

PEREIRA, J. R. A.; ROSSI Jr, P. Manual prático de avaliação nutricional de alimentos, Piracicaba: FEALQ, 1996.

RESENDE, H.; ALVIM, M.J. Produção de leite em pastagem de Cynodon dactylon cv. Coastcross.. In: WORKSHOP SOBRE O POTENCIAL FORRAGEIRO DO GÉNERO CYNODON, 1996, Juiz de Fora, Anais. Juiz de Fora: EMBRAPA, CNPGL, 1996, p. 77-92.

SILVA, D. J. Análise de alimentos (métodos químicos e biológicos). Viçosa. Universidade Federal de Viçosa, 1990.

SOLLENBERGER, L. E.; CHERNEY, D. J. R. Evaluating Forage Production and Quality. The Science of Grassland Agriculture. lowa State University Press, 1995, p. 97-110.

STOBBS,T.H. The effect of plant struture on the intake of tropical pastures. I Variation in the bite size of grazing cattle. Australian Journal of Agricultural Research, v.24, p. 809-819, 1973.

ULYATT, M. J. The feeding value of herbage. In: Chemistry and biochemistry of herbage, New Zealand, p. 131-174, 1973. 
VAN SOEST, P.J.; ROBERTSON, J.B.; LEWIS, B.A. Methods for dietary fiber, neutral detergent fiber and nonstarch polysaccharides in relation to animal nutrition. J. Dairy Science. v.74, p. 3583-3597,1991.

VILELA, D. \& ALVIM, M.J. Manejo de pastagens do gênero Cynodon: intodução, caracterização e evolução do uso no Brasil. . SIMPÓSIO SOBRE MANEJO DE PASTAGeM, 15, Piracicaba, 1998. Anais. Piracicaba: FEALQ, 1998, p. 23-54.

WILSON, J.R. ; MINSON, D. J. Prospects for improving the digestibility and intake of tropical grasses. Tropical Grassland, v.14, p.253-259, 1980. 


\section{ANEXO I}


Massa $x$ altura régua

Tifton 85

\begin{tabular}{|c|c|c|}
\hline MÉS & EQUAÇÃO & $\mathrm{R}^{2}$ \\
\hline Agosto & $2565+222 \mathrm{~h}$ & 88.4 \\
\hline Setembro & $2972+181 \mathrm{~h}$ & 66.7 \\
\hline Outubro & $3041+243 \mathrm{~h}$ & 80.5 \\
\hline Novembro & $1949+300 \mathrm{~h}$ & 69.1 \\
\hline Dezembro & $2263+286 \mathrm{~h}$ & 86.1 \\
\hline Janeiro & $1172+238 \mathrm{~h}$ & 88.2 \\
\hline Fevereiro & $150+299 \mathrm{~h}$ & 89.0 \\
\hline Março & $827+290 \mathrm{~h}$ & 76.2 \\
\hline Abril & $1017+280 \mathrm{~h}$ & 84.5 \\
\hline
\end{tabular}

Massa $x$ altura plate

\begin{tabular}{|c|c|c|}
\hline MËS & EQUAÇĀO & $\mathrm{R}^{2}$ \\
\hline Agosto & $3010+135 \mathrm{~h}$ & 89.6 \\
\hline Setembro & $3364+118 \mathrm{~h}$ & 62.6 \\
\hline Outubro & $3410+154 \mathrm{~h}$ & 74.9 \\
\hline Novembro & $2733+178 \mathrm{~h}$ & 72.1 \\
\hline Dezembro & $2491+189 \mathrm{~h}$ & 90.1 \\
\hline Janeiro & $1733+146 \mathrm{~h}$ & 73.8 \\
\hline Fevereiro & $800+195 \mathrm{~h}$ & 85.6 \\
\hline Março & $1685+169 \mathrm{~h}$ & 73.1 \\
\hline Abril & $1429+164 \mathrm{~h}$ & 81.7 \\
\hline
\end{tabular}


Florakirk

Massa $x$ altura régua

\begin{tabular}{|c|c|c|}
\hline MËS & EQUAÇÃO & $\mathrm{R}^{2}$ \\
\hline Agosto & $2298+180 \mathrm{~h}$ & 79.9 \\
\hline Setembro & $2532+153 \mathrm{~h}$ & 76.1 \\
\hline Outubro & $3469+173 \mathrm{~h}$ & 47.5 \\
\hline Novembro & $2871+174 \mathrm{~h}$ & 52.4 \\
\hline Dezembro & $2588+206 \mathrm{~h}$ & 81.1 \\
\hline Janeiro & $1760+194 \mathrm{~h}$ & 84.7 \\
\hline Fevereiro & $1145+190 \mathrm{~h}$ & 76.3 \\
\hline Março & $1281+234 \mathrm{~h}$ & 77.4 \\
\hline Abril & $1776+190 \mathrm{~h}$ & 78.9 \\
\hline
\end{tabular}

Massa $x$ altura plate

\begin{tabular}{|c|c|c|}
\hline MÉS & EQUAÇĀO & $R^{2}$ \\
\hline Agosto & $2594+124 h$ & 85.2 \\
\hline Setembro & $2781+107 \mathrm{~h}$ & 75.0 \\
\hline Outubro & $3673+112 \mathrm{~h}$ & 50.9 \\
\hline Novembro & $3398+104 \mathrm{~h}$ & 40.9 \\
\hline Dezembro & $3077+130 \mathrm{~h}$ & 77.6 \\
\hline Janeiro & $2086+131 \mathrm{~h}$ & 80.6 \\
\hline Fevereiro & $1615+122 \mathrm{~h}$ & 79.2 \\
\hline Março & $1873+144 \mathrm{~h}$ & 79.5 \\
\hline Abril & $2010+123 \mathrm{~h}$ & 69.3 \\
\hline
\end{tabular}




\section{Coastcross}

Massa $\times$ altura régua

\begin{tabular}{|c|c|c|}
\hline MÉS & EQUAÇĀO & $\mathrm{R}^{2}$ \\
\hline Agosto & $2154+110 \mathrm{~h}$ & 87.6 \\
\hline Setembro & $1535+157 \mathrm{~h}$ & 74.1 \\
\hline Outubro & $2077+141 \mathrm{~h}$ & 83.8 \\
\hline Novembro & $1375+207 \mathrm{~h}$ & 77.9 \\
\hline Dezembro & $1734+198 \mathrm{~h}$ & 82.2 \\
\hline Janeiro & $512+229 \mathrm{~h}$ & 88.7 \\
\hline Fevereiro & $225+248 \mathrm{~h}$ & 90.3 \\
\hline Março & $1139+193 \mathrm{~h}$ & 82.2 \\
\hline Abril & $828+208 \mathrm{~h}$ & 84.6 \\
\hline
\end{tabular}

\section{Massa $\mathrm{x}$ altura plate}

\begin{tabular}{|c|c|c|}
\hline MËS & EQUAÇĀO & $\mathrm{R}^{2}$ \\
\hline Agosto & $2650+116 \mathrm{~h}$ & 90.6 \\
\hline Setembro & $1886+112 \mathrm{~h}$ & 72.6 \\
\hline Outubro & $2155+122 \mathrm{~h}$ & 71.2 \\
\hline Novembro & $1818+135 \mathrm{~h}$ & 76.2 \\
\hline Dezembro & $1939+139 \mathrm{~h}$ & 82.0 \\
\hline Janeiro & $910+153 \mathrm{~h}$ & 81.6 \\
\hline Fevereiro & $801+168 \mathrm{~h}$ & 90.7 \\
\hline Março & $1400+146 \mathrm{~h}$ & 84.5 \\
\hline Abril & $1124+133 \mathrm{~h}$ & 85.6 \\
\hline
\end{tabular}

